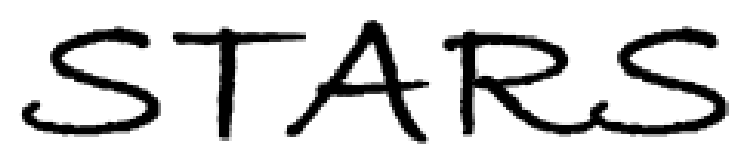

University of Central Florida

STARS

2011

\title{
Addressing the Achievement Gap and Disproportionality Through the Use of Culturally Responsive Teaching Practices
}

Angela Griner

University of Central Florida

Part of the Educational Assessment, Evaluation, and Research Commons

Find similar works at: https://stars.library.ucf.edu/etd

University of Central Florida Libraries http://library.ucf.edu

This Doctoral Dissertation (Open Access) is brought to you for free and open access by STARS. It has been accepted for inclusion in Electronic Theses and Dissertations by an authorized administrator of STARS. For more information, please contact STARS@ucf.edu.

\section{STARS Citation}

Griner, Angela, "Addressing the Achievement Gap and Disproportionality Through the Use of Culturally Responsive Teaching Practices" (2011). Electronic Theses and Dissertations. 6641.

https://stars.library.ucf.edu/etd/6641

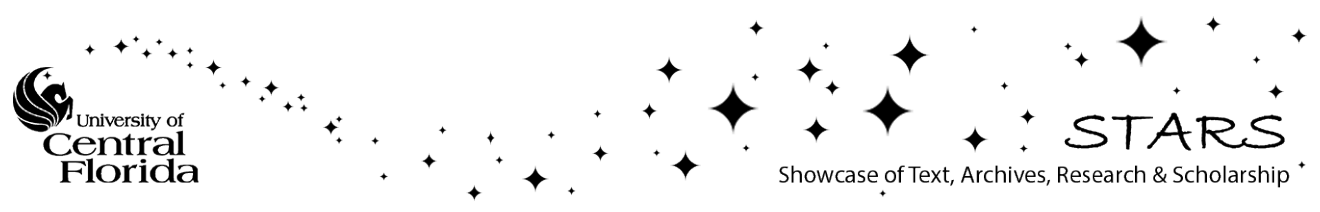


ADDRESSING THE ACHIEVEMENT GAP AND DISPROPORTIONALITY THROUGH THE USE OF CULTURALLY RESPONSIVE TEACHING PRACTICES

by

\begin{abstract}
ANGELA GRINER
B.A. Southeastern University, 1998

M.A. University of South Florida, 2005
A dissertation submitted in partial fulfillment of the requirements for the degree of Doctor of Education in the College of Education Orlando, Florida at the University of Central Florida
\end{abstract}

Summer Term 2011

Major Professor: Martha S. Lue Stewart, Ph.D. 
(C) 2011 Angela Griner 


\begin{abstract}
Culturally responsive teaching practices in schools and classrooms have been shown to be an effective means of addressing the achievement gap, as well as the disproportionate representation of racially, culturally, ethnically, and linguistically diverse students in programs serving students with special needs. While there has been a recent influx in research discussing these issues, teachers and school staff lack clear examples and tools for best practices that will aid them in addressing the achievement gap and disproportionality effectively within their schools. Conducted in three phases, this research provides a framework for developing, implementing, and evaluating a culturally responsive tool for schools and school staff in order to impact beliefs and practices related to culturally responsive teaching, leading to the enhanced learning outcomes of all students.
\end{abstract}


This work is dedicated to the women in my life that have breathed life into me from the time of my conception and birth, to this moment. Women that have spoken and lived words of sustaining encouragement, support, unconditional love, honest correction, and hope for who I am and who I am becoming. My voice and tone have been brought forth from vocal cords that have been strengthened and inextricably tied to the unyielding cords and glorious vibrations of sound you have shared with me, from each of your own unique voices. "I thank my God every time I remember you," (Phil.1:3, NIV). 


\section{ACKNOWLEDGMENTS}

I am overwhelmed with gratitude for the people in my life that have been so kind and gracious to me during this process. To my best friend, husband, and witness to my life these past 15 plus years, Kyle, I am most thankful for your undying loyalty and resolute belief that I am exceedingly more capable and intelligent than I can possibly imagine. Your belief in my work at times exceeds my own and you never seem to tire or scoff at my unrelenting passion. Our dear son Elliot will be the better for your example of support and deep love. For my parents, I cannot thank you enough for the values you've bestowed on me in regards to the importance of serving others and the value of a life embedded in relationship over power, position, and prestige; I am particularly thankful for my father's generosity and my mother's words of affirmation and patience. To friends that have provided support through prayer, words of encouragement, the "exchanging of children", and helping me to not take myself too seriously, I am grateful: Lauren, Mandy, Ginny, Kate, Amanda, Naomi, Michelle, Aaron, Anissa, Kendra, Misty. Thanks to Reid for keeping my computer alive and finding solutions to what would have otherwise been catastrophic events in the data world.

For the academic and experiential processes in the community and at UCF I must thank the following: My academic advisor, mentor, and chair Dr. Martha Lue Stewart. Your belief and support for my own story, as well as my personal and professional goals began before I ever sat down in your office for the first time. I cannot express enough my gratitude for your time, patience, trust, and commitment to my time and learning process during this doctoral program. I am grateful that you have allowed me to be a part of and to carry on some of the important work that you started over 20 years ago. To my committee professors, Dr. Carolyn Walker-Hopp, Dr. Mary Little, Dr. Underberg, and Dr. Katzemeyer, I am thankful for your time, support for 
helping me "find my voice", and your belief in this work. Each of you has provided a network of connections for me as I continue my story from here. I am also thankful to those in my cohort that provided special support: Lee-Anne, Dawn, Mary-Ellen and Leyzia. To Shanta and her children at New Image Youth Center, I am indebted to your openness, trust, and willingness to allow me into your family. The time I've been able to spend has truly been a gift on many levels. To Grand Avenue Elementary School, I am grateful for the chance to get to know your staff and students and am inspired by your work with families and the community. Similarly, to the UCF/CREATE staff and Dr. Stella Sung, it has been a pleasure being a small part of the work you are doing with research, art, technology, and education in the community.

Finally, to others whose work has helped me find the language to articulate my beliefs about building relationships and serving others, I am indebted to you: Chris and Phileena Heuertz and the Word Made Flesh contributors to The Cry, Aaron and Michelle Moore, Dr. Courtney Bentley, Dr. Marleen Pugach, Dr. Paula Webster, Mary Crawford, and Phil Hissom. Key authors that have introduced me to a world of new hope for more sustainable, humanizing, and equitable educational experiences for our children and their families are: Paulo Friere, Dr. Cornel West, Bell Hooks, Lisa Delpit, Gloria Ladson-Billings, Pearl S. Buck, Bishop Desmund Tutu, Maya Angelou, and the rest on a list that is too long to recount here. I am deeply indebted to everyone mentioned here and I'm sure to many that were not. My most sincere thanks rest here. 


\section{TABLE OF CONTENTS}

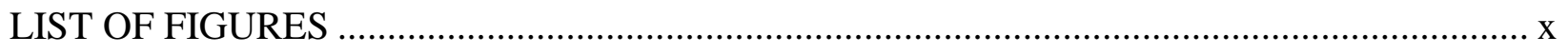

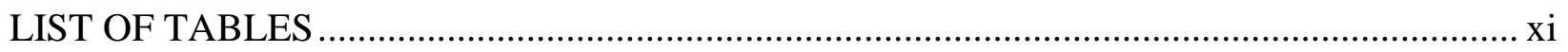

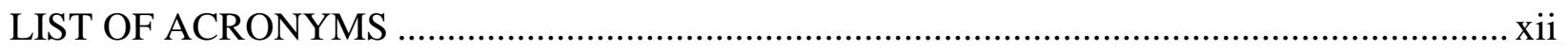

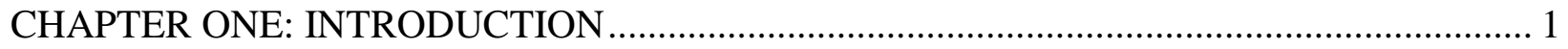

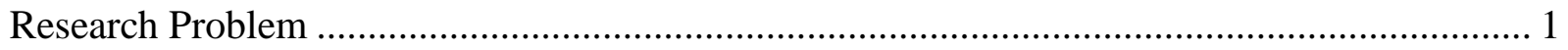

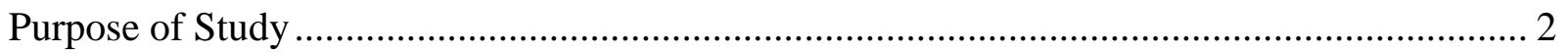

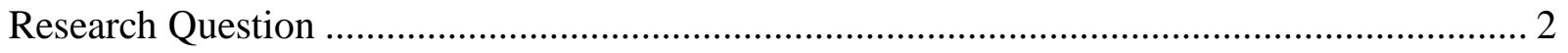

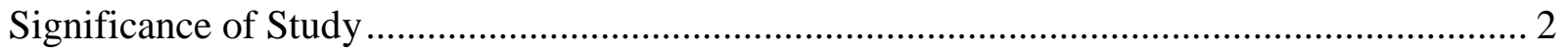

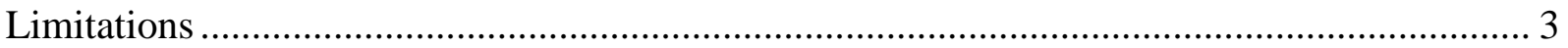

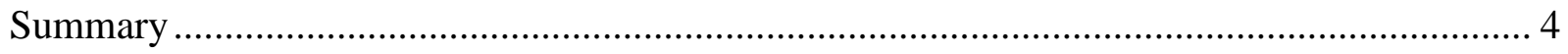

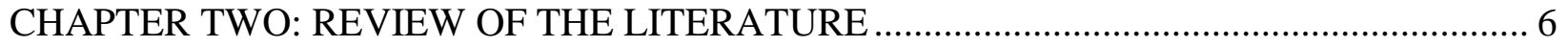

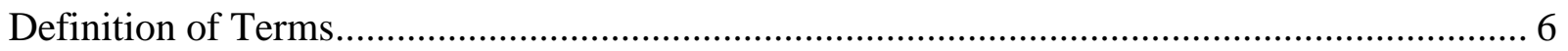

Racially, Culturally, Ethnically, Linguistically Diverse Students .......................................... 6

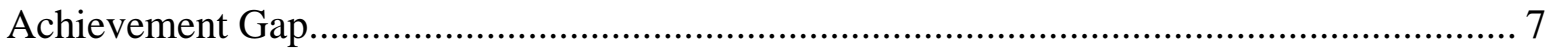

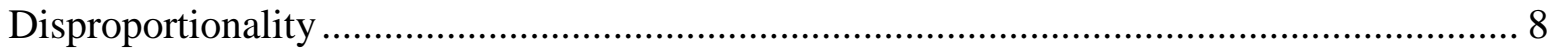

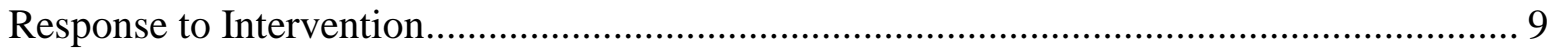

The Culture Divide ………………….................................................................... 12

Culturally Responsive Teaching ...................................................................................... 14

The Need for a Culturally Responsive Pedagogy ………............................................... 15

Barriers to Culturally Responsive Teaching ..................................................................... 20

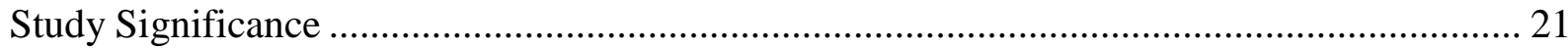

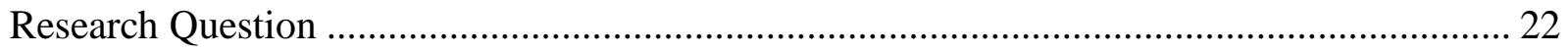

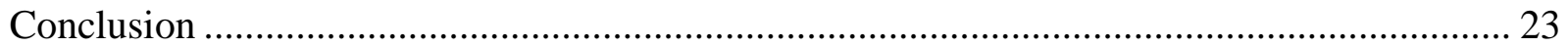

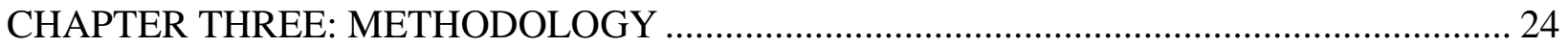

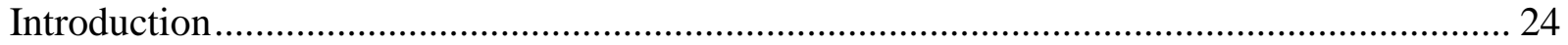

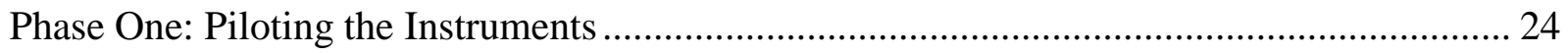

Piloting the Common Beliefs Survey …………………............................................... 24

Piloting the Delphi Study Procedure............................................................................... 26

Phase Two: Developing the Culturally Responsive Teaching Tool ......................................... 28

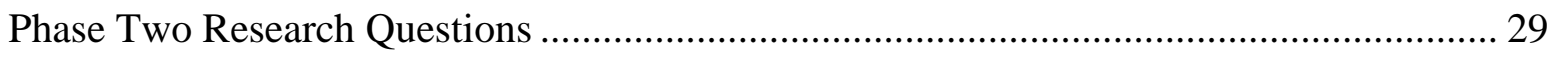

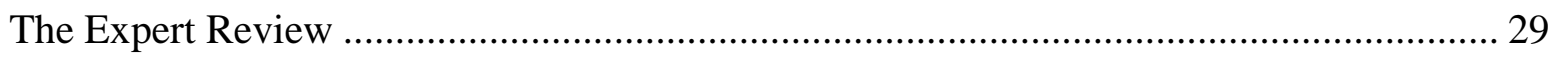

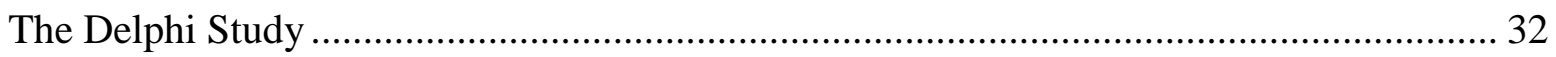




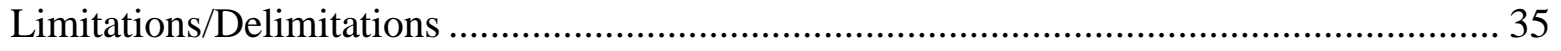

Phase Three: Implementing the Culturally Responsive Teaching Tool ................................... 35

Quantitative Study .................................................................................................... 36

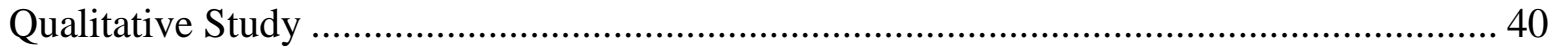

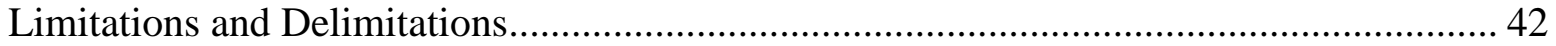

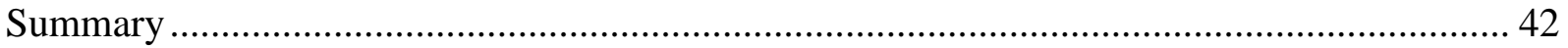

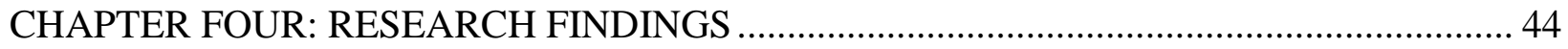

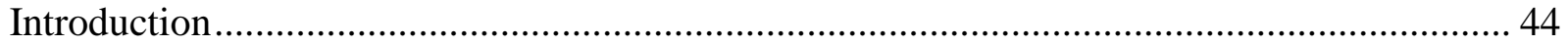

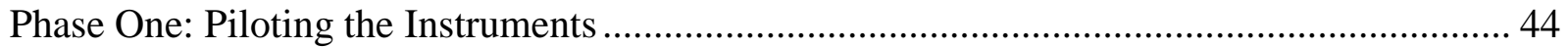

The Common Beliefs Survey.......................................................................................... 44

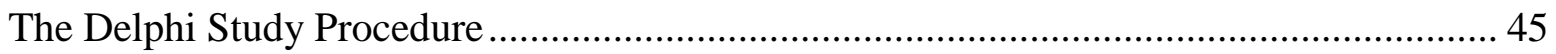

Phase Two: Developing the Culturally Responsive Teaching Tool ......................................... 47

The Expert Review ……………………………...................................................... 47

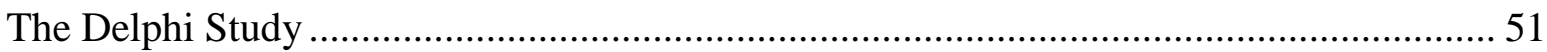

Phase Three: Implementing the Culturally Responsive Teaching Tool ................................... 54

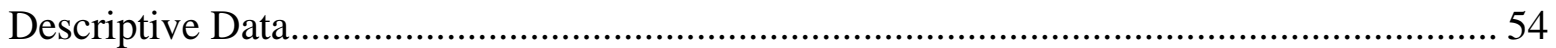

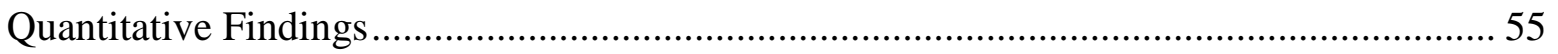

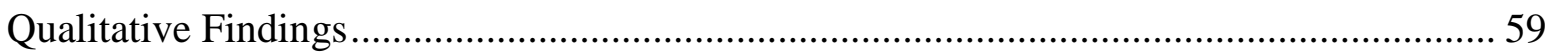

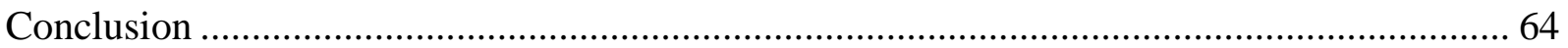

CHAPTER FIVE: CONCLUSIONS, DISCUSSION, AND SUGGESTIONS FOR FUTURE

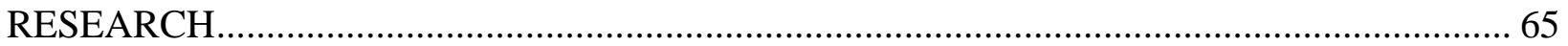

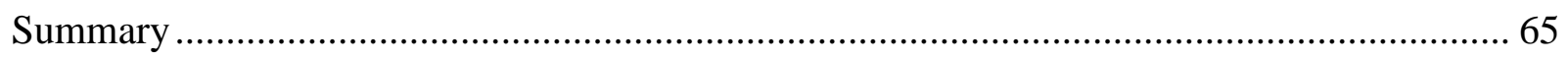

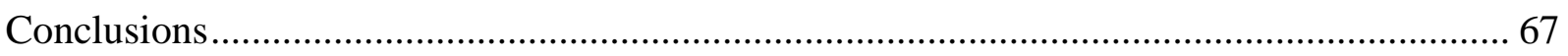

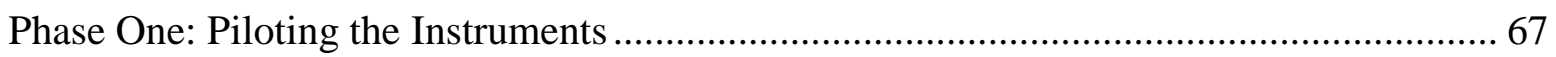

Phase Two: Developing the Culturally Responsive Teaching Tool ...................................... 68

Phase Three: Implementing the Culturally Responsive Teaching Tool ................................ 69

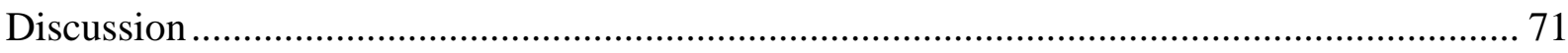

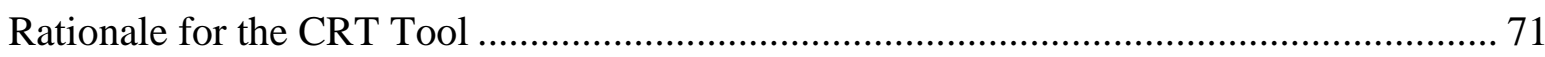

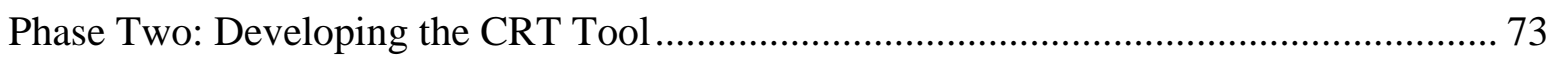

Phase Three: Implementing and Evaluating the Culturally Responsive Tool ...................... 75

Suggestions for Practice and Future Research................................................................. 78

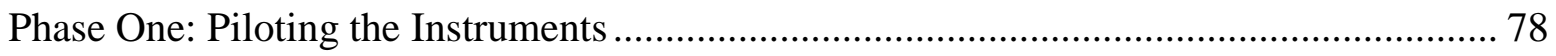

Phase Two: Developing the Culturally Responsive Tool ................................................. 80

Phase Three: Implementing and Evaluating the Tool...................................................... 81 


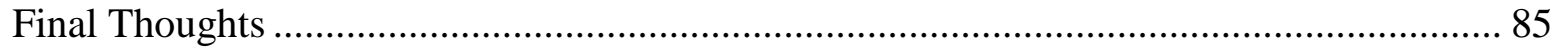

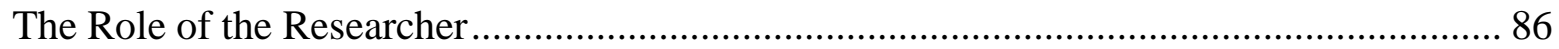

APPENDIX A: PILOT QUESTIONS REVIEWING THE COMMON BELIEFS SURVEY

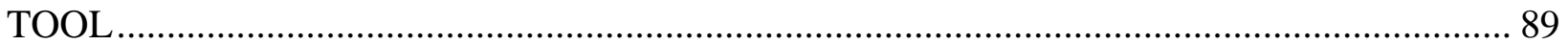

APPENDIX B: INITIAL VERSION OF THE CRT TOOL_.................................................... 92

APPENDIX C: SECOND VERSION OF THE CRT TOOL USED IN ROUND TWO OF THE

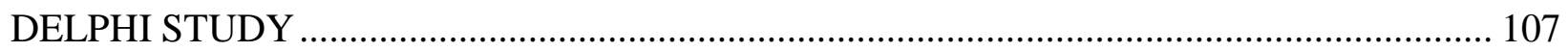

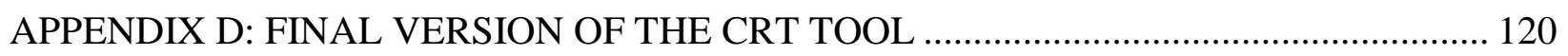

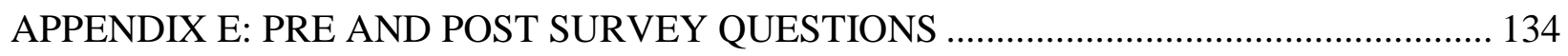

APPENDIX G: LEVELS OF USE INTERVIEW SEQUENCE ……………………............... 162

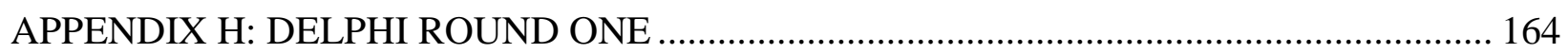

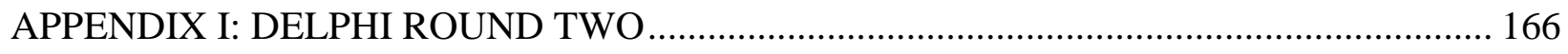

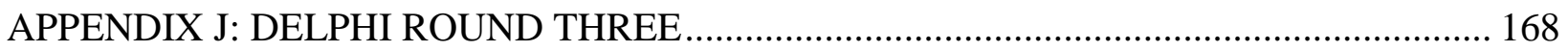

APPENDIX K: MULTICULTURAL SELF-ASSESSMENT ITEMS …………………......... 170

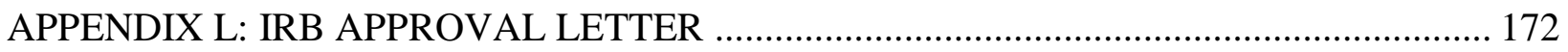

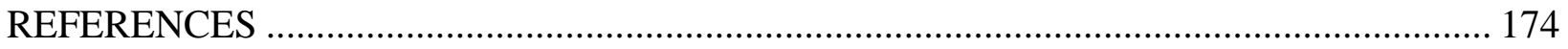




\section{LIST OF FIGURES}

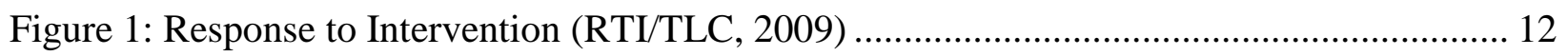




\section{LIST OF TABLES}

Table 1: Percentage of Participant Responses to the Common Beliefs Survey........................ 45

Table 2: Percentage of Participant Responses Piloting First Round Delphi Questions............... 46

Table 3: Summary of Participant Responses from the Expert Review ..................................... 48

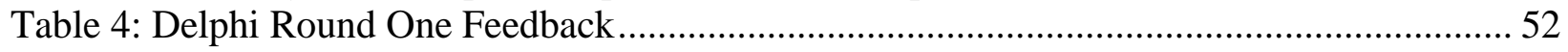

Table 5: Delphi Round Two Feedback ........................................................................... 53

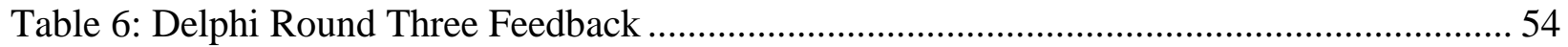

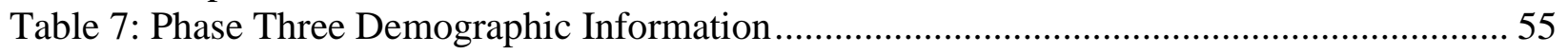

Table 8: Participant Responses to the Common Beliefs Survey ............................................ 57

Table 9: Percentage of Participant Responses to the Levels of Use Survey............................... 58

Table 10: Levels of Use Individual Pre and Post Scores ......................................................... 58

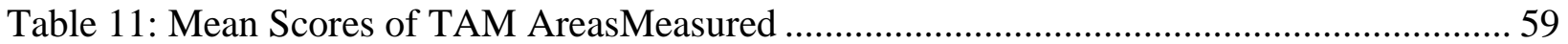

Table 12: Individual Mean Scores of TAM Areas Measured ................................................... 59

Table 13: Summary of Practices from Participants' Response ................................................ 61

Table 14: Summary of Participant Action Plan Responses ................................................... 62

Table 15: Summary of Interview Themes for Beliefs and Practice ......................................... 63 


\section{LIST OF ACRONYMS}

CBS

CEIS

CRT

EBD

ESOL

IDEA

LD

NAEP

NCES

NEA

RCELD

RTI

SED

TAM

SPLC/TDSI
The Common Beliefs Survey

Coordinated Early Intervention Services

Culturally Responsive Teaching

Emotional Behavioral Disorders

English Speakers of Other Languages

Individuals with Disabilities Education Act

Learning Disability

National Assessment of Educational Progress

National Center for Educational Statistics

National Education Association

Racial, Cultural, Ethnic, and Linguistic Diversity

Response to Intervention

Severally Emotionally Disturbed

Teacher Acceptance Model

Southern Poverty Law Centers' Teaching Diverse Students Initiative 


\section{CHAPTER ONE: INTRODUCTION}

\section{$\underline{\text { Research Problem }}$}

Kozol $(1992,2006,2008)$ poignantly illustrates the many injustices that continue to plague our education system. The inequitable distribution of resources, the underachievement of racially, culturally, ethnically, and linguistically diverse (RCELD) students, and further, the disproportionate representation of RCELD students in programs serving students with special needs, provides evidence of how far we have to go to realize a more just and equitable education for all of our students. Many researchers posit that a major cause of the underachievement of RCELD students, commonly referred to as the achievement gap, and the disproportionate representation of RCELD students in programs serving students with special needs is the divide between home and school cultures.

This culture divide presents several barriers to helping RCELD students adapt to school processes and expectations, which severely inhibits learning. Researchers argue that many students a part of the dominant culture group have an advantage at school, because home and school cultures align more easily, whereas, those coming from other racial, cultural, ethnic and linguistic diverse backgrounds (RCELD) do not (Anton, 1999; Banks, 2004, 2007; Bennett, 2003; Cho \& Reich, 2008; Cochran-Smith, 2004; Delpit, 2006; Paez, 2009; Sleeter, 2001). Schools and teachers that have adopted a culturally responsive pedagogy have the ability to act as change agents in their schools to help bridge the divide and encourage more equitable schooling experiences for RCELD students. (Banks, 2007; Cochran-Smith, 2004; Delpit, 2006; Gay, 2000; Kopkowski, 2006; Kraft, 2007; Ladson-Billings, 2009; Lalas, 2007; Meece, 2003; Moll, Amanti, Neff, \& Gonzalez, 2005; Montgomery, 2001;Noddings, 2005; Risko, Walker- 
Dalhouse, 2008). Furthermore, while there has been a recent influx in research discussing culturally responsive practice as a means of addressing inequity in education, teachers and school staff lack clear examples and tools for best practices that will aid them in addressing the achievement gap and disproportionality effectively within their schools and classrooms (Feildler et al., 2008).

\section{Purpose of Study}

The purpose of this study was to gather and interpret best practices related to culturally responsive teaching discussed in the literature, and create a "teacher-friendly" tool to encourage reflective culturally responsive practice in schools and classrooms. Voices of administrators, teachers, related school faculty and staff, as well as parent and family members of racially, culturally, ethnically, and linguistically diverse students were sought to inform the construction of this tool to ensure its quality and practical usefulness for teachers with their students.

\section{$\underline{\text { Research Question }}$}

The study was guided by the following question: To what degree does the use of a culturally responsive tool impact the beliefs and practice of schools and school staff related to culturally responsive teaching?

\section{Significance of Study}

This research was conducted in the following three phases: Phase one involved piloting the instruments that were used in phase two and three of the study. In phase two, content review procedures for developing a culturally responsive tool for use in professional development were conducted. Finally, in phase three, the culturally responsive tool was implemented and evaluated within the context of a professional development program centering on culturally responsive practice. This study contributes to literature in the field of culturally responsive teaching 
discussed in chapter two, through presenting a comprehensive review of best practices related to culturally responsive pedagogy and presenting the rationale behind the use of culturally responsive practices as a means of addressing the achievement gap and the disproportionate representative of students from racially, culturally, ethically, and linguistically diverse backgrounds (RCELD) in programs serving students with special needs. In chapter three, the research methodology presented provides a framework for developing, implementing, and evaluating tools for educational practice. Suggestions in the chapter five of this research provide specific examples for refining the methodology presented here, to improve upon future practice in the development, implementation, and evaluation of such tools. Finally, in chapters four and five, a framework and an educational product is presented that has been developed, validated, and evaluated through the process of this research, for use in future studies and professional development programs centered on addressing the needs of diverse student populations and their families.

\section{$\underline{\text { Limitations }}$}

The nature of the final phase of this study presented several limitations. It is possible that there are other factors that may have affected causality other than the program that was implemented. Since there was no randomization and the participants were not randomly selected, there may be other variables that are not addressed in this phase of the study. The number of participants was also small which affects issues of generalizability. There is also the concern that the pretest itself could have possibly influenced outcomes on the post test.

For the three phases of this study, the hope is that a model tool for professional development can be implemented that encourages a "stance of inquiry", over a staunch list of do's and don'ts related to culturally responsive teaching. The goal is that administrators, 
teachers, and students and their parents, families, and related community members become involved in a broader view of the learning process, that involves reflective and reflexive praxis, (Duarte \& Fitzgerald, 2006; Slattery, 2006). The intended purpose of the CRT tool is to help educators engage in reflective practice, rather than to present a "quick-fix" list of best practices. It is not to be used as a punitive evaluative measure for schools and teachers who are not addressing all of the quality indicators listed. It is crucial that authority figures at the state, district, and school levels understand the inherent purpose of the tool as discussed here. Otherwise, the culturally responsive tool presented here, would lose its intended purpose and essentially become another piece of paperwork to check off the long to do lists of administrators, instructional staff, and other members of the school community.

\section{Summary}

This research study was conducted in three phases, with the final goal to create a useful tool that may impact teacher and other school staff members', beliefs, and practices related to culturally responsive teaching, thus leading to the enhanced learning outcomes of racially, culturally, ethnically, and linguistically diverse (RCELD) students. Phase one involved piloting two of the instruments that were used in phases one and two of this research. Phase two focused on developing the culturally responsive teaching (CRT) tool that was implemented in phase three. Finally, phase three included a mixed methods case study designed for implementing and evaluating the CRT tool in the context of a professional development module.

The initial version of the culturally responsive tool (appendix B) was used in phase one and at the beginning of phase two. The final version of the culturally responsive teaching tool (appendix D) was developed using the findings from both content reviews in phase two. After the culturally responsive tool was implemented within the context of a professional development 
program, findings indicated that participation in the professional development program using the tool had little to no impact on participants' beliefs. However, there were statistically significant results indicating that participation in the professional development program using the tool had an impact on participants practice.

Several implications for ways to enhance the methodology presented in the three phases are discussed in the final chapter of this research. Also presented, are several suggestions for ways to adapt the culturally responsive tool for future practice in professional development programs within various contexts. It was the ultimate purpose of this research to provide a model for practice in developing tools for educational use and to provide strategies for implementing change at the individual, school, district, and broader community levels, in order to support the needs of our underserved and more vulnerable student populations. 


\section{CHAPTER TWO: REVIEW OF THE LITERATURE}

In recent years, the research addressing the issue of culture and education has proliferated significantly. Many in the field of education consider the disconnect between the cultures of RCELD students and the educational institutions serving them, as a fundamental cause of the achievement gap and the disproportionate representation of RCELD students in programs serving students with special needs. The practice of CRT within the literature has been discussed quite extensively as an effective means of addressing this unjust imbalance in education. The purpose of this literature review is twofold. First, this review will review and summarize best practices related to CRT through the lens of key researchers in the field. The second purpose, of the literature review is to support an argument for a culturally responsive pedagogy as a necessary means of addressing the culture divide, leading to enhanced learning outcomes for all students.

\section{Definition of Terms}

Racially, Culturally, Ethnically, Linguistically Diverse Students

The term racially, culturally, ethnically, and linguistically diverse (RCELD) students is used throughout this study. The RCELD acronym is used to refer also to historically underserved groups, (Artiles, Kozleski, Trent, Osher, \& Ortiz, 2010). Artiles, et al. (2010) uses this term to describe RCELD students, but also includes students that come from economically disadvantaged backgrounds, that have "experienced sustained school failure over time," (p.280). For the purposes of this study, the acronym RCELD will include economically disadvantaged groups as well as any groups that have been historically underserved by the education system in the U.S. 


\section{Achievement Gap}

The achievement gap is a term that looms over the hearts and minds of those of us in the field of education. Numerous studies conducted indicate that many racially, culturally, ethnically, and linguistically diverse (RCELD) students are not achieving at the academic levels of their peers. The National Center for Education Statistics (NCES) reports that in 2009, the achievement gap in reading between White and Black $4^{\text {th }}$ graders was 26 points. The gap between White and Hispanic students was 25 points. For $8^{\text {th }}$ grade students, the reading achievement gap for both groups was relatively the same. In mathematics, the achievement gap between White and Black $4^{\text {th }}$ graders was 26 points and the White-Hispanic gap was 21 points. In 2009 , for $8^{\text {th }}$ grade students, the White-Black gap was 32 and the White-Hispanic gap was 26 points. These gaps have differed little since the early 1990's.

Further, the National Assessment of Educational Progress (NAEP) Arts Assessment show that Black and Hispanic students scored lower than White and Asian/Pacific Islander students in both music and visual arts. This same report, while showing increases in high school completion rates for all students, indicates that still many Black and Hispanic students are not completing high school at the rate of their peers. This same pattern follows for the completion of higher education degrees. The underachievement of RCELD students at the K-12 levels leads to higher instances of poverty amongst these students as they become adults, contributing to a cycle of inequality that is seemingly endless (National Center for Education Statistics, 2010). However, we are not without hope. While there are certainly larger, societal issues of inequity that contribute to the achievement gap, schools that implement evidenced-based educational programs have been able to narrow this gap significantly, (Armor, 2006, Hursh, 2007, Gorey, 2009). 


\section{Disproportionality}

Disproportionality refers to "the extent to which membership in a given group affects the probability of being placed in a specific special education disability category," (Oswald, Coutino, Best, \& Sing, 1999). While there have been various arguments over the significance of this problem in education, recent research provides clear evidence that it is, in fact, an issue that must be addressed as we seek to ensure that all students are receiving an equitable education (Klinger et al., 2005). For example, African American children are significantly over represented in special education programs, specifically in the categories of mild mental retardation (MMR) and severely emotionally disturbed (SED) (Oswald et al., 1999). Students coming from other RCELD groups are also overrepresented in the following categories: mild mental retardation (MMR), learning disability (LD), and emotional/behavioral disorder (EBD), (Artiles et al., 2010). As well, RCELD students are underrepresented in gifted programs (National Education Association, 2007).

Students that are inappropriately placed in these programs may suffer many consequences. Upon identification for programs serving students with special needs, it is likely this label will remain with students throughout their entire education experience. Other consequences may follow: diminished expectations, unequal access to the curriculum, lack of opportunities to connect with peers that haven't been labeled, and the continued within-school segregation between RCELD students and their peers (National Education Association, 2007). In order to address this pressing issue, Klinger et al. (2005) argues that there must be collaboration across the three domains of policy, practice, and people. At the policy level, federal, state, district, and school levels can enact guidelines for allocating resources to address disproportionality. At the federal level, states and school districts are required to address 
disproportionality. The two requirements are termed as follows: "disproportionate representation as a monitoring priority area" and "significant disproportionality." IDEA 2004 requires that states monitor whether or not significant disproportionality based on race or ethnicity is occurring in a district in the following areas:

Identification for Eligibility: States determine if significant disproportionality exists among students with disabilities. This analysis does not consider if the identification is appropriate or inappropriate. Identification for a Particular Category: States determine if significant disproportionality exists among students in particular eligibility categories. This analysis does not consider if the identification is appropriate or inappropriate. Educational Settings: States determine if there is significant disproportionality among students with disabilities in particular educational settings, such as the general education classroom. Discipline: States determine if there is significant disproportionality among students with disabilities receiving discipline, including the number of incidences, duration, and type of disciplinary actions, such as suspensions and expulsions. (p. 4)

IDEA requires that districts found to have significant disproportionality must conduct a state review of policies and practices, publicly report related findings, and finally districts must reserve 15 percent of IDEA funds for coordinated early intervening services (CEIS) (Office of Special Education and Early Intervention Services, 2009).

\section{Response to Intervention}

At the state level, many states have adopted a 3-tiered intervention model to address the needs of RCELD students at the general education level before inappropriate placement can happen. The National Education Association (NEA, 2010) has declared that addressing the issue 
of disproportionality is an important part of the efforts of state and local initiatives toward addressing the differences in achievement of students from RCELD backgrounds. The three tiers of Response to Intervention provide opportunities for both general and special education teachers to move beyond traditionally isolated roles, to full collaboration in efforts to appropriately identify students for placement in special education programs. Reschly (2009) reports the inappropriate placement of RCELD students in special education programs largely depends on what occurs at tiers one and two in the RTI model. The goal is to identify problems and implement sustained, effective interventions, before they become "too severe and difficult to resolve," (p. 15)

The IDEA funds allotted to coordinated early intervention services (CEIS), is one step toward addressing this issue. Klinger et al. (2005) argues that these resources be allocated towards implementing culturally responsive educational systems in order to effect practice that would lead to a narrowing of the achievement gap and lower the incidences of inappropriate placement of RCELD students in special education programs (OSE-EIS, 2009). Response to Intervention (RTI) is a 3-tiered intervention model that aligns with many of the key tenets of CRT. Response to Intervention (RTI) presents a systematic model for addressing the individual needs of students, based on formative and summative assessment data, with a focus on outcomes to provide high quality instruction and intervention effectively and efficiently (Hosp, 2008).

Figure 1 illustrates the flow of RTI (RTI/TLC, 2009). Howell, Patton, and Deiotte (2008) define RTI as "the practice of (1) providing high-quality instruction matched to student needs and (2) using learning rate over time and level of performance to (3) make important educational decisions," (p.9). These core principals of RTI drive what happens within the three-tiers. While there are different interpretations of the model, the basic flow of the tiers is as follows: Tier 1 
involves high quality instruction with all students that includes differentiated instructional strategies and continuous assessment. Tier 2 is for those students not making adequate progress at Tier 1 to receive targeted interventions and ongoing formal and informal assessments. Finally, at Tier 3 , students that are still not making adequate progress are targeted to receive individualized intensive interventions. (Howard, 2009; RTI Action Network, 2011)

Response to Intervention addresses students' behavioral needs, as well as their academic needs. Positive behavioral supports are implemented throughout each tier of intervention. The need for the entire school staff to work collaboratively to address the needs of all students cannot be understated. The RTI model presents a framework for helping teachers to move from a "culture of isolation to a culture of collaboration," (DuFour, DuFour, Eaker, \& Many, 2010).This is particularly important when addressing the issue of disproportionality. Collaboration between general and special education teachers should move beyond the traditional roles in order to appropriately identify students for special education programs (Seidl \& Pugach, 2009). The systematic process of RTI not only helps to hold instructional decision makers accountable for how they are addressing the needs of all students, but provides the support for them to do so effectively. 


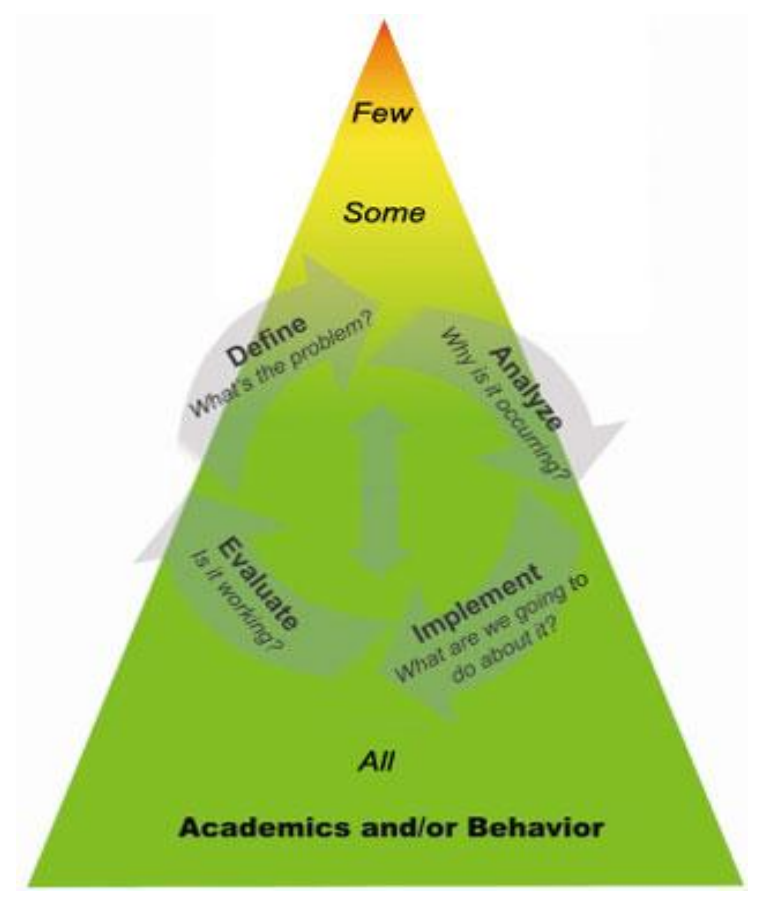

Figure 1: Response to Intervention (RTI/TLC, 2009)

The Culture Divide

Researchers in the field of education, specifically in the field of multicultural education, attribute the cultural disconnect between RCELD students and their schools and teachers as the cause for why many RCELD students are not achieving at the levels of their peers (Anton, 1999; Banks, 2004, 2007; Bennett, 2003; Cho \& Reich, 2008; Cochran-Smith, 2004; Delpit, 2006; Paez, 2009; Gardner, 2007; Jay, 2003; Sleeter, 2001). One of every three students enrolled in either elementary or secondary school is of racial or ethnic minority backgrounds, while nearly 87 percent of the teachers are white and female (Cross, 2003; Sleeter, 2001; Villegas \& Lucas, 2002). To illustrate the increasing diversity of students and families coming into our schools, a recent article in the Wall Street Journal reports that the U.S. is moving toward a majority minority. "America's changing face has transformed race relations from the traditional divide of Black and White to a more complex mix of race, language and religion. 
There are new strains on schools and social services, while immigration has emerged as one of the nation's most contentious issues," (Dougherty, 2010).

The lack of student-teacher connections, led by the culture divide between many schools and the communities in which they are situated continues to overwhelm the educational community. This divide, specifically between teachers and their students, can lead to devastating learning experiences for students (Anton, 1999; Cho \& Reich, 2008; Paez, 2009).Many RCELD students struggle to make the same connections for learning that may come easier to their peers that belong to the more dominant culture group represented within the institution. This culture divide presents several barriers to RCELD students in adapting to school processes and expectations, which impedes positive learning outcomes and too often leads to inappropriate placement programs serving students with special needs (Gardner, 2007; Ogbu, 1992; Willis, 1995).

\section{Themes}

The literature shows that one or more of the following factors contribute to this divide: Communication Barriers. This can involve language issues of students' whose first language isn't English or simple struggles of some students and families with terms and communication methods used by school personnel (Anton, 1999); Conflicting Expectations. There may be distinct differences in student behaviors expected by the school and the classroom teacher and behaviors expected by students' parents, family members, and peers (Sharkey, Layzer, 2000); Access to Resources. This might involve varying definitions about what is considered a valued resource by the school and students' parents, family members, and peers (Moll, Amanti, Neff, \& Gonzalez, 2005; Risko \& Walker-Dalhouse, 2008). Also, to be considered is students' level of 
home access to resources that the school and related personnel expect and assume that students have access to (Bennett, 2008; Sharkey, Layzer, 2003).

\section{Culturally Responsive Teaching}

Researchers in the field of education that address the issue of the culture divide are associated with several related terms: multicultural education (Banks, 2007, Bennett, 2003, Sleeter, 2001), transformative education (Kincheloe, 2007), liberating education (Hooks, 2004; Shor \& Freire, 1987; Kincheloe, 2007), culturally relevant teaching (Ladson-Billings, 2001), culturally responsive teaching (Gay, 2000, Jay, 2003; Ladson-Billings, 2001, 2007; Sleeter, 2001), teaching for social justice (Bennett, 2001; Lalas, 2007), TESOL (Teaching English to Speakers of Other Languages), and democratic education (Beane, 2002). Within the literature using these terms, common themes overlap as these researchers examine institutional and teacher practices that have been shown to build cross cultural connections between the home and school, which result in improved learning outcomes for all students. For the purposes of this research, culturally responsive teaching (CRT) as defined by Gay (2000) will be used:

Culturally responsive teaching can be defined as using the cultural knowledge, prior experiences, frames of reference, and performance styles of ethnically diverse students to make learning encounters more relevant to and effective for them...Culturally responsive teaching has the following characteristics:

- It acknowledges the legitimacy of the cultural heritages of different ethnic groups, both as legacies that affect students' dispositions, attitudes, and approaches to learning and as worthy content to be taught in the formal curriculum.

- It builds bridges of meaningfulness between home and school experiences as well as between academic abstractions and lived sociocultural realities.

- It uses a wide variety of instructional strategies that are connected to different learning styles.

- It teaches students to know and praise their own and each others' cultural heritages.

- It incorporates multicultural information, resources, and materials in all the subjects and skills routinely taught in schools. (p. 29) 
The Need for a Culturally Responsive Pedagogy

Many researchers posit that teachers who are educated in the use of CRT strategies have the ability to act as change agents in their schools to help bridge the divide and encourage more equitable schooling experiences for, racially, culturally, ethnically, and linguistically diverse (RCELD) students (Banks, 2007; Cochran-Smith, 2004; Delpit, 2006; Gay, 2000; Kopkowski, 2006; Kraft, 2007; Ladson-Billings, 2009; Lalas, 2007; Meece, 2003; Moll, Amanti, Neff, \& Gonzalez, 2005; Noddings, 2005; Risko, Walker-Dalhouse, 2008). Schools and teachers that are culturally responsive consider it their responsibility to begin the work of building bridges and deconstructing barriers in order to assist students in negotiating the three worlds of school, home, and peers (Schoorman \& Jean-Jaques, 2004).

Once these connections are made, teachers can begin the work of facilitating students in using their backgrounds to understand and negotiate the culture of the school, encouraging students to become successful learners in the particular academic setting that they are in. It is crucial that they also be armed with the ability to "code switch" between the spheres of home, school, and peers. This is a vital tool they will need throughout their lives (Delpit, 2006). Furthermore, students thrive in classrooms that incorporate their own cultural backgrounds, as well as other cultures and perspectives within the curriculum (Slattery, 2006). Critical, reflective teaching practice along with implementing characteristics of CRT creates a rich and complex classroom environment. Slattery (2006) makes a crucial point about the complex dynamic of teaching and learning within the classroom: "Learning and teaching involve multifaceted human beings in complex interactions. The curriculum in the postmodern era will acknowledge this complexity and move beyond narrow definitions and practices," (p.54). CRT encourages these 
complex interactions of the socio cultural realities of students' lives outside of the classroom, with school and classroom experiences (Gay, 2000). Kopkowski (2006) further offers:

...it is about understanding students' home life, their language, music, dress, behavior, jokes, ideas about success, the role of religion and community in their lives, and more. It is bringing the experiences of their 24-hour day into the seven-hour school day to give them information in a familiar context. (p.1)

As described by Ladson-Billings (1994, 1995), CRT recognizes the importance of including students' cultural references in all aspects of learning. Further, Gay (2000) explains four foundational components of CRT: (1) The power of caring, (2) culture and communication in the classroom, (3) ethnic and cultural diversity in the curriculum and in media, and (3) cultural congruity in teaching and learning. Villegas and Lucas (2002) noted that teachers seeking to enact this type of culturally responsive curriculum within their classrooms are (a) socioculturally conscious,(b) have affirming views of students from diverse backgrounds, (c) see themselves as responsible for and capable of bringing about change to make schools more equitable, (d) understand how learners construct knowledge and are capable of promoting knowledge construction, (e) know about the lives of their students, (f) and design instruction that builds on what their students already know, while stretching beyond the familiar.

Culturally Responsive Teaching as Social Justice in Education

Teachers and school staff who seek to practice culturally responsive teaching consider themselves as change agents, or to use Giroux's term, transformative intellectuals (2010, p.38), acknowledging that there is a dominant culture that pervades the day to day practices and curriculum of our schools. Nieto \& Bode (2008) affirm that one of the primary roles of an educator is that of interrupting the cycle of inequality and oppression. In lieu of this, it is argued that a transformative approach to enact social justice in our schools is necessary. Critical 
pedagogy provides a lens for teachers to view culturally responsive practice as a part of developing a "critical consciousness" regarding structural inequalities that exist within their schools and classrooms. Critical pedagogy involves reflective process regarding the implementation of classroom practices that address such inequalities (Freire, 2007/1997; Kincheloe, 2007). CRT is a means of enacting such practices. CRT is a practice that addresses the imbalance of a school culture that caters to the needs of the dominant culture group, (Gay, 2000; McIntosh, 1988; Jay, 2003; Villegas \& Lucas, 2007). The goal of CRT is to provide a bridge, initiated by the teacher to students' sociocultural realities at home so they are able to learn and utilize the cultural tools necessary to succeed in the school and classroom environment.

Some argue against this view, asserting that such practices support a social justice agenda that is biased and argue instead for teacher neutrality. There has recently been an influx of national debate that seems to pit higher standards, accountability, and standardization against curriculum that is culturally responsive (Carr, 2008). The polarization of this debate makes it seem as though curriculum practices that focus on incorporating students' cultural funds of knowledge, compromise the ability for educators to uphold high academic standards for their students (Carr, 2008; Moll \& Gonzales, 2003). However, many expert practitioners and researchers in the field of education present evidence to the contrary, indicating that it is through CRT practices that teachers become more highly effective in raising their students to higher levels of academic achievement (Delpit, 2006; Ladson-Billings, 2001; Lemov, 2010; Sears \& Hughes, 2006). Banks (2003) argues that the two sides of the debate represent conflicting perspectives on what knowledge is valuable and necessary for moving different political and social agendas forward. 
The argument from both sides of the debate is certainly more complex than what is summarized here, with validated concerns that need to be addressed from both sides. Still, the argument coming from those that are not proponents of "multiculturalism" is that educators, both in K-12 and higher education settings, should remain neutral as they consider traditional texts and curriculum used in today's classrooms (Banks, 2003, p.129). For example, while referring to higher education, Horowitz (2006) cautions against faculty introducing their "overtly political agendas" into their university classrooms which would "indoctrinate" their students. Item number eight in his Academic Bill of Rights states, "academic institutions and professional societies should maintain a posture of organizational neutrality with respect to the substantive disagreements that divide researchers on questions within, or outside, their fields of inquiry.", thereby discouraging faculty from including controversial issues irrelevant to the subject matter they are teaching. The question then is: Who gets to decide what is irrelevant and controversial? The claim of academic institutions at any level, as neutral spheres of inquiry is critically and powerfully argued against.

Freire (2007/1997) claims the impossibility of education as a neutral practice. Giroux (2010) articulates this argument well by saying that teachers as transformative intellectuals should:

View schools as economic, cultural and social sites that are inextricably tied to the issues of power and control. Schools do more than pass on in an objective fashion a common set of values and knowledge. On the contrary, schools are places that represent forms of knowledge, language practices, social relations and values that are representative of a particular selection and exclusion from the wider culture. As such schools serve to introduce and legitimate particular forms of social life. Rather than being objective institutions removed from the dynamics of politics and power, schools actually are contested spheres that embody and express a struggle over what forms of authority, types of knowledge, forms of moral regulation, and version of the past and future should be legitimated and transmitted to students. (p.38) 
Applebaum (2009) also refutes this notion of neutrality by asserting that it is only through social justice education that teaching can become more evenhanded. The ominous achievement gap, the disproportionate number of RCELD students being labeled as at-risk(Garcia \& Guerra, 2004; Ladson-Billings, 2001), the negative connotations of difference as a deficit when students fail to assimilate with normative school practices (Swartz, 2009; Weiner, 2006), and the often misguided assumptions of educators that tend to alienate students that don't identify with the recognized, dominant, social group (Kincheloe, 2007), provide overwhelming evidence of the injustice going on in our schools and classrooms. Leistyna (2007) goes even further, accusing schools of acting as institutions reflecting the larger social order. He claims that schools as such, are not making the necessary efforts to provide students with inviting spaces where they are given opportunities to engage in education that is challenging, culturally responsive and humanizing. These schools, he charges, are contributing to the large number of impoverished youths, many students coming from RCELD backgrounds that make up a portion of our prison population in America today. In the face of such injustice, "to be neutral, is to have chosen sides already. It is to support the status quo," (Tutu, 2007, p.67).

Kraft (2007) adds that teachers who practice teaching for social justice incorporate teaching strategies that are "culturally relevant to the diverse student bodies of each school," (p.81). Furthermore, Paez (2009) asserts that ensuring that immigrant/ESL students have full access to the curriculum and educational opportunities afforded to their non-immigrant/ESL peers is a social justice issue that must be a priority at all levels in the US education system; from federal, state, district, school, as well as individual classrooms. Education is not a neutral act and teaching for social justice and equity takes courage, moving ourselves and our students beyond self-interest (Beane, 2002). Teachers that choose to take the stance as transformative 
intellectuals (Kincheloe, 2007), can pursue nothing less than a practice of critical pedagogy and emancipatory education "that can affirm the collective humanity of all students-teachers-families and the cultures and groups they represent," (Swartz, 2009, p.1044). The author contends that regardless of the discomfort that often accompanies change and facing one's own hidden biases (Applebaum, 2008; Aveling, 2006; Bennett, 2003; Cross, 2003; Giroux, 2001; Hooks, 1994; Jay, 2003; North, 2009; Mitchell, 2007; Sleeter, 2001; Slattery, 2006), engaging in a transformative, liberatory education is a benefit to everyone involved (Hooks, 1994; Kincheloe, 2007).

\section{Barriers to Culturally Responsive Teaching}

Bowman (1994) observes that teachers, like all of us, make generalizations about other people, ideas, and events on the basis of their personal constructions of reality. Additionally, Gay (2002) asserts there are two major obstacles to CRT that also are associated with teacher quality: negative teacher attitudes and expectations for students of color and inaccurately linking disability and diversity. Many educators are faced with limited understanding of cultures other than their own and the possibility that this limitation will negatively affect their students' ability to become successful learners (Delpit, 2006). Conversely, many educators may exhibit minimal awareness of distinctive "funds of knowledge" students have gained from their home, community, and school, and use that knowledge in designing instructional activities that are more meaningful for students. Moll \& Gonzalez (1993) define "funds of knowledge" as the various social and linguistic practices and the historically accumulated bodies of knowledge that are essential to students' homes and communities.

Hence, educators must critically assess their relationships with their students and their families and seek to develop an understanding of the racial, language, ethnic, and cultural 
diversities represented. Their perceptions of these families, students, and cultures may inadvertently impact student learning, resilience, and their academic achievement (Weiner, 2006). It is then our educational challenge to present an empowering school culture, one as described by Baughn, Bos, and Schumm (1997) that promotes gender, racial, and social-class equity. Adding, "establishing such a culture involves examining the school culture for biases and prejudices, developing strategies to alleviate them, and replacing them with opportunities that promote positive self-esteem for all students" (Vaughn, Bos, \& Schumm, 1997). The failure of educators to address the diverse backgrounds of their students continues to contribute to the hidden bias in our schools and curriculum, thus supporting the hegemonic voices in the classroom and society as a whole (Jay, 2003; Slattery, 2006; Weiner, 2006).

It is the responsibility of schools and teachers to tap into these students' funds of knowledge, seek to understand the lived socio cultural realities of their students' lives (Moll, et al., 2005), and develop a culturally responsive pedagogy in order to bridge the divide, both culturally and academically (Villegas, 2002). For no matter how isolated many of us may feel we are in our seemingly separate communities, the tragic circumstances surrounding many of our young, struggling ESOL, African-American, and many other RCELD students, becomes our own tragedy, whether or not we are conscious of it, or choose to acknowledge it. (CochranSmith, 2004; Freire, 2007/1997; Hooks, 1994; Ladson-Billings, 2001; Tutu, 2007)

\section{$\underline{\text { Study Significance }}$}

Teachers and schools that are armed with the tools to enact a culturally responsive pedagogy are capable of effectively addressing the achievement gap and disproportionate representation of RCELD students in special education programs. (Artiles et al., 2005; Banks, 2007; Cochran-Smith, 2004; Delpit, 2006; Gay, 2000; Klinger et al., 2005; Kopkowski, 2006; 
Kraft, 2007; Ladson-Billings, 2009; Lalas, 2007; Meece, 2003; Moll, Amanti, Neff, \& Gonzalez, 2005; Noddings, 2005; Risko, Walker-Dalhouse, 2008). Fortunately, the work of Phuntsog (2001) shows that there are many teachers that believe that CRT is a vital link in working with diverse populations. The problem however, lies in the gaps between policy, theory, and practice. A common issue in the practice of research in education is the struggle to provide educational practitioners with practical strategies and tools that can be used, beyond the rhetoric of research. Often times, there is a major difference between what researchers and policy makers say works and what's actually being implemented in classrooms (Cohen, 1990; Petrina, 2004; Tabak, 2006).

While there has been a recent influx in research discussing these issues, teachers and school staff lack clear examples and tools for best practices that will aid them in addressing the achievement gap and disproportionality effectively within their schools and classrooms. As Klinger et al. (2005) asserts, there must be collaboration between policy, practice, and people to merge this gap. This study seeks to contribute to both knowledge and practice in the field through the development and implementation of a culturally responsive checklist for schools and teachers, involving collaboration between policy makers, practitioners, and parents and families of RCELD students.

\section{$\underline{\text { Research Question }}$}

The study was guided by the following question: To what degree does the use of a culturally responsive tool in professional development, impact the beliefs and practices of schools and school staff related to culturally responsive teaching? 


\section{$\underline{\text { Conclusion }}$}

Teaching is not a neutral practice, but rather a transformational act. Teachers and schools that practice CRT according to the best practices described here can potentially reverse the cycle of inequality in education that continues to be indicated by data supporting the severity of the achievement gap and the disproportionate representation of students from RCELD backgrounds in programs serving students with special needs. However, the steps toward addressing the underlying beliefs and habits of teachers and schools are not quite so linear. Multiple strategies within a variety of contexts need to be utilized to engage educators to become more culturally responsive. Through the development and evaluation of a CRT tool, this research seeks to provide one such resource to help educators develop these transformational teaching practices. 


\section{CHAPTER THREE: METHODOLOGY \\ $\underline{\text { Introduction }}$}

This research study was conducted in three phases, with the final purpose to create a useful tool that may impact teacher and other school staff member, beliefs, and practices related

to CRT, thus leading to the enhanced learning outcomes of racially, culturally, ethnically, and linguistically diverse (RCELD) students. Phase one involved piloting two of the instruments that were used in phases one and two of this research. Phase two focused on developing the CRT (CRT) tool that was implemented in Phase three. Finally, phase three included a mixed methods case study designed for implementing and evaluating the CRT tool in the context of a professional development module.

\section{Phase One: Piloting the Instruments}

In order to strengthen the construct and content validity of the Common Beliefs Survey and the questions and content used for the Delphi study, both instruments were tested with a smaller group of individuals, matching similar criteria as the participants that would be completing the instruments in phase two of this study.

\section{Piloting the Common Beliefs Survey}

The Common Beliefs Survey Tool is a product created by the Southern Poverty Law Center's Teaching Diverse Students Initiative (TDSI) project. This survey tool helps identify the underlying beliefs that teachers and other school staff members hold that can affect the instruction and treatment of RCELD students in the school setting. The TDSI site uses this tool to help participants reflect on their beliefs and practices, while providing resources for learning related to each statement on the survey. 


\section{$\underline{\text { Participants }}$}

There were 12 participants included in this portion of the study. A purposive criterion sample was used to select participants based upon the following criteria: (1) must be currently employed at an urban elementary school. (2) Must hold one of the following positions: Administrator, general or special education teacher, or other instructional support staff position. Participants included one administrator, one member of instructional support staff, and ten general education teachers from grades K-5.

$\underline{\text { Setting }}$

Participants that completed the survey worked at the same school in an urban school district in Central Florida. The school is a Title I school, with $96 \%$ of students on free and reduced lunch (OCPS, 2010). The student demographic information reported by the Florida Department of Education in 2009was as follows: 1.5\% Caucasian, 90.6\% Black, 5.4\% Hispanic, and $19.2 \%$ ELL. This school was selected for this portion of the research, because it fit the criteria that would be used to select participant schools in phase two and three of this research.

\section{Materials/Instrumentation}

For the purposes of this research, the Common Beliefs Survey tool was adapted slightly. Answer choices were reduced from a Likert Scale of 6 to one of four. The original instrument ranked choices as follows: Agree strongly, agree, neither agree nor disagree, disagree, disagree strongly. The adapted instrument used the following answer choices: Strongly agree, agree, disagree, and strongly disagree. Other changes included the addition of specific demographic information for the purposes of disaggregating data relevant to the research, and a revised set of directions to appropriately address the tool in its new format. 


\section{$\underline{\text { Procedure }}$}

Each participant was provided a copy of the Common Beliefs Survey tool via email and asked to complete a questionnaire evaluating the content of the tool (appendix A). In the introductory email to participants, the questionnaire was provided through Survey Monkey link. Results were tallied based on participant responses to each question related to the Common Beliefs Survey tool and any changes relevant to the validity of the tool were made based upon participant feedback. All responses were kept confidential according to University of Central Florida's Institutional Review Board (IRB). Data was collected through Survey Monkey and all responses were deleted after data had been reviewed and analyzed.

\section{Piloting the Delphi Study Procedure}

Taylor-Powell (2002) recommends pre-testing the questionnaire for the first round of the Delphi study to ensure proper wording and that any ambiguities or vagueness have been addressed. Because the questionnaire was being developed solely by the researcher, it was important to have the content reviewed by similar experts in the field to be sure the questions were addressing the goal of the Delphi Study.

\section{$\underline{\text { Participants }}$}

Five participants were selected to complete this portion of the study. A purposive criterion sample was used to select participants based upon the following criteria: Participants must be researchers or practitioners experienced whose work focuses on the addressing the educational needs of diverse learners, including, race, culture, ethnicity, language, and ability. Participants include two professors in higher education with a research focus on diversity initiatives, one instructor in higher education with a history of working with RCELD elementary 
students and a research focus on diversity and literacy, and one general education middle school Math teacher and doctoral student with a focus on addressing the needs of ESOL learners and the issue of disproportionality affecting this population of student, and one bilingual middle school teacher and doctoral student with a research focus on motivation in Mathematics for students of RCELD backgrounds. These participants represent the variety of backgrounds for participants that were to be selected for the Delphi Study portion of this research.

$\underline{\text { Setting }}$

Two of the participants in this study currently work within two separate urban school districts in Central Florida. Three of the participants in higher education work at one of the largest research universities in the nation, serving students from all 50 states and 140 countries. This portion of the study was conducted via email.

\section{Materials/Instrumentation}

Each of the five participants were provided a copy of the first version of the CRT tool being evaluated (appendix B) the questionnaire to be used for round one of the Delphi study(appendix H) and were asked to respond to the following questions via email: (1)Were the instructions for completing the Delphi study clear? (2)Are there any questions you would change the wording on? If yes, please explain which ones, recommended changes, and why. (3)Are there any questions or topics that you feel should have been included with this Delphi study of the checklist tool that was not? (4) Was the layout clear and user-friendly? (5) Any additional comments or suggestions?

$\underline{\text { Procedure }}$

Participants provided their responses to the five questions above via email within one week of the first request. Responses were tallied by question and each issue brought up by 
participants that affected content validity of the first questionnaire was addressed before using it in phase two of the study. Participant responses were kept confidential according the UCF's Institutional Review Board. Responses were collected solely through email and responses were deleted once data had been reviewed and analyzed.

\section{Phase Two: Developing the Culturally Responsive Teaching Tool}

The purpose of this phase of the study was to analyze the content and goals of the CRT tool that will be implemented and evaluated in phase three of this research. There were two primary goals for this phase of the study. The first goal was to illicit the perspectives of expert parent, family, and community members representing students from RCELD backgrounds on the content of the tool. The second goal was to analyze the content and usability of the tool using expert researchers and practitioners in the field. These procedures were adapted from a model presented by Feildler, Chiang, Van Haren, Jorgensen, Halberg, and Boreson (2008). Feildler, et. al (2008), for creating a checklist for addressing disproportionality in partnership with university professors, school district personnel, administrators, and instructional support staff.

After conducting an extensive review of the literature, Feilder et al. (2008) created a checklist of best practices. Once the initial items were created, they used focus groups to analyze and discuss items for relevance and importance. Ongoing use of the checklist continued to allow for changes to be made that would best suit the needs of the specific school using it. The adapted procedures used here add to Feilder et al.'s (2008) model, by including the parent, family, and community voice in the process, as well as a more structured approach to the content analysis. An expert review with parents and community members representing students from CLD backgrounds was conducted, as well as a Delphi study, including researchers and practitioners in 
the area of CRT, working with diverse populations, and/or special education, in order to evaluate the content of the tool for future use in professional development with teachers with a focus on culturally responsive practice. The initial procedure, including parent and community participants was crucial to address the need for these voices to be included in the creation of the instrument. Once this procedure was completed, the Delphi study was conducted to analyze the content and design of the tool for use in professional development with teachers.

\section{Phase Two Research Questions}

Does the tool adequately address the key components of culturally responsive practice, according to expert participants in a Delphi study and an expert review?

What are the factors in the design and layout of the tool affecting usability, according to expert participants in a Delphi study?

\section{The Expert Review}

The first goal was to illicit the perspectives of expert parent, family, and community members representing students from RCELD backgrounds on the content of the tool. There is often a lack of parent, family, and community voice in the creation and implementation of such instruments. If educators want to meet the needs of students from diverse backgrounds, then they must listen to the perspectives of the parents, family, and community members that represent them. This is the first focus of this study, to illicit such participants to evaluate the content of the tool up front.

\section{$\underline{\text { Participants }}$}

Participants were chosen for the expert review through a snowball sample procedure. Five participants were selected to participate in this phase of the research. Experts were chosen 
first beginning with two contacts that work closely with students and families from RCELD backgrounds. Then, based upon their contact suggestions, other participants were selected. The first person interviewed was the head of a local community youth center in an urban neighborhood. The director of the youth center is also a state certified counselor. This participant recommended two parents to interview whose children have or still attend her youth center. The last two participants were from a school in the same urban neighborhood area. The principal of this school was contacted to provide a suggestion of who fit the selection criteria. The fourth participant he suggested was the school's family intervention specialist. The final participant was a parent that regularly attends support group sessions at the family resource center for the school and was suggested by the family intervention specialist.

\section{$\underline{\text { Setting }}$}

The first three participants were connected with a community youth center situated within a local urban neighborhood. The youth center services approximately 50 children from ages five to 19 from the surrounding neighborhoods, providing after school tutoring, all day summer care. Approximately $75 \%$ of the students are from Haitian/Haitian American families. Nearly $5 \%$ of the children are first generation immigrants, while the others are second generation immigrants. Another $5 \%$ of the students are currently in special education programs at their schools. The last two participants were connected with an elementary school situated within another urban neighborhood area. This school is a Title I school, with $98 \%$ of its students on free and reduced lunch. The National Center for Education Statistics (2010) reported school demographic data as follows: $87 \%$ Black, 4\% White, and 9\% Hispanic. 


\section{Materials/Instrumentation}

The original version of the tool (appendix B) was used to guide an interview format with participants to gather data about the content. Both the researcher and the participants, side by side, reviewed each critical question (see section I of the tool) and each quality indicators (see section II of the tool). Participants were asked about which questions and quality indicators they thought would best address the needs of students and their families representing RCELD backgrounds. Participants were also asked to provide suggestions, based on their own experiences, for ways to enhance the tool. This involved suggestions for what should be omitted or suggestions on additional content that needed to be covered.

\section{$\underline{\text { Procedure }}$}

Procedures for conducting the expert review were as follows: both the researcher and each participant, side by side, reviewed each critical question (see section I of the tool) and each quality indicators (see section II of the tool). Participants were asked about which questions and quality indicators they thought would best address the needs of students and their families representing RCELD backgrounds. Participants were also asked to provide suggestions, based on their own experiences, for ways to enhance the tool. This involved suggestions for what should be omitted or suggestions on additional content that needed to be covered. The data collected was analyzed for themes and specific strategies suggested by participants to enhance the tool were implemented before beginning the Delphi study. Suggestions made by participants were reviewed to combine repetitious information, compare any discrepancies within participant suggestions, summarize key ideas presented by participants, and omit information as suggested by participants. Changes were made to the tool, based upon the data collected. The adapted version of the tool was presented to participants in the Delphi Study procedure. All participant 
responses were kept confidential during and after study in accordance with UCF's IRB guidelines. Once data was reviewed and analyzed, responses were discarded. There was no identifiable information that could be traced back to participants in the final reporting of the data.

\section{The Delphi Study}

This portion of the study addressed content, as well as the design of the CRT tool to evaluate usability. Turoff (2002) recommends using at least two of the following dimensions as a part of questionnaires to guide participant responses: Desirability (effectiveness or benefits), Feasibility (practicality), Importance (priority or relevance), and Confidence (in validity of arguments or premise). Each dimension can be rated on a 4-point scale. For the purposes of this study, feasibility (practicality) and importance (priority or relevance) were used for evaluating the content of the tool.

\section{$\underline{\text { Participants }}$}

For the Delphi study, a purposive criterion sample was used to select 15-20 experts to participate in the study. Participants had to fit the following criteria to be included in the study: He or she had to be an experienced researcher or practitioner in the area of culturally responsive teaching, working with diverse populations, and/or special education. A request was sent out to a minimum of 25 participants that fit the criteria. There were 16 expert participants in the Delphi Study that included five general and special education teachers, three instructional support staff, two administrators, six professors and researchers with a focus on working with diverse student populations.

$\underline{\text { Setting }}$

Participants in the Delphi study work in a variety of settings. Six participants work at a higher education institution, one of the largest research universities in the nation, serving 
students from all 50 states and 140 countries. Eight of the participants work at an elementary school situated within an urban neighborhood area. This school is a Title I school, with $98 \%$ of its students on free and reduced lunch. The National Center for Education Statistics (2010) reported school demographic data as follows: $87 \%$ Black, $4 \%$ White, and $9 \%$ Hispanic. One participant works at a doctoral research institution in the north-central region of the United States. Finally, one other participant is an administrator at a local urban elementary school and a doctoral student at a research institution, with a research focus on urban and multicultural education.

Materials/Instrumentation

A Delphi study was also used to analyze feedback related to the evaluation questions. Feedback was collected using online surveys and email. For statistical purposes, an initial goal was to receive a consensus from participants of at least $80 \%$ stating the tool to be very important to important, (on a scale of 1-4: very important, important, slightly important, unimportant), and $80 \%$ stating the tool to be definitely feasible to possibly feasible, (on a scale of 1-4: definitely feasible, possibly feasible, possibly unfeasible, unfeasible). However, it was also important that the opinions and suggestions of any participants that fell outside the consensus group be considered. It was up to the researcher to analyze the data from both study procedures to determine the most significant changes to make to the instrument for the purpose of future work with teachers.

$\underline{\text { Procedure }}$

For the Delphi study, participants were asked to provide a total of three rounds of feedback on the tool, that had been adapted based upon the first procedure with expert parent and community participants. The three rounds of the study allowed participants to comment on the 
design and layout of the tool, as well as the content of the questions and critical quality indicators. For the first round, participants were provided with the initial version of the tool and asked to a series of questions rating each item for importance and overall feasibility. Quantitative feedback from this first round was summarized according to mean and qualitative feedback was coded for $\mathrm{I}=$ factors affecting importance and $\mathrm{F}=$ factors affecting feasibility.

For the first round of the study, the checklist tool was presented to participants for their review and they were asked to complete an online survey asking questions specifically related to their perspectives on the level of importance of content and feasibility (appendix $\mathrm{H}$ ). For the second round of feedback, participants were provided a synthesis of feedback from round one and asked to review the feedback and complete an online survey again, addressing levels of importance and feasibility, (appendix I). Also, included in this round was the original document unchanged, as well as a second document with changes made based upon the feedback from the first round. For example, if $80 \%$ or more of participants stated that a particular question was unimportant or the layout of the tool is affecting feasibility, the second document reflected changes based upon that feedback, so that participants might see how their comments were perceived and used to make changes.

Round three was conducted in a similar manner. Participants were provided with a synthesis of prior feedback; the original document, the adapted document, and were asked to complete a final round of feedback addressing issues of importance and feasibility, (appendix J).Once at least an $80 \%$ consensus was reached by round 3 changes were made to the checklist tool to reflect suggested changes. However, it was also important that the opinions and suggestions of any participants that fell outside the consensus group be considered. Participants remained anonymous from one another during and after the study. Although participant 
responses from each round were summarized and presented back to all participants, all responses were kept confidential in accordance with UCF's IRB guidelines. All data was discarded after review and analysis were conducted. In the final reporting of the data, there was no identifiable information included that could be traced back to individual participants.

\section{Limitations/Delimitations}

The final decision was up to the researcher, to analyze the data from both study procedures to determine the most significant changes to make to the instrument for the purpose of future work with teachers. The limitations of this method of study are that Delphi participants had to review the tool online, when in actual use, the tool would be presented in hard copy format and participants would receive training before, during, and afterwards to assist them in

completing it. Some of the factors that Delphi participants reported as affecting feasibility could be addressed in the way the tool is presented to staff in professional development. Also, the tool is intended to be adapted for specific needs of school sites. There are changes that have been made from Delphi participant consensus and feedback, that may not be as relevant to particular school sites.

\section{Phase Three: Implementing the Culturally Responsive Teaching Tool}

The final phase of this study was conducted using a mixed methods case study design, in order to implement and evaluate the CRT tool in the context of a professional development program. The goal of this portion of the research is to answer the research question guiding this study: To what degree does the use of a culturally responsive tool in professional development impact the beliefs and practice of schools and school staff related to culturally responsive teaching? 


\section{Quantitative Study}

\section{$\underline{\text { Participants }}$}

There were a total of 15 participants that participated in this phase of the study. A purposive criterion sample was used to select participants based upon the following criteria: (1) must be currently employed at an urban elementary school within a district cited for disproportionate representation of RCELD students in programs serving students with special needs. (2) Must hold one of the following positions at the school: administrator, special education teacher, general education teacher, or hold an instructional support staff position. Of the fifteen participants, there was one administrator, four general education teachers, six special education teachers, and four instructional support personnel.

\section{Setting}

All of the participants work at the same elementary school in a district that has been cited for disproportionate representation of RCELD students in programs serving students with special needs. This school meets similar criteria as the school used in phase one of this research: Piloting the Common Beliefs Survey Tool. Both schools, from phase one and phase three are Title I schools. The Public School Review (2011) reported the student demographic information as follows: 1\% Asian, 3\% Hispanic, 33\% Black, 61\% White, with 69\% of students on free and reduced lunch. While the demographic information between the pilot school and this school differ in racial and ethnic percentages, this school has a unique history of special education programs that provides a unique perspective to this research. This school once provided the only setting for the county's full time exceptional education classes and currently contains a center within the school that takes in students with severe disabilities up to age 22 . Of the 52 teachers 
and instructional support staff that hold full time positions, 21 specialize in working with exceptional education students.

\section{Materials/Instrumentation}

The Common Beliefs Survey Tool

The Common Beliefs Survey Tool (appendix E) is a product created by the Southern Poverty Law Center's Teaching Diverse Students Initiative (TDSI) project. This survey tool helps identify the underlying beliefs that teachers and other school staff members hold that can affect the instruction and treatment of RCELD students in the school setting. The TDSI site uses this tool to help participants reflect on their beliefs and practices, while providing resources for learning related to each statement on the survey. For the purposes of this research, the Common Beliefs Survey tool was adapted slightly. Answer choices were reduced from a Likert Scale of 6 to one of four. The original instrument ranked choices as follows: Agree strongly, agree, neither agree nor disagree, disagree, disagree strongly. The adapted instrument used the following answer choices: Strongly agree, agree, disagree, and strongly disagree. Other changes included the addition of specific demographic information for the purposes of disaggregating data relevant to the research, and a revised set of directions to appropriately address the tool in its new format. This tool was piloted to test for construct and content validity in phase one of this research.

Levels of Use

A portion of the Levels of Use Survey Tool, a component of the Concerns Based Adoption Model (CBAM) was used to assess level of practice and implementation. This third phase of the research is evaluating possible changes in beliefs and practices teachers are reporting before and after professional development. However, change in both areas take extensive time and support (Loucks-Horsley, 1996). The framework for CBAM, when used 
holistically, includes three areas for measuring implementation of practices participants have been trained to use in professional development over time so that facilitators can provide ongoing support for changes implemented (Frank, 2009). The three areas measured are Stages of Concern, Levels of Use, and Innovation Configurations.

Due to the design and limited timeline available for this study, the Levels of Use Survey was used to assess where participants identified themselves on the survey. Appendix F shows general descriptions of the seven levels. For the purposes of this research, the following levels were used: 0-Have little or no knowledge of what culturally responsive teaching (CRT) involves 1-Have recently received information about CRT practices and am considering how strategies might be used in my school or classroom. 2-Have made the decision to begin implementing CRT practices in my school or classroom, establishing a time to begin. 3-Am implementing CRT practices in my school or classroom, but have had little time to reflect and integration is mostly surface-level. 4-Am routinely using CRT practices in my school or classroom 5-Am collaborating with colleagues in order to achieve a collective impact on students through the use of CRT practices. 6-Am examining latest developments in the research on CRT practices and have begun exploring new strategies to use, based upon the specific needs of the students at my school and within my classroom.

\section{Teacher Acceptance Model}

Participants were also assessed using an adaptation of Venkatesh and Davis' Teacher Acceptance Model (TAM 2) Measurement Scale (2000). The test measures four areas, using a 7-point Likert scale, where 1=strongly disagree, 2- moderately disagree, 3=somewhat disagree, $4=$ neutral, $5=$ somewhat agree, $6=$ moderately agree, and $7=$ strongly agree, to predict teachers' use of particular tools and practices within their classrooms. The four areas measured are as 
follows: perceived usefulness, ease of use, attitude, and intention to use. This measure has been used and improved upon over the past 25 years in the area of instructional technology and has been proven for predictive validity (Venkatesh \& Davis, 2000).

\section{$\underline{\text { Procedure }}$}

The three survey tools were combined and provided to participants to complete online through Survey Monkey as a single pre and post survey. Participants were provided with an online module via email to complete the pre survey before the professional development and the post survey afterwards. Pre and post-test scores from the three instruments were analyzed to gain insight into whether or not the program was an effective means of influencing participants' beliefs, level of implementation, and intentions to use the practices covered in the professional development program. In order to determine whether or not there was a significant difference between the pre-test and post-test scores, a dependent t-test was used. An Excel spreadsheet program was used to calculate the dependent t-test. All participant responses were kept confidential in accordance with UCF's IRB guidelines. In the final reporting of the data, there was no identifiable information that could be traced back to individual participants. All responses were discarded once the data was reviewed and analyzed.

\section{Limitations}

The nature of this study presented several limitations. It is possible that there are other factors that may have affected causality other than the program that was implemented. Since there was no randomization and the participants were not randomly selected, there may be other variables that are not addressed in this study. The number of participants was also small which 
affects issues of generalizability. There is also the concern that the pretest itself could have possibly influenced outcomes on the post test.

\section{Qualitative Study}

\section{$\underline{\text { Participants }}$}

There were two qualitative measures used in this phase of the research. One measure included written, open-ended response and the other measure was a set of interviews with select participants. For the open-ended response, all of the 15 participants were invited to respond. Of those fifteen, eleven participants responded. This included one administrator, six special education teachers, two general education teachers, and two instructional support members. For the interviews, eight participants were randomly selected to be interviewed, five of those eight participants agreed to be interviewed. This included one administrator, two instructional support staff, one general education teacher, and one special education teacher.

\section{$\underline{\text { Setting }}$}

The setting for both the quantitative portion of this phase of the research and the qualitative portion were the same.

\section{$\underline{\text { Materials/Instrumentation }}$}

As a part of the professional development program participants were asked the following open ended response questions: (1) Are there any specific quality indicators from the CRT tool that you plan to implement in your school or classroom? If yes, which ones? (2) Create a three to five step action plan for implementing one or more of the quality indicators you plan on implementing from the above question. The first question addresses intentions to use the strategies listed. The second question allows participants to create an action plan for implementing those strategies. Research shows that when participants create a plan of action, 
they are more likely to implement those practices on their own in the future (Hoffman, Dahlman, Zierdt, 2009). The action plan possible here, however is limited due to the scope and limited timeframe for completing this portion of the study.

The second qualitative procedure was conducting a structured interview via phone with select participants. The interview questions were as follows: (1) How do you feel participation in the professional development module impacted your beliefs about working with students from culturally and linguistically diverse backgrounds? (2) How do you feel participation in the professional development module will impact your practice in working with students from culturally and linguistically diverse backgrounds? (3) What, if any, activities, (i.e. the surveys, the questionnaire, the ppt.) from the module was most effective in impacting your beliefs? Why? (4) What, if any, activities (i.e. the surveys, the questionnaire, the ppt.) from the module, do you feel will impact your practice? In what ways? Why? What strategies do you intend to use? (5) Were there any items on the survey, Ppt., or questionnaire that you found to be unhelpful in addressing issues related to your beliefs and culturally responsive practice?

\section{$\underline{\text { Procedure }}$}

The open ended response questions were given to participants to complete during the professional development program. Participants were provided with the two questions after completing the CRT tool through Survey Monkey. The responses were coded based upon reported "new" practices that they would be implementing and "confirmed" practices that were already being implemented within their schools and/or classrooms to support any claims regarding the degree of impact participation in the professional development program on participants' practices. The interviews were conducted after participants had completed the professional development. Interview responses were coded for responses related to beliefs and 
practices. These themes were analyzed with results from the open ended responses, as well as the surveys.

\section{Limitations and Delimitations}

The nature of this study presents several limitations. It is quite possible that there are other factors that may affect causality other than the program being implemented. Since the study is being conducted at only one school site, rather than all schools in noncompliance for issues of disproportionality, the number of participants is likely to be small which affects issues of generalizability. There is also the concern that the pretest itself may influence outcomes on the post test. In order to address data quality and trustworthiness the qualitative measure will help to triangulate the data found through the quantitative measure. The goal would be that the interviews confirm data gathered from the pre and post survey instruments. Transferability may be confirmed through the data related to the specific setting of the participating school and criteria for the teachers involved in the professional development, with how the information can be generalized to similar school settings and teachers. It must be noted that due to the nature of this study, there are limitations to transferability, as well as dependability. Other questions follow related to the validity and reliability of the study. What part might miscommunication, values of participants, and the assumptions of the researcher play in the results of the data?

\section{Summary}

The three phases of this research has led to the completion, implementation, and evaluation of a CRT tool to help support educators in becoming more culturally responsive with their students. The intent of phase one was to validate the instruments. Phase two engaged multiple voices and perspectives on how to enhance the tool for implementation in the context of 
professional development focused on CRT. Finally, phase three provided an opportunity to implement and evaluate the tool for use within a unique school setting. The next chapter of findings will provide insights into how effective these procedures were, as well as present areas for continuous improvement of the tool and the process. 


\section{CHAPTER FOUR: RESEARCH FINDINGS \\ $\underline{\text { Introduction }}$}

Findings from each of the three phases of this research are listed in detail in this chapter. This research study was conducted in three phases, with the final purpose to create a useful tool that may impact teacher and other school staff member, beliefs, and practices related to culturally responsive teaching (CRT), thus leading to the enhanced learning outcomes of racially, culturally, ethnically, and linguistically diverse (RCELD) students. Phase one involved piloting two of the instruments that were used in phases one and two of this research. Phase two focused on developing the (CRT) tool that was implemented in Phase three. Finally, phase three included a mixed methods case study designed for implementing and evaluating the CRT tool in the context of a professional development module.

\section{Phase One: Piloting the Instruments}

In order to strengthen the construct and content validity of the Common Beliefs Survey and the questions and content used for the Delphi study, both instruments were tested with a smaller group of individuals, matching similar criteria as the participants that would be completing the instruments in phase two of this study.

\section{The Common Beliefs Survey}

\section{Descriptive Data}

There were 12 participants included in this portion of the study. Participants included one administrator, one member of instructional support staff, and ten general education teachers from grades K-5. Participants that completed the survey worked at the same school in an urban school district in Central Florida. The school is a Title I school, with 96\% of students on free and 
reduced lunch (OCPS, 2010). The student demographic information reported by the Florida

Department of Education in 2009 was as follows: 1.5\% Caucasian, 90.6\% Black, 5.4\% Hispanic,

and $19.2 \%$ ELL.

$\underline{\text { Research Findings }}$

Table 1 below shows the percentage of participant response to each of the questions on

the survey asking them to evaluate the Common Beliefs Survey tool.

Table 1: Percentage of Participant Responses to the Common Beliefs Survey

\begin{tabular}{|c|c|}
\hline Survey Question & Response Description \\
\hline $\begin{array}{l}\text { Approximately how long did it take you to complete the } \\
\text { survey? }\end{array}$ & $\begin{array}{l}58 \% \text { reported } 5-10 \text { minutes } \\
17 \% \text { reported } 10-15 \text { minutes } \\
25 \% \text { reported } 15-20 \text { minutes }\end{array}$ \\
\hline Were the instructions for completing the survey clear? & $100 \%$ answered "yes" \\
\hline $\begin{array}{l}\text { Were any survey questions unclear or ambiguous? If yes, } \\
\text { which ones? }\end{array}$ & $100 \%$ answered "no" \\
\hline $\begin{array}{l}\text { Did you object to answering any questions? If yes, please } \\
\text { explain which questions and why. }\end{array}$ & $100 \%$ answered "no" \\
\hline $\begin{array}{l}\text { Are there any questions you feel should be omitted from the } \\
\text { survey? If yes, please explain which questions and why. }\end{array}$ & $100 \%$ answered "no" \\
\hline $\begin{array}{l}\text { Are there any questions you would change the wording on? If } \\
\text { yes, please explain which questions and include } \\
\text { recommendations for changes. }\end{array}$ & $100 \%$ answered "no" \\
\hline $\begin{array}{l}\text { Are there any questions or topics that you feel should have } \\
\text { been included with this survey that were not? If yes, please } \\
\text { include recommendations here. }\end{array}$ & $100 \%$ answered "no" \\
\hline Overall, what are your feelings about this survey? & $\begin{array}{l}83 \% \text { reported "mostly positive" } \\
17 \% \text { reported "neutral" }\end{array}$ \\
\hline $\begin{array}{l}\text { Finally, please provide any suggestions for ways this survey } \\
\text { could be improved for future use with teachers and other } \\
\text { instructional support staff for assessing beliefs related to } \\
\text { diversity issues in schools and classrooms. }\end{array}$ & $\begin{array}{l}4 \text { of the } 12 \text { participants responded to this question that } \\
\text { they had no suggestions to add. }\end{array}$ \\
\hline
\end{tabular}

The Delphi Study Procedure

\section{Descriptive Data}

Five participants were selected to complete this portion of the study. Participants include

two professors in higher education with a research focus on diversity initiatives, one instructor in

higher education with a history of working with RCELD elementary students and a research

focus on diversity and literacy, and one general education middle school Math teacher and 
doctoral student with a focus on addressing the needs of ESOL learners and the issue of disproportionality affecting this population of student, and one bilingual middle school teacher and doctoral student with a research focus on motivation in Mathematics for students of RCELD backgrounds. These participants represent the variety of backgrounds for participants that were to be selected for the Delphi Study portion of this research. Two of the participants in this study currently work within two separate urban school districts in Central Florida. Three of the participants in higher education work at one of the largest research universities in the nation, serving students from all 50 states and 140 countries.

\section{$\underline{\text { Research Findings }}$}

Table 2 shows the percentage of participant response to each of the questions asking them to evaluate the first round of questions for the Delphi study.

Table 2: Percentage of Participant Responses Piloting First Round Delphi Questions

\begin{tabular}{|l|l|}
\hline Question & Participant Responses \\
\hline $\begin{array}{l}\text { Were the instructions for completing the Delphi study } \\
\text { clear? }\end{array}$ & $\begin{array}{l}2 / 5 \text { participants responded with "yes" } \\
3 / 5 \text { participants stated that directions needed to be } \\
\text { clarified by differentiating between the survey and the } \\
\text { CRT tool and placing the directions in multiple places } \\
\text { since there were so many pages to be reviewed. }\end{array}$ \\
\hline $\begin{array}{l}\text { Are there any questions you would change the wording } \\
\text { on? If yes, please explain which ones, recommended } \\
\text { changes, and why. }\end{array}$ & $\begin{array}{l}4 / 5 \text { participants responded with "no" } \\
1 / 5 \text { suggested changing "students with RCELD" to } \\
\text { RCELD students or students } \text { of RCELD }\end{array}$ \\
\hline $\begin{array}{l}\text { Are there any questions or topics that you feel should } \\
\text { have been included with this Delphi study of the CRT } \\
\text { tool that were not? }\end{array}$ & \begin{tabular}{l}
$5 / 5$ participants responded with "no" \\
\hline Was the layout clear and user-friendly?
\end{tabular} \\
$\begin{array}{l}4 / 5 \text { participants responded with "yes" } \\
1 / 5 \text { suggested that formatting for the CRT tool be } \\
\text { adapted to allow all quality indicators for each question } \\
\text { to fit on one page. }\end{array}$ \\
\hline Any additional comments or suggestions? & $\begin{array}{l}2 / 5 \text { participants responded with "no: } \\
3 / 5 \text { participants suggested the following: Add an N/A } \\
\text { option to the survey, clarify who will participate in } \\
\text { completing the CRT tool, and consider taking out one of } \\
\text { the terms "unclear" or "ambiguous" due to redundancy }\end{array}$ \\
\hline
\end{tabular}




\title{
Phase Two: Developing the Culturally Responsive Teaching Tool
}

\author{
The Expert Review
}

\section{Descriptive Data}

There were five participants that participated in the expert review. The first person interviewed was the head of a local community youth center situated within a local urban neighborhood. The director of the youth center is also a state certified counselor. This participant recommended two parents to interview whose children have or still attend her youth center. The youth center services approximately 50 children from ages five to 19 from the surrounding neighborhoods, providing after school tutoring, all day summer care. Approximately $75 \%$ of the students are from Haitian and Haitian American families. Nearly $5 \%$ of the children are first generation immigrants, while the others are second generation immigrants. Another $5 \%$ of the students are currently in special education programs at their schools.

The last two participants were connected with an elementary school situated within an urban neighborhood area. This school is a Title I school, with 98\% of its students on free and reduced lunch. The National Center for Education Statistics (2010) reported school demographic data as follows: $87 \%$ Black, $4 \%$ White, and 9\% Hispanic. The principal of this school was contacted to provide a suggestion of who fit the selection criteria. The fourth participant he suggested was the school's family intervention specialist. The final participant was a parent that regularly attends support group sessions at the family resource center for the school and was suggested by the family intervention specialist.

\section{$\underline{\text { Research Findings }}$}

Table 3 is a summary of data collected from participants with each question 
from the original tool (appendix B), as well as any additional information that was not included

with the adapted version (appendix C) of the tool: (Note: Places where there is no response listed

is due to the following: information was only confirmed or mentioned with a previous question

or the subject matter of particular questions were specifically relevant to professional school

staff.)

Table 3: Summary of Participant Responses from the Expert Review

\begin{tabular}{|c|c|}
\hline Question & Quality Indicators Provided by Participants (P) \\
\hline 1. & $\begin{array}{l}\text { P1. Provide student outreach programs to ensure inclusion in field trips and to meet other economic } \\
\text { needs, i.e. winter jackets, uniforms, other supplies needs to participate in school activities. } \\
\text { P2. Better representation on committees of parents/families from diverse backgrounds. Better } \\
\text { representation in schools texts. Allow parents a voice in text book adoption. Education on parent } \\
\text { backgrounds to determine needs and ways to reach out. Meet people where they're at: i.e. home visits, } \\
\text { understand what's important to families during holidays. Give teachers homework to learn about the } \\
\text { communities and backgrounds of their students. Create decision making committees that include } \\
\text { representation from core students groups. Update every } 4 \text { years. } \\
\text { P3. } \\
\text { P4. } \\
\text { P5. }\end{array}$ \\
\hline 2. & $\begin{array}{l}\text { P1. Consistent discipline procedures for all students, written, consequences already in place. Provide } \\
\text { counseling or access/partnership with clinical mental health counselors. } \\
\text { P2. } \\
\text { P3. } \\
\text { P4. } \\
\text { P5. }\end{array}$ \\
\hline 3. & $\begin{array}{l}\text { P1.Same expectations for all students regardless of ability. Provide mentoring and collaboration in } \\
\text { classrooms. } \\
\text { P2. } \\
\text { P3. } \\
\text { P4. } \\
\text { P5. }\end{array}$ \\
\hline 4. & $\begin{array}{l}\text { P1. } \\
\text { P2. } \\
\text { P3. } \\
\text { P4. } \\
\text { P5. }\end{array}$ \\
\hline 5. & $\begin{array}{l}\text { P1.Open lines of communication that includes students' social family members. Work collaboratively } \\
\text { with tutors and after school care staff. Take a case management approach for each child to understand } \\
\text { root of the problem, using more in-depth assessment follow through. } \\
\text { P2. } \\
\text { P3. Provide release forms and space during registration to include social family members on access to } \\
\text { student academic and behavioral information. } \\
\text { P4. } \\
\text { P5. }\end{array}$ \\
\hline
\end{tabular}




\begin{tabular}{|c|c|}
\hline Question & Quality Indicators Provided by Participants (P) \\
\hline 6. & $\begin{array}{l}\text { P1. } \\
\text { P2. } \\
\text { P3. } \\
\text { P4. } \\
\text { P5. }\end{array}$ \\
\hline 7. & $\begin{array}{l}\text { P1.Take a case management approach including previous records and teacher notes with better } \\
\text { documentation; include previous teachers' information, as well as content area teachers currently } \\
\text { working with students. } \\
\text { P2. } \\
\text { P3. Provide professional development for teachers on how to adapt to various personalities and } \\
\text { backgrounds of students and their families. Provide accountability and follow through when } \\
\text { leadership/administration changes within a school. } \\
\text { P4. } \\
\text { P5. }\end{array}$ \\
\hline 8. & $\begin{array}{l}\text { P1. Work with outside counselors for additional assistance. } \\
\text { P2.Teachers in K-5 are well educated in this; } 6+\text { need more assistance. Determine if IEP is needed in } \\
\text { 2ndary school for follow through. Foster school community and communication amongst all staff: } \\
\text { paras, general and special ed. teachers, across content areas, with administration } \\
\text { P3. Provide counseling for students and their families as a part of planning for interventions } \\
\text { P4. } \\
\text { P5. Recruit school staff to provide tutoring throughout the day: i.e. library tutoring, reading coach } \\
\text { providing one-on-one intervention, along with other instructional support staff. }\end{array}$ \\
\hline 9. & $\begin{array}{l}\text { P1. } \\
\text { P2. } \\
\text { P3. } \\
\text { P4. } \\
\text { P5. }\end{array}$ \\
\hline 10. & $\begin{array}{l}\text { P1. Have more parental incentives. Get rid of parent/student contracts- not relevant to the parents that } \\
\text { the school is trying to reach. } \\
\text { P2.Use email or phone calls for important information rather than having students responsible for } \\
\text { written information. Include mentoring programs amongst students, consider in grouping strategies. } \\
\text { P3. } \\
\text { P4. } \\
\text { P5. }\end{array}$ \\
\hline 11. & $\begin{array}{l}\text { P1.Clear supervision and accountability } \\
\text { P2. } \\
\text { P3. } \\
\text { P4. } \\
\text { P5. }\end{array}$ \\
\hline
\end{tabular}




\begin{tabular}{|c|c|}
\hline Question & Quality Indicators Provided by Participants (P) \\
\hline 12 & $\begin{array}{l}\text { P1. Implement professional development for teachers on how to work with diverse students populations. } \\
\text { Have representatives from area neighborhoods, representing diverse student populations to provide } \\
\text { stories of their experiences during professional development. Provide parent incentives for coming to } \\
\text { school: potlucks } \\
\text { Be aware of parent/family literacy and language. Provide recorded voicemail in parents' native } \\
\text { language. Reach out to parents to find ways to celebrate the culture of every child. Consider sharing } \\
\text { food from other cultures } \\
\text { P2. } \\
\text { P3. } \\
\text { P4.Provide forum for parent support groups on site at school. Foster an open door policy for parents; } \\
\text { ensure confidentiality, (anti-gossip); allow parents access to school resources regularly: i.e. provide list } \\
\text { of phone numbers to resources or to find answers to questions. Allow students' daily access to the } \\
\text { library. Treat parents like family. Provide transportation for parents to school functions and meetings. } \\
\text { Provide crisis funds for families in need of supplies. } \\
\text { P5. Conduct parent surveys to get feedback on school issues and decisions to be made. Use } \\
\text { representatives from community as resources: i.e. credit union, nutrition, addiction specialists. Have a } \\
\text { parent/family resource center for parents for computer access and to check out games and other learning } \\
\text { materials for additional work with their children. Implement parent group sessions that are upbeat and } \\
\text { relevant to parent needs. Use survey information to determine need and parent interest. Have family } \\
\text { nights that foster quality family interaction within the family, as well as the school. }\end{array}$ \\
\hline 13. & $\begin{array}{l}\text { P1. } \\
\text { P2. } \\
\text { P3. } \\
\text { P4. Mentoring programs should also be implemented school wide, across grade levels. } \\
\text { P5. }\end{array}$ \\
\hline 14. & $\begin{array}{l}\text { P1. } \\
\text { P2. Be consistent in process. Don't suspend for the small things. Consider reasons behind behavior: } \\
\text { hyperactivity, boredom. Better parent/teacher communication and partnership to solve problems. Use } \\
\text { language that is connecting. Attempt to learn from student. Use varied learning styles. Implement } \\
\text { positive rewards. Call home about good news. } \\
\text { P3. Celebrate various ethnic groups in school, not just "Black History" for a month. Provide } \\
\text { complimentary learning experiences between teachers and their students about backgrounds that } \\
\text { empower students. } \\
\text { P4. } \\
\text { P5. }\end{array}$ \\
\hline 15. & $\begin{array}{l}\text { P1. } \\
\text { P2. } \\
\text { P3. } \\
\text { P4. } \\
\text { P5. }\end{array}$ \\
\hline 16. & $\begin{array}{l}\text { P1. } \\
\text { P2. } \\
\text { P3. Behavior must be dealt with, but grades and behavior should be separate. } \\
\text { P4. } \\
\text { P5. }\end{array}$ \\
\hline 17. & $\begin{array}{l}\text { P1. Same expectations for students no matter the disability. } \\
\text { P2. } \\
\text { P3. } \\
\text { P4. } \\
\text { P5. }\end{array}$ \\
\hline
\end{tabular}




\begin{tabular}{|c|c|}
\hline Question & Quality Indicators Provided by Participants (P) \\
\hline 18. & $\begin{array}{l}\text { P1. } \\
\text { P2. } \\
\text { P3. } \\
\text { P4. } \\
\text { P5. }\end{array}$ \\
\hline 19. & $\begin{array}{l}\text { P1. Make learning interactive, using visuals, technology, hands on games. Make learning relevant to } \\
\text { students' socio-cultural experiences } \\
\text { P2. Differentiate instruction in upper grades. Teachers should be more consistent to better coordinate } \\
\text { homework requirements. } \\
\text { P3. } \\
\text { P4. } \\
\text { P5. }\end{array}$ \\
\hline 20. & $\begin{array}{l}\text { P1. } \\
\text { P2. Take the child out of the atmosphere over suspension. } \\
\text { P3. } \\
\text { P4. } \\
\text { P5. Mentoring programs that include consistent person over time, utilizing school staff as mentors and } \\
\text { local community members. }\end{array}$ \\
\hline $\begin{array}{l}\text { Other } \\
\text { Suggested } \\
\text { Strategies } \\
\text { and } \\
\text { Activities }\end{array}$ & $\begin{array}{l}\text { P1. } \\
\text { P2. Summer phone calls; postcards/notes home every } 3 \text { months, birthday cards, celebrate student birthdays in } \\
\text { school. } \\
\text { P3. } \\
\text { P4. Specific programs to foster parent/family involvement: Parents as guest readers in classrooms, holiday parties } \\
\text { including parents/families/community members, Tiny Tots program, Showers for new parents. (School staff show } \\
\text { energized, engaging personalities, greeting parents when they pass by expressing happiness to see the parent in the } \\
\text { school.) } \\
\text { P5. Develop a sustainable relationship with families through partnering with early childhood programs for students } \\
\text { that will be coming into Kindergarten. Partner with adult basic education programs for parents to complete high } \\
\text { school diploma. Invest in the neighborhood. Look at where area crime is coming from, work towards changing the } \\
\text { cycle of poverty for students and their families. Other ideas: Blessing in a Basket, utilize local university } \\
\text { volunteers. "It takes a village." }\end{array}$ \\
\hline
\end{tabular}

The Delphi Study

$\underline{\text { Descriptive Data }}$

There were sixteen expert participants in the Delphi Study that included five general and special education teachers, three instructional support staff, two administrators, six professors and researchers with a focus on working with diverse student populations. Participants in the Delphi study work in a variety of settings. Six participants work at a higher education institution, one of the largest research universities in the nation, serving students from all 50 states and 140 countries. Eight of the participants work at an elementary school situated within an urban neighborhood area. This school is a Title I school, with $98 \%$ of its students on free and reduced 
lunch. The National Center for Education Statistics (2010) reported school demographic data as follows: $87 \%$ Black, $4 \%$ White, and 9\% Hispanic. One participant works at a doctoral research institution in the north-central region of the United States. Finally, one other participant is an administrator at a local urban elementary school and a doctoral student at a research institution, with a research focus on urban and multicultural education.

\section{$\underline{\text { Research Findings }}$}

The following table is a summary of data collected from round one:

Table 4: Delphi Round One Feedback

Factors affecting feasibility: (50\% of respondents noted the tool as "definitely feasible"; $50 \%$ noted the tool as "possibly feasible".)

- Length-time, wording, and amount of questions may be intimidating to future participants

- Lay out-spacing is an issue;; headings should be included with each question; sections of the checklist aren't relevant to all staff; "N/A" should be added to rubric column; question format should be consistent

- Language: not appropriate for many family/community members to participate in; may be difficult for new teachers or particular staff members to complete; some inconsistencies in terms such as what/who makes up an instructional team; ensure language is relevant to participants; some confusion on roles of specific staff members listed, i.e. Reading Coach

Factors affecting importance: (67\% noted the tool as "very important"; $27 \%$ noted the tool as "important"; $6 \%$ noted the tool as slightly important.)

- Questions-some questions are redundant; some questions deter from focus on students coming from RCELD (racial, cultural, ethnic, and linguistically diverse) backgrounds; questions related to RTI (Response to Intervention) and PBS (positive behavioral supports) may not be as important since RTI and PBS are already mandated in Florida schools and could also deter from primary focus of the tool; questions should allow for schools to include more site based needs and initiatives

- Overall content-question of the purpose of the tool; issue with underlying assumptions that focus on traditional roles for special education teachers; tool should address participant beliefs, expectations, and attitudes towards students RCELD backgrounds; some questions and quality indicators appear to support surface level integrations of diversity and may subvert the stated intentions of tool; disability should be included in RCELD definition; include professional development examples and resources 
The following is a summary of the data collected from round 2:

Table 5: Delphi Round Two Feedback

Factors affecting feasibility: (57\% of respondents noted the tool as "definitely feasible"; $43 \%$ noted the tool as "possibly feasible".)

- Specific directions are needed on exactly how to complete the questionnaire and how to use the quality indicators section to answer the questions. (a)

- The open-ended response section for each question needs to clearly specify what participants are to do. (b)

- Language must be consistent within the answer choices to each question. (c)

- Feasibility of the tool depends on how it is presented to staff. Must have buy-in from staff and provide guidance during completion.(d)

- Consider a rating system of 1-4 or 1-10 for answer choices, instead of multiple choice rubric statements. $(h)$

Factors affecting importance: (57\% noted the tool as "very important"; $43 \%$ noted the tool as "important".)

- Some questions, like 3 \& 4 could be combined, while others, like 1 and 5 need to be split apart. (e)

- Need to incorporate a focus on Bank's Social Action approach throughout overall content of questionnaire. $(f)$

- Need to address ways to facilitate professional development and conversations regarding individual beliefs and assumptions about racial, cultural, and linguistic issues. ( $g$ )

- $\quad$ There was an even mix of participants stating that resources were either important or not important. (i)

For the third round, participants were provided the above feedback and then asked to address three questions based upon that feedback: (1) Are there any statements above that you particularly agree with? (2) Are there any statements above that you particularly disagree with? (3) Are there any final recommendations that you'd like to add? Using the letters in parenthesis on Table 5, the following is data collected from this round: 
Table 6: Delphi Round Three Feedback

\begin{tabular}{|l|l|l|}
\hline Statement & Agree & Disagree \\
\hline$a$. & 10 & 0 \\
\hline$b$. & 8 & 0 \\
\hline$c$. & 10 & 0 \\
\hline$d$. & 4 & 1 \\
\hline$e$. & 4 & 1 \\
\hline$f$. & 1 & 1 \\
\hline$g$. & 6 & 0 \\
\hline$h$. & 4 & 3 \\
\hline$i$. & 2 & 0 \\
\hline $\begin{array}{l}\text { Additional } \\
\text { Suggestions: }\end{array}$ & $\begin{array}{l}\text { 1-Still need to } \\
\text { shorten }\end{array}$ & 0 \\
& & \\
\hline
\end{tabular}

The final draft of the instrument was adapted based upon this feedback. Statements a, b, and c were particularly important to address, as each statement was also mentioned in prior rounds. Appendix D shows the final version of the tool to be used in future professional development with schools and teachers on CRT.

\section{Phase Three: Implementing the Culturally Responsive Teaching Tool}

\section{Descriptive Data}

There were a total of 15 participants that participated in this phase of the study. Of the fifteen participants, there was one administrator, four general education teachers, six special education teachers, and four instructional support personnel. All of the participants work at the same elementary school in a district that has been cited for disproportionate representation of RCELD students in programs serving students with special needs. This school is a Title I school. The Public School Review (2011) reported the student demographic information as follows: 1\% Asian, 3\% Hispanic, 33\% Black, 61\% White, with $69 \%$ of students on free and reduced lunch. This school has a unique history of special education programs that provides a unique perspective to this research. This school once provided the only setting for the county's full time 
exceptional education classes and currently contains a center within the school that takes in profoundly handicapped students up to age 22 . Of the 52 teachers and instructional support staff that hold full time positions, 21 specialize in working with exceptional education students.

\section{Quantitative Findings}

\section{Common Beliefs Survey}

The following table shows the reported demographic information for each of the 15 participants:

Table 7: Phase Three Demographic Information

\begin{tabular}{|l|l|l|l|l|l|l|}
\hline Participant & $\begin{array}{l}\text { Years } \\
\text { Experience }\end{array}$ & Age & $\begin{array}{l}\text { Ge } \\
\text { nde } \\
\text { r }\end{array}$ & $\begin{array}{l}\text { Race/ } \\
\text { Ethnici } \\
\text { ty }\end{array}$ & $\begin{array}{l}\text { Linguistic } \\
\text { Background }\end{array}$ & $\begin{array}{l}\text { Religious } \\
\text { Affiliation }\end{array}$ \\
\hline 1 & $11-15$ & $36-40$ & F & W & English/French & Christianity \\
\hline 2 & $11-15$ & $46-50$ & F & W & $\begin{array}{l}\text { English/some } \\
\text { Spanish and Sign }\end{array}$ & Christianity \\
\hline 3 & $0-3$ & $26-30$ & M & W & English & Christianity \\
\hline 4 & $21+$ & $51-55$ & F & W & English & Christianity \\
\hline 5 & $0-3$ & $21-25$ & F & W & English/ASL & Christianity \\
\hline 6 & $0-3$ & $26-30$ & F & W & English & $\begin{array}{l}\text { Non- } \\
\text { religious }\end{array}$ \\
\hline 7 & $11-15$ & $51-55$ & F & W & English & Christianity \\
\hline 8 & $5-10$ & $26-30$ & F & W & English/French & Christianity \\
\hline 9 & $21+$ & $51-55$ & M & W & English/French & Christianity \\
\hline 10 & $21+$ & $51-55$ & F & W & English & Spiritualism \\
\hline 11 & $21+$ & $46-50$ & F & W & English/Sign & Christianity \\
\hline 12 & $11-15$ & $41-45$ & F & W & English & Christianity \\
\hline 13 & $5-10$ & $31-35$ & F & W & English & Judaism \\
\hline 14 & $16-20$ & $56+$ & F & W & English & Unitarianism \\
\hline 15 & $0-3$ & $26-30$ & F & W & English & Christianity \\
\hline
\end{tabular}




\section{Common Belief Statements}

Scores on the pre and post Common Beliefs Survey were analyzed using a dependent ttest and did not show a significant difference in the mean scores of participants before and after participation in the professional development program. There was no statistically significant difference found, as $\mathrm{p}>.05$ and $\mathrm{t}=0.298$. The mean score of participants for the pre survey was 30.2. The mean score for the post survey was 30.4. The following table shows the percentage of participant response to each of the Common Belief statements. The percentages are listed according to the total percentage of participants that agreed or strongly agreed with the statement and the total percentage of participants that disagreed or strongly disagreed with the statement. 
Table 8: Participant Responses to the Common Beliefs Survey

\begin{tabular}{|c|c|c|}
\hline Common Belief Statement & Pre Survey & Post Survey \\
\hline $\begin{array}{l}\text { 1. I don't think of my students in terms of their race or ethnicity; I am } \\
\text { color blind when it comes to my teaching. }\end{array}$ & $\begin{array}{l}73 \% \text { Agreed } \\
27 \% \text { Disagreed }\end{array}$ & $\begin{array}{l}60 \% \text { Agreed } \\
40 \% \text { Disagreed }\end{array}$ \\
\hline $\begin{array}{l}\text { 2. The gap in the achievement among students of different races is about } \\
\text { poverty, not race. }\end{array}$ & $\begin{array}{l}80 \% \text { Agreed } \\
20 \% \text { Disagreed }\end{array}$ & $\begin{array}{l}73 \% \text { Agreed } \\
27 \% \text { Disagreed }\end{array}$ \\
\hline $\begin{array}{l}\text { 3. Teachers should adapt their instructional practice to the distinctive } \\
\text { cultures of African Americans, Latino, Asian, and Native American } \\
\text { students. }\end{array}$ & $\begin{array}{l}73 \% \text { Agreed } \\
27 \% \text { Disagreed }\end{array}$ & $\begin{array}{l}93 \% \text { Agreed } \\
7 \% \text { Disagreed }\end{array}$ \\
\hline $\begin{array}{l}\text { 4. In some cultures, students are embarrassed to speak in front of others so } \\
\text { I take this into account and don't call on these students in class. }\end{array}$ & $\begin{array}{l}40 \% \text { Agreed } \\
60 \% \text { Disagreed }\end{array}$ & $\begin{array}{l}47 \% \text { Agreed } \\
53 \% \text { Disagreed }\end{array}$ \\
\hline $\begin{array}{l}\text { 5. When students come from homes where educational achievement is not } \\
\text { a high priority, they often don't do their homework and their parents don't } \\
\text { come to school events. This is lack of parental support undermines my } \\
\text { efforts to teach these students. }\end{array}$ & $\begin{array}{l}67 \% \text { Agreed } \\
33 \% \text { Disagreed }\end{array}$ & $\begin{array}{l}67 \% \text { Agreed } \\
33 \% \text { Disagreed }\end{array}$ \\
\hline $\begin{array}{l}\text { 6. It is not fair to ask who are struggling with English to take on } \\
\text { challenging academic assignments. }\end{array}$ & $\begin{array}{l}13 \% \text { Agreed } \\
87 \% \text { Disagreed }\end{array}$ & $\begin{array}{l}13 \% \text { Agreed } \\
87 \% \text { Disagreed }\end{array}$ \\
\hline $\begin{array}{l}\text { 7. I believe that I should reward students who try hard; even if they are not } \\
\text { doing well in school because building their self-esteem is important. }\end{array}$ & $\begin{array}{l}\text { 93\% Agreed } \\
7 \% \text { Disagreed }\end{array}$ & $\begin{array}{l}\text { 93\% Agreed } \\
7 \% \text { Disagreed }\end{array}$ \\
\hline $\begin{array}{l}\text { 8. I try to keep in mind the limits of my students' ability and give them } \\
\text { assignments that I know they can do so they so not become discouraged. }\end{array}$ & $\begin{array}{l}53 \% \text { Agreed } \\
47 \% \text { Disagreed }\end{array}$ & $\begin{array}{l}40 \% \text { Agreed } \\
60 \% \text { Disagreed }\end{array}$ \\
\hline $\begin{array}{l}\text { 9. Students of different races and ethnicities often have different learning } \\
\text { styles and good teachers will match their instruction to these learning } \\
\text { styles. }\end{array}$ & $\begin{array}{l}93 \% \text { Agreed } \\
7 \% \text { Disagreed }\end{array}$ & $\begin{array}{l}40 \% \text { Agreed } \\
60 \% \text { Disagreed }\end{array}$ \\
\hline $\begin{array}{l}\text { 10. Grouping students of different levels of achievement for instruction } \\
\text { may benefit some students but it can undermine the progress that could } \\
\text { otherwise be made by higher achieving students. }\end{array}$ & $\begin{array}{l}53 \% \text { Agreed } \\
47 \% \text { Disagreed }\end{array}$ & $\begin{array}{l}60 \% \text { Agreed } \\
40 \% \text { Disagreed }\end{array}$ \\
\hline $\begin{array}{l}\text { 11. With all the pressures to raise student achievement, finding and using } \\
\text { examples for the cultural, historic and everyday lived experiences of my } \\
\text { students takes away valuable time from teaching and learning. }\end{array}$ & $\begin{array}{l}7 \% \text { Agreed } \\
93 \% \text { Disagreed }\end{array}$ & $\begin{array}{l}7 \% \text { Agreed } \\
93 \% \text { Disagreed }\end{array}$ \\
\hline $\begin{array}{l}\text { 12. Before students are asked to engage in complex learning tasks, they } \\
\text { need to have a solid grasp of basic skills. }\end{array}$ & $\begin{array}{l}\text { 64\% Agreed } \\
36 \% \text { Disagreed }\end{array}$ & $\begin{array}{l}73 \% \text { Agreed } \\
27 \% \text { Disagreed }\end{array}$ \\
\hline $\begin{array}{l}\text { 13. Talking about race with my colleagues could open up a can of worms; } \\
\text { little good is likely to come from it. }\end{array}$ & $\begin{array}{l}7 \% \text { Agreed } \\
93 \% \text { Disagreed }\end{array}$ & $\begin{array}{l}7 \% \text { Agreed } \\
93 \% \text { Disagreed }\end{array}$ \\
\hline
\end{tabular}

\section{Levels of Use Survey Question}

Scores on the pre and post Levels of Use Survey question were analyzed using a dependent t-test and showed a significant difference in the mean scores of participants before and after participation in the professional development program. There was a statistically significant difference found, as $\mathrm{p}<.05$ and $\mathrm{t}=2.874$. The mean score of participants for the pre survey was

1.5. The mean score for the post survey was 2.5. Table 9 shows the percentage of where participants ranked themselves on the Levels of Use question for the pre and post surveys. Table 
10 illustrates the difference between individual responses from the pre and post Levels of Use survey question.

Table 9: Percentage of Participant Responses to the Levels of Use Survey

\begin{tabular}{|l|l|l|}
\hline Levels of Use & Pre Survey & Post Survey \\
\hline 0-Have little or no knowledge of what culturally responsive teaching (CRT) involves & $53 \%$ & $7 \%$ \\
\hline $\begin{array}{l}\text { 1-Have recently received information about CRT practices and am considering how } \\
\text { strategies might be used in my school or classroom. }\end{array}$ & $7 \%$ & $27 \%$ \\
\hline $\begin{array}{l}\text { 2-Have made the decision to begin implementing CRT practices in my school or } \\
\text { classroom, establishing a time to begin. }\end{array}$ & $0 \%$ & $20 \%$ \\
\hline $\begin{array}{l}\text { 3-Am implementing CRT practices in my school or classroom, but have had little } \\
\text { time to reflect and integration is mostly surface-level. }\end{array}$ & $27 \%$ & $13 \%$ \\
\hline 4-Am routinely using CRT practices in my school or classroom & $7 \%$ & $20 \%$ \\
\hline $\begin{array}{l}\text { 5-Am collaborating with colleagues in order to achieve a collective impact on } \\
\text { students through the use of CRT practices. }\end{array}$ & $7 \%$ & $13 \%$ \\
\hline $\begin{array}{l}\text { 6-Am examining latest developments in the research on CRT practices and have } \\
\text { begun exploring new strategies to use, based upon the specific needs of the students at } \\
\text { my school and within my classroom. }\end{array}$ & $0 \%$ & $0 \%$ \\
\hline
\end{tabular}

Table 10: Levels of Use Individual Pre and Post Scores

\begin{tabular}{|l|l|l|}
\hline Participant & $\begin{array}{l}\text { Pre Test } \\
\text { LOU } \\
\text { Identified }\end{array}$ & $\begin{array}{l}\text { Post Test } \\
\text { LOU } \\
\text { Identified }\end{array}$ \\
\hline 1 & 0 & 4 \\
\hline 2 & 4 & 4 \\
\hline 3 & 3 & 2 \\
\hline 4 & 3 & 5 \\
\hline 5 & 3 & 3 \\
\hline 6 & 1 & 2 \\
\hline 7 & 0 & 1 \\
\hline 8 & 0 & 1 \\
\hline 9 & 0 & 4 \\
\hline 10 & 5 & 5 \\
\hline 11 & 3 & 3 \\
\hline 12 & 0 & 0 \\
\hline 13 & 0 & 2 \\
\hline 14 & 0 & 1 \\
\hline 15 & 0 & 1 \\
\hline
\end{tabular}

\section{$\underline{\text { Teacher Acceptance Model }}$}

Scores on the pre and post surveys were analyzed using a dependent t-test and show a significant difference in the mean scores of participants in three of the four areas measured 
before and after participation in the professional development program. The four areas measured are as follows: perceived usefulness, ease of use, attitude, and intention to use. A statistically significant difference was found for the following areas $(\mathrm{p}<.05)$ : perceived usefulness, $t=-$ 3.117, perceived ease of use, $t=-2.512$, and intention to use, $\mathrm{t}=-2.256$. There was not a statistically significant difference found for the area of attitude, with $\mathrm{p}>.05$ and $t=-1.373$. Tables 11 and 12 show the mean scores of the four measured areas.

Table 11: Mean Scores of TAM Areas Measured

\begin{tabular}{|l|l|l|}
\hline Measured Area & $\begin{array}{l}\text { Pre-Survey } \\
\text { Scores }\end{array}$ & $\begin{array}{l}\text { Post-Survey } \\
\text { Scores }\end{array}$ \\
\hline Perceived Usefulness & 5.72 & 6.15 \\
\hline Perceived Ease of Use & 4.98 & 5.55 \\
\hline Attitude & 5.78 & 6.07 \\
\hline Intention to Use & 5.57 & 5.97 \\
\hline
\end{tabular}

Table 12: Individual Mean Scores of TAM Areas Measured

\begin{tabular}{|c|c|c|c|c|}
\hline Participant & $\begin{array}{l}\text { Perceived } \\
\text { Usefulness } \\
\text { Pre/Post }\end{array}$ & $\begin{array}{l}\text { Perceived } \\
\text { Ease of Use } \\
\text { Pre/Post }\end{array}$ & $\begin{array}{l}\text { Attitude } \\
\text { Pre/Post }\end{array}$ & $\begin{array}{l}\text { Intention } \\
\text { To Use } \\
\text { Pre/Post }\end{array}$ \\
\hline 1 & $6 / 6$ & $5 / 5.25$ & $6 / 6$ & $5 / 5.5$ \\
2 & $7 / 7$ & $6.5 / 6.25$ & $7 / 7$ & $7 / 7$ \\
3 & $5.5 / 5.75$ & $3.5 / 4.5$ & $5 / 4.67$ & $5 / 5.5$ \\
4 & $6.25 / 6.75$ & $6.25 / 6.75$ & $6.67 / 7$ & $7 / 7$ \\
5 & $6 / 6.5$ & $5.25 / 6$ & $6 / 6.33$ & $6 / 6$ \\
6 & $7 / 7$ & $6.5 / 6.25$ & $7 / 7$ & $7 / 7$ \\
7 & $4 / 4.25$ & $4 / 4.75$ & $4 / 4$ & $4 / 4.5$ \\
8 & $4 / 5$ & $4 / 3.5$ & $4 / 5$ & $4 / 5$ \\
9 & $4 / 6$ & $4 / 6.5$ & $4 / 7$ & $4 / 6.5$ \\
10 & $6 / 6.25$ & $5 / 4.5$ & $5.33 / 5.33$ & $4 / 4$ \\
11 & $6.25 / 7$ & $6 / 6.75$ & $6.67 / 7$ & $6.5 / 6.5$ \\
12 & $4 / 4$ & $4 / 4$ & $4 / 4$ & $4 / 4$ \\
13 & $7 / 7$ & $5.75 / 6$ & $7 / 7$ & $7 / 7$ \\
14 & $6.75 / 7$ & $4.75 / 6$ & $7 / 6.67$ & $6 / 7$ \\
15 & $6 / 6.75$ & $4.25 / 6.25$ & $7 / 7$ & $7 / 7$ \\
& & & & \\
\hline
\end{tabular}

\section{Open-Ended Response}

\section{Qualitative Findings}

For the open-ended response, eleven participants responded. This included one administrator, six special education teachers, two general education teachers, and two 
instructional support members. The responses were coded based upon reported "new" practices that they would be implementing and "confirmed" practices that were already being implemented within their schools and/or classrooms to support any claims regarding the degree of impact participation in the professional development program on participants' practices. Findings for the two open-ended response questions are listed below:

(1) Are there any specific quality indicators from the CRT tool that you plan to implement in your school or classroom? If yes, which ones?

Six participants included new practices that they plan to implement within their school or classroom. Four participants listed confirmed practices, or practices that are already being implemented within their school or classroom. One participant responded with "not sure at this time". The following table is a summary of new or confirmed practices included in participant responses to this question: 
Table 13: Summary of Practices from Participants' Response

\begin{tabular}{|c|c|}
\hline New Practices & Confirmed Practices \\
\hline $\begin{array}{l}\text { - "I would like to concentrate on parent/family } \\
\text { involvement in the educational process of their } \\
\text { child." } \\
\text { "We are struggling to with how to have our } \\
\text { parents involved in the problem solving } \\
\text { process. Time is what we need more of. I would } \\
\text { like to include parents in the [RTI] process } \\
\text { more." } \\
\text { - "Meeting with parents in the community is a } \\
\text { great idea. Often our parents have not had } \\
\text { pleasant school experiences and may be } \\
\text { reluctant to come to the school." } \\
\text { "I would like to work on enlarging our peer } \\
\text { tutoring program." } \\
\text { "Positive behavioral interventions, consistent } \\
\text { discipline expectations, systematic use of } \\
\text { curriculum based assessment." } \\
\text { "School staff validates students' cultural } \\
\text { identities in classroom practices (understands } \\
\text { and integrates students' family makeup, } \\
\text { immigration history and experiences, individual } \\
\text { concerns, strengths, talents and interests into } \\
\text { the curriculum; utilizes students' native } \\
\text { language resources.)" } \\
\text { "Include PBS and Social Skills Instruction as a } \\
\text { part of my daily routine with reading groups." } \\
\text { "I would like to be more culturally aware } \\
\text { during large group academic times. Am I } \\
\text { calling certain students more than others?" }\end{array}$ & $\begin{array}{l}\text { - } \text { "Our PBS is exemplary and school wide } \\
\text { expectations ensure that all students are treated } \\
\text { equally and fairly." } \\
\text { "Yes, we are discussing the logistics of } \\
\text { including parents in discussions during our } \\
\text { problem solving process." } \\
\text { "We already use [a program that centers on } \\
\text { building relationships with our students]." } \\
\text { "Yes, excessive absences or family mobility are } \\
\text { discussed by the instructional team with } \\
\text { detailed and incisive analysis of the impact on } \\
\text { the continuity of general education classroom } \\
\text { instruction for the RCELD students, and } \\
\text { recommendations on how to minimize the } \\
\text { instructional impact in the future." }\end{array}$ \\
\hline
\end{tabular}

(2) Create a three to five step action plan for implementing one or more of the quality indicators you plan on implementing from the above question.

The action plans recorded by participants ranged from general to specific plans. While

considering whether or not the action plans incorporated "new practices" or "confirmed

practices", the action plans were also tallied based on specific culturally responsive themes or

specific quality indicators that were identified in the CRT tool. 
Table 14: Summary of Participant Action Plan Responses

\begin{tabular}{|c|c|}
\hline New Practices & Confirmed Practices \\
\hline $\begin{array}{l}\text { - Four participant action plans focused on plans } \\
\text { for overall parent/family involvement in school } \\
\text { processes, such as: RTI, PBS, absenteeism, } \\
\text { homework, building positive parent-teacher and } \\
\text { parent-child interactions, stronger parent- } \\
\text { teacher collaboration with parents of ESE } \\
\text { students. } \\
\text { Two participant action plans included specific } \\
\text { quality indicators from the CRT tool to support } \\
\text { PBS implementation within their school. } \\
\text { Three participant action plans focused on } \\
\text { building a classroom environment based on } \\
\text { CRT strategies to enhance teacher-student and } \\
\text { student-student relationships. } \\
\text { One participant action plan focused on specific } \\
\text { CRT strategies for incorporating students' } \\
\text { cultures into the curriculum } \\
\text { One participant action plan focused on } \\
\text { collaborating with instructional support staff to } \\
\text { analyze and reflect on potentially biased } \\
\text { behaviors during whole class instruction. }\end{array}$ & $\begin{array}{l}\text { - One participant set up an action plan based } \\
\text { upon PBS strategies already in place at the } \\
\text { school site. }\end{array}$ \\
\hline
\end{tabular}

\section{$\underline{\text { Interviews }}$}

For the interviews, five participants agreed to be interviewed. This included one administrator, two instructional support staff, one general education teacher, and one special education teacher.Interview responses were coded for responses related to beliefs and practices. These themes were analyzed with results from the open ended responses, as well as the surveys. The summary of findings for participant responses related to beliefs and practices, from five structured interview questions are listed below:

(1) How do you feel participation in the professional development module impacted your beliefs about working with students from culturally and linguistically diverse backgrounds?

(2) How do you feel participation in the professional development module will impact your practice in working with students from culturally and linguistically diverse backgrounds?

(3) What, if any, activities, (i.e. the surveys, the questionnaire, the ppt.) from the module was most effective in impacting your beliefs? Why? 
(4) What, if any, activities (i.e. the surveys, the questionnaire, the ppt.) from the module, do you feel will impact your practice? In what ways? Why? What strategies do you intend to use?

(5) Were there any items on the survey, Ppt., or questionnaire that you found to be unhelpful in addressing issues related to your beliefs and culturally responsive practice?

Table 15: Summary of Interview Themes for Beliefs and Practice

\begin{tabular}{|l|l|l|}
\hline Participant & Beliefs & Practice \\
\hline 2 & $\begin{array}{l}\text { Beliefs were confirmed. The module } \\
\text { information helped clarify my responses to the } \\
\text { pre and post surveys. }\end{array}$ & $\begin{array}{l}\text { "The questions made me reflect on a more personal } \\
\text { level. I'm more aware and sensitive [about my } \\
\text { practice." }\end{array}$ \\
\hline 5 & $\begin{array}{l}\text { Stated that beliefs were supported to help to } \\
\text { think more deeply. "I don't reflect as much as I } \\
\text { should. Made me question more about what I do } \\
\text { in my classroom." }\end{array}$ & $\begin{array}{l}\text { "I'm going to reflect more. I get overloaded. It was } \\
\text { need to be more collaborative and reflective." }\end{array}$ \\
\hline 9 & $\begin{array}{l}\text { Prior beliefs were confirmed. Stated that beliefs } \\
\text { have been developed through prior life } \\
\text { experiences. }\end{array}$ & $\begin{array}{l}\text { "I would like to see this used with newer teachers. It } \\
\text { presents [strategies] in an easy to understand format } \\
\text { when they haven't had the life experiences." }\end{array}$ \\
\hline 10 & $\begin{array}{l}\text { Beliefs were validated. The pre and post survey } \\
\text { responses didn't change much. }\end{array}$ & $\begin{array}{l}\text { Confirmed the need to reflect more. "I need } \\
\text { reminders to keep from bad behaviors and old } \\
\text { habits that can be comfortable to fall back into." }\end{array}$ \\
\hline 14 & $\begin{array}{l}\text { Beliefs were confirmed due to already working } \\
\text { in a diverse school. However, stated that, "It } \\
\text { made me think about some things I need to do." }\end{array}$ & $\begin{array}{l}\text { Focused on wanting to implement strategies to get } \\
\text { the community involved and hold parent meetings } \\
\text { in community places. "The biggest piece I got from } \\
\text { this was how to enhance parent involvement } \\
\text { through using local community resources." }\end{array}$ \\
\hline
\end{tabular}

Additional findings from the interviews gave insight into how to enhance the professional development program to support more meaningful outcomes for participants. During the interviews, it was realized that unless participants had printed out their survey responses or the CRT tool, they didn't have the material to refer back to reflect and provide more detailed responses to the interview questions. Two of the interview participants mentioned the need for the program to be completed with a facilitator, allowing for group discussions on the topics. One participant stressed the need for ongoing, follow up support for the strategies listed on the CRT tool, so that the specific needs of individual teachers and staff could be addressed and supported. Two participants also mentioned the need to have the whole staff involved in the professional 
development so that everyone would be on the "same page". Finally, it was suggested by one participant to clarify the place the exceptional student description has in the diversity component.

\section{$\underline{\text { Conclusion }}$}

The findings listed in this chapter from each of the three phases of this research will be synthesized and discussed in the next chapter: Phase one, piloting two of the instruments that were used in phases one and two of this research; Phase two, developing the culturally responsive teaching (CRT) tool; Phase three, a mixed methods case study designed for implementing and evaluating the CRT tool in the context of a professional development module. Findings were listed in sequential order, as findings from phase one led to decisions made for phase two, and findings from phase two led to decisions for phase three. Chapter five will discuss conclusions from these findings as well as implications for future research to improve the CRT for use in other professional development programs with a focus on culturally responsive teaching. 


\section{CHAPTER FIVE: CONCLUSIONS, DISCUSSION, AND SUGGESTIONS FOR FUTURE RESEARCH}

\section{Summary}

Conducted in three phases, the intent of this research was to design and implement a userfriendly, culturally responsive tool to encourage culturally responsive practices in schools and classrooms in hopes of addressing the achievement gap and disproportionality in education. Each phase built upon the last. The intent of phase one was to pilot two of the instruments that would be used in the second and final stages of the research, to ensure content and construct validity of those tools. The two instruments piloted were The Common Beliefs Survey tool and the first round of questions for the Delphi study. Although The Common Beliefs Survey tool had already been developed and validated by the Southern Poverty Law Centers Teaching Diverse Students Initiative, due to a few changes made to the tool, it needed to be piloted with those changes in place to ensure those changes did not affect the validity of the tool.

Phase two centered on the development of a culturally responsive tool to be used in a professional development program with school staff members. The following questions were the center of this phase of the research: (1) Does the tool adequately address the key components of culturally responsive practice, according to expert participants in a Delphi study and an expert review?(2) What are the factors in the design and layout of the tool affecting usability, according to expert participants in a Delphi study? The address the first question, an expert review to illicit the perspectives of expert parent, family, and community members representing students from RCELD backgrounds was conducted for a content analysis of the tool. Then, a Delphi study procedure was followed to answer both questions one and two above. 
During each of the three rounds of the Delphi study, participants were provided with their own feedback, as well as the feedback from other participants and given the opportunity to confirm, change, or add new perspectives and comments on the tool. Precedence was given to the suggestions from the expert review, as changes were begin made based upon participant feedback. Once the final round of the Delphi study was completed, the final version of the tool (appendix D) was drawn up to be included in phase three of this research.

The goal of phase three was to address the overarching research question of this entire study: To what degree does the use of a culturally responsive tool impact the beliefs and practice of schools and school staff related to culturally responsive teaching? To answer this research question, a mixed-method, case study design was implemented with 15 participants from an elementary school in a county that has been cited for disproportionality. The participants included an administrator, general and special education teachers, as well as other instructional support staff. Quantitative data to assess the degree of impact the use of the CRT tool within the context of professional development had on participants' beliefs and practices, was gathered through the use of pre and post surveys. The Common Beliefs Survey tool was used to asses beliefs, the Levels of Use survey tool was used to analyze level of implementation, and the Teacher Acceptance Model was used to assess intentions to use the strategies introduced through the CRT tool and the professional development program. Results were analyzed using dependent t test to measure the statistical significance of all three surveys.

The Qualitative data to assess the degree of impact the use of the CRT tool within the context of professional development had on participants' beliefs and practices, was gathered through open-ended response questions imbedded within the CRT tool and follow-up interviews with five of the 15 participants. Results for the open-ended response questions were coded 
according to reported "new practices" and reported "confirmed practices" to support any claims that the use of the CRT tool during the professional development had an impact on participants' reported practices. The results from the interviews were coded for responses related to beliefs and content related to practice. This qualitative data provides support for findings from the quantitative portion of this phase of the study.

\section{$\underline{\text { Conclusions }}$}

Phase One: Piloting the Instruments

\section{The Common Beliefs Survey Tool}

Findings from piloting The Common Beliefs Survey Tool indicated that there were no issues reported from the participants that needed to be addressed, considering the changes made by shortening the answer response scale from 1-6, to 1-4 and adding the questions pertaining to demographic information. The majority of participants reported "mostly positive" feelings about completing the survey, with one participant reporting feeling "neutral". Due to these findings, there were no additional changes made to the version of The Common Beliefs Survey tool introduced in this research (appendix E).

The Delphi Study Procedure

The main consensus of findings from piloting the first round of the Delphi study questions was the need to clarify the instructions for reviewing the CRT tool, as well as completing the survey evaluating and analyzing the tool. Suggestions regarding the need to clarify instructions included the need to clarify who would ultimately be using the CRT tool when it would be implemented within the context of a professional development program. Overall, participants reported their approval of the content of both the evaluation questions and the CRT tool; however, a few suggestions were made regarding formatting and language. Due to 
the amount of text and information presented in the CRT tool, it was suggested to reformat the quality indicators to ensure that everything related to the critical questions being addressed were able to be viewed on the same page. The phrase "students with RCELD" was also suggested to be changed to either "students of RCELD" or "RCELD students". It was reported that the phrase used initially led participants to feel that the acronym "RCELD" held a negative stigma, rather than a positive description.

\section{Phase Two: Developing the Culturally Responsive Teaching Tool}

\section{$\underline{\text { The Expert Review }}$}

All five participants in the expert review shared positive feelings about the importance of the tool and confirmed much of its content. There were no questions or critical quality indicators that participants felt needed to be omitted, however, there were several that participants suggested needed to be clarified, included, or rephrased to provide more specific examples of strategies for implementing more CRT for the benefit of RCELD students and their families. Table 3 shows the specific suggestions participants had for each of the questions on the initial version of the tool. These suggestions were reviewed to combine repetitious information, compare any discrepancies within participant suggestions, summarize key ideas presented by participants, and omit information as suggested by participants. Changes were made to the tool, based upon the data collected. The adapted version of the tool was presented to participants in the Delphi Study procedure.

The Delphi Study

Appendices B, C, and D show the progress of changes made to the CRT tool based upon feedback collected from both the expert review and the Delphi study. One of the key issues reported by participants that affected feasibility or usability of the tool was the length and layout 
of the tool. Eventually, based upon continued feedback from each of the three rounds, the questions were condensed from the initial 20, to ten. The quality indicators were analyzed multiple times to reorganized based on question themes and what content could be combined. Feedback related to the level of importance of content in the tool was also analyzed to help condense the amount of text and questions addressed. The consensus on what questions were most important helped to prioritize which questions needed to be kept in their original format, and which ones could be omitted from the initial version of the CRT tool.

Other factors that participants reported that needed to be considered was the directions for completing the tool. Several participants noted concerns that they weren't sure how the quality indicators were to be used to answer the questions. The final version of the tool (appendix D) reflects those concerns. Another important issue brought up by participants was how to engage individuals that would be completing the CRT tool in the context of a professional development program, into deeper levels of understanding about diversity. Much of this would have to be addressed by the way the use of the CRT tool would be facilitated within professional development. Overall, each participant reported the tool to be either "important or very important" and "definitely feasible" or "possibly feasible".

Phase Three: Implementing the Culturally Responsive Teaching Tool

\section{Quantitative}

Quantitative findings indicated that there was no statistically significant difference between the pre and post scores of participants related to beliefs, from The Common Beliefs Survey tool. The measure of attitude within the Teacher Acceptance Model supported these findings, as this section also indicated no statistically significant difference between the pre and post scores in this area. There were however, statistically significant data indicated from the pre 
and post scores of the Levels of Use survey and the following areas measured by the Teacher Acceptance Model: perceived usefulness, perceived ease of use, and intentions to use. While quantitative scores did not show an impact in participant beliefs, overall quantitative scores do show an impact in participants reported practice or intentions to use practices associated with culturally responsive teaching as introduced in the CRT tool.

Qualitative

Qualitative data supported the quantitative findings. All of the interview participants reported that rather than seeing a change in their beliefs due to participation in the professional development, beliefs were confirmed, validated, or supported by the strategies presented. Also supporting the quantitative findings, there were differences reported in practice in the qualitative data. For the open ended response questions, the majority of participants reported new practices they plan on implementing and specific strategies were also reported in their action plans for implementing strategies from the CRT within their school or classroom. Furthermore, while the interviews reported little difference in beliefs, participants did site specific strategies that they would implement that they hadn't considered before, or renewed practices related to selfreflection that they wanted to implement. Practices associated with finding more effective ways to facilitate the involvement of RCELD parents and families into school processes was most commonly reported. Other practices included strategies for implementing culturally responsive curriculum, fostering a more culturally responsive classroom environment, and building a culture of reflection. 


\section{$\underline{\text { Discussion }}$}

\section{Rationale for the CRT Tool}

The CRT tool is designed to be instructive for teachers, as well as to provide guidance for ways to more effectively instruct their students. Davis and Krajcik (2005) use the term educative curriculum materials to describe materials that "help to increase teachers' knowledge in specific instances of instructional decision making but also help them develop more general knowledge that they can apply flexibly in new situations,"'(p. 3). This tool is intended to be a fluid document that involves people at various levels within the school systems: general education teachers, special education teachers, administration, instructional support staff, parents, family, and related community members of RCELD students. It is intended to promote a way of thinking, as well as a means of practice.

Petrina (2004) argues that education at any level is a political process. He continues by stating that in order to create curriculum materials intended to marry the worlds of theory, policy, curriculum design and practice that bring about reforms in education, a critical curriculum reform rationale should be adopted. As with critical pedagogy, critical curriculum reform rationale recognizes inequitable power structures that privilege certain voices over others. In line with Klinger et al. (2005), including the voices of policy makers, practitioners, and stakeholders provide opportunities for a more equitable approach to enacting curriculum reforms. Following an adapted model used by Feildler, Chiang, Van Haren, Jorgensen, Halberg, and Boreson (2008)to create their tool to address disproportionality, this CRT tool has and will continue to go through several stages of development; each stage involving voices at various levels within the education system. 
The initial version of the CRT tool was created from several resources. The template began from Feildler et al.'s (2008) work. Through an extensive review of the literature related to culturally responsive teaching, policy affecting disproportionality in education, and the merger of Lue Stewart's (2009) inventory and Considerations for Culturally Responsive Teaching, this tool was analyzed, edited, adapted, and expanded.

$\underline{\text { Limitations/Delimitations }}$

The process of attending to both the educational and socio-cultural dimension within the teaching-learning dynamic involving any instructional tool, calls for an engaged pedagogy (Hooks, 1994). This type of "engaged pedagogy" (Hooks, 1994) can only be developed through a stance of inquiry (Cochran-Smith, 2004), rather than a set of "best practices". It involves a humble stance where one is willing to dialogue and share decision-making power with all of those involved in our students' development as individuals, and as members and contributors to our communities (Sleeter, 2004). Therefore, the author cautions the use of the CRT tool as a "quick fix" approach to addressing the complex issues of the achievement gap and disproportionality.

For the three phases of this study, the hope is that a model tool for professional development can be implemented that encourages this "stance of inquiry", over a staunch list of do's and don'ts related to culturally responsive teaching. The goal is that administrators, teachers, and students and their parents, families, and related community members become involved in a broader view of the learning process, that involves reflective and reflexive praxis, (Duarte \& Fitzgerald, 2006; Slattery, 2006). The process involved with creating and using the CRT tool seeks to empower the school community to enact changes addressing the specific needs of their student population (Klinger et al., 2005). Furthermore, the intended purpose of the 
tool is more to help educators engage in reflective practice. It is not to be used as a punitive evaluative measure for schools and teachers who are not addressing all of the quality indicators listed. It is crucial that authority figures at the state, district, and school levels understand the inherent purpose of the tool as discussed here.

Phase Two: Developing the CRT Tool

The data collection process in this study indicated findings and recommendations for ways to enhance this tool for future professional development practice from its initial format (appendix B) to the final format used in phase three (appendix D). The following questions were addressed: Does the tool adequately address the key components of culturally responsive practice, according to expert participants in a Delphi study and an expert review? What are the factors in the design and layout of the tool affecting usability, according to expert participants in a Delphi study? Once all the recommendations were addressed, there was more than $80 \%$ consensus reached that the tool was feasible and important. However, the specific recommendations offered by participants in both studies, helped to refine the tool so that it is more user-friendly and addresses more than just a surface level of diversity (Banks, 2007; Bennett, 2003; Delpit, 2006). Garcia \& Guerra (2004) and Weiner's (2006) work both address the need to view RCELD students and their families as assets. Many of their suggestions about dispositions and strategies for fostering a school environment that treats diverse students and their families as assets were reiterated by both the parent and community experts in the first review, as well as the experts in the Delphi study.

There was one area of discrepancy between the literature, feedback from the expert review, and feedback from one participant in the Delphi study. Banks (2007) addresses the four levels of multicultural curriculum reform: Contributions Approach, Additive Approach, 
Transformation Approach, and Social Action Approach. Although Banks (2007) argues that all of the approaches are important at various levels of curricular reform, some argue that only the last two of his approaches are able to bring about meaningful change. These researchers argue that a more critical look at the role of race and culture in teaching and learning needs to happen before educators can truly address the inequities occurring in education (Gorey, 2009; Kraft, 2007; Ladson-Billings, 1995, 2007; Moll, et.al., 2005; Schofield, 2007; Seidl \& Pugach, 2009; Shealy, 2006; Sleeter, 2001, Stevenson, 2008.)

In line with these researchers, a few of the expert participants in the Delphi study criticized question one from the first version of the tool: Does the school culture support and celebrate diversity and view students of RCELD (racial, cultural, ethnic and linguistic diversity) as assets? Their criticism expressed concerns that this question allowed teachers and schools to continue addressing diversity issues on a surface level, which can actually be a detriment to the development of CRT in schools (Jay, 2003). However, all of the parent and community participants in the expert review had recommendations confirming the importance of celebrating these "surface level", cultural contributions regularly at school. While it is agreed that deeper conversations and critical thinking must occur to break the inequitable structures that exist in our schools, I also agree with Bank's (2007) assertion that all levels of reform are important and useful. With these two conflicting ideas, I chose to keep the surface level suggestions that those in the expert review shared, while including the need for professional development to address the Transformation and Social Action Approaches as well.

Data from phase two led to recommendations that the final version of the tool be piloted for use as intended, within the context of professional development addressing culturally responsive practices in schools. It was also recommended that a more flexible approach to the 
tool would be used, as necessary to address the specific needs of each school site. In line with one of the major priorities driving this study, parent and community voices at each particular school site should be included in the development and completion of this questionnaire in order to include what is most meaningful to the particular socio-cultural contexts of each setting. It would be interesting to see ways the tool could be adapted for the needs of several school sites and compare strategies that appear to be generalizable, with those that are more contex-specific.

While the intent is to provide a practical, succinct, user-friendly tool to introduce participants to culturally responsive strategies, the instrument should also be considered as a means of revealing deeper issues that may be addressed at each school site. Once those deeper issues are identified, more professional development and mediated experiences will need to be facilitated to address issues of power, race, culture, language, ethnicity in creating a more equitable educational experience for our students and their families (Seidl \& Pugach, 2009).

Phase Three: Implementing and Evaluating the Culturally Responsive Tool $\underline{\text { Beliefs }}$

Findings from both quantitative and qualitative findings showed that the use of the CRT tool within the professional development program had relatively no impact on participants' beliefs. All of the interview participants reported that rather than having a change in their beliefs as a result of completing the professional development program, their beliefs were confirmed and supported. Three of the interview participants mentioned life experiences and the history of working in their school, which has a strong focus on diversity, especially on meeting the individual needs of students with special needs. The benefit of having a school with such a strong history of working with diverse students participate in this research is the unique perspectives participants were able to provide on the components of the CRT tool. 
Many of the participants fit the expert criteria from the Delphi study in phase two.

Findings from phase two led to recommendations to pilot the CRT in the context of a professional development module, not only to answer the research question: To what degree does the use of a CRT tool in professional development impact the beliefs and practices of teachers? But, also to address ways to enhance the tool for the specific needs of school sites, which was discussed in the "Rationale for the CRT tool" section of this chapter (p.69).

Research on the Concerns Based Adoption Model stresses the need for extended ongoing support if professional development is to bring about meaningful reform in participants' beliefs and practices (Frank, 2009; Loucks-Horsley, 1996). Three of the interview participants discussed the need for facilitation and extended support for helping school staff members implement the practices addressed in the CRT tool. For school staff members that were not already characterized by having dispositions toward diversity, the CRT tool would need to be implemented within the context of mediated discussions about race and culture, opportunities for authentic experiences spending time with and learning about unfamiliar cultures represented within the community, and ongoing professional development and resources for implementing these practices within their schools and classrooms (Seidle \& Pugach, 2009). Change in beliefs can be difficult and uncomfortable. Our beliefs are deeply embedded in the history of our family, personal experiences, and the various areas of our unique culture and traditions (Applebaum, 2008; Aveling, 2006; Bennett, 2003; Cross, 2003; Giroux, 2001; Hooks, 1994; Jay, 2003; North, 2009; Mitchell, 2007; Sleeter, 2001; Slattery, 2006).

\section{$\underline{\text { Practices }}$}

Findings from both quantitative and qualitative findings showed that the use of the CRT tool within the professional development program had a significant impact on participants' self- 
reported practices and intentions to use the culturally responsive strategies addressed by the CRT tool. The majority of participants reported new practices and specific strategies from the CRT tool that they plan on implementing that they hadn't considered before, or reported a renewed commitment to practices related to self-reflection that they wanted to implement. Practices associated with finding more effective ways to facilitate the involvement of RCELD parents and families into school processes was most commonly reported. Other practices included strategies for implementing culturally responsive curriculum, fostering a more culturally responsive classroom environment, and building a culture of reflection.

However, this is where the CBAM research is again relevant. In order to ensure the implementation of such practices, extended ongoing support is needed (Frank, 2009; LoucksHorsley, 1996; Seidl \& Pugach, 2009). While the Teacher Acceptance Model (TAM) showed an overall increase in participants' perceptions regarding the perceived usefulness, ease of use, and intentions to use from the pre survey to the post survey, several individual responses to specific questions on the TAM survey related to ease of use suggest the need for resource support and ongoing professional development training in strategies that can be implemented within the specific content of their day to day lesson plans.

One positive factor from this research, however, that supports the claim that participation in the professional development program using the CRT tool will affect future practice, was the evidence of administrator support for implementing many of the suggested strategies in the CRT tool. Specific goals and strategies were stated by this participant in order to increase and enhance the involvement of the parents and family members of RCELD in school processes. The work of Provost, Boscardin, and Wells (2010) presents principles for principal leadership that aligns with the models of site-based management and instructional leadership that support 
educational reform. While collaboration and shared leadership amongst an entire school faculty and staff is important for reform, the role of the administrator is significant.

\section{$\underline{\text { Suggestions for Practice and Future Research }}$}

Based upon the findings from each of the three phases of this research, suggestions for phases one and two include suggestions for enhancing the research procedures. Suggestions for phase three will include suggestions for enhancing the research procedures, as well as enhancing practice, as evidenced by the findings from this portion of the research. As with any research process, there are limitations to the design method that is chosen, as well as limits to what can be deemed as generalizable findings. The case study design in phase three, does not allow for claims of generalizability; however, implications for ways to improve educational practice, based upon similar settings can and are addressed.

Phase One: Piloting the Instruments

\section{The Common Beliefs Survey}

Piloting the Common Beliefs Survey tool was done completely via email and online survey. Due to time limitations, participants that completed the review of this instrument did not provide detailed responses on ways to enhance the tool. Also, participants were not required to turn in a copy of the Common Beliefs Survey they were asked to complete and evaluation. Recommendations for enhancing this portion of the research would include the following: (1) Include specific directions to have participants complete and turn in their responses to the Common Beliefs Survey that they are being asked to review and evaluate. It is important that participants completed the survey to ensure that their responses evaluating the tool were meaningful. The process completed in this portion of this study, did not provide proof that each 
participant fully completed the Common Beliefs Survey before answering the evaluation questions. (2) If possible, have participants complete the Common Beliefs Survey tool and the evaluation questionnaire in person, with a facilitator. Permission and time was not given to allow for this review to be done in person, however results could be more verifiable if done with a facilitator. (3) Finally, require a response to the open-ended response questions on the questionnaire evaluating the tool. Participants were not required to answer any of the open-ended response questions, which would have certainly encouraged more detailed responses. The Delphi Study

The Delphi study process itself takes a significant amount of time. It is not possible to pilot every question presented in every round, nor is it required. Taylor-Powell (2002) recommends pre-testing the questionnaire for the first round of the Delphi study to ensure proper wording and that any ambiguities or vagueness have been addressed. Because the questionnaire was being developed solely by the researcher, it was important to have the content reviewed by similar experts in the field to be sure the questions were addressing the goal of the Delphi Study. Two of the participants reviewing the first round of Delphi study questions at first, responded as a Delphi participant, rather than a reviewer addressing the questions. This confusion was addressed over the course of a few emails. Suggestions for avoiding this discrepancy in future studies would be to send an introductory email requesting participation. Then, provide an initial phone call or face to face meeting to go over the purpose of the Delphi study and the role you are asking them to fill to review the first set of Delphi questions. 
Phase Two: Developing the Culturally Responsive Tool

\section{The Expert Review}

The participants in this portion of the study provided valuable feedback on the tool. Each of the five participants represented students that lived and attended schools within relatively the same neighborhood area. All participants were African-American. The acronym RCELD addresses diverse racial, cultural, ethnic, and linguistic student populations. I would recommend for future practiced, as time allows, that a more diverse group of participants be included in the expert review. Planning focus group sessions at various local community centers and schools ensuring that parents, family, and community members from RCELD groups of individuals could possibly provide the opportunity for other perspectives to be considered that were not in this study. Specifically, when working with participants whose first language is not English, planning for a translator is important. The timeline for this research, did not allow for such an in depth review. Future research could focus solely on the expert review portion of this study to include the voices of policy makers, practitioners, and stakeholders provide opportunities for a more equitable approach to enacting curriculum reforms (Klinger et al., 2005).

\section{The Delphi Study}

The three rounds of the Delphi study, including 16 participants took an extensive amount of time. While the initial planning stages of this portion of the study was to allow a total of two months to complete all three rounds, based on the suggestion of Turoff and Linstone (2002) and Hsu and Sandford (2007), participants should be provided enough time to provide meaningful feedback for each round and a limited time, so the pitfalls of having each succeeding round fall out of the perimeters of participants' short term memories. A maximum of two weeks was given to participants to complete each round of responses; however, to prevent attrition, a significant 
amount of additional time was given to participants after the two week deadline. This stretched the timeline from two months to nearly five months. I would recommend having more participants initially to allow room for attrition in order to keep to important deadlines.

Another issue to be addressed in future research using this method, which related to the timeline issue, was that each round of feedback required more time on the part of participants to complete. It was predicted that each questionnaire would take up to 30 minutes, when participants reported up to an hour to an hour and a half to review the information thoroughly and provide meaningful feedback. In the future, I would recommend that the initial questionnaires be condensed with the goal of shortening the time required of participants. Allowing for more open-ended responses encouraged more in depth feedback, which although took more time to review, provided opportunities for shared perspectives that would not have been included if only quantitative questions were used. The nature of the questionnaires could be adapted to only include qualitative or quantitative responses, depending upon the goal of the researcher using this method.

Phase Three: Implementing and Evaluating the Tool

\section{Quantitative Procedures}

For future research using the survey tools, the Common Beliefs Survey, the Levels of Use survey, and the TAM measure, some changes are suggested. The results from the Common Beliefs Survey showed no statistically significant difference in the scores between the pre and post survey. I would recommend that the initial response options offered by the Southern Poverty Law Center's Teaching Diverse Students Initiative be used, to allow for neutral responses, as well as open-ended response. This change might encourage a broader range of responses. Also, based upon feedback within the interviews, it seemed as though some participants were trying to 
find the "right" answer. The correct response to each of the statements, based upon the instruction provided by modules on the Southern Poverty Law Centers Teaching Diverse Students Initiative, would be for participants disagree or fall neutral to each of the statements, based upon the complexity surrounding each of the belief statements. Most participants however, agreed with most statements, and there was no consistency between agreement and disagreement between the two pre and post test responses. In fact, many participants changed beliefs from disagreement to agreement from the pre and post measures.

Even though the piloting of the instrument in phase one initially confirmed construct and content validity, findings from this final phase of the research, has put that into question, as the Common Beliefs Survey tool may not adequately measure beliefs specifically addressed in the professional development program. I would recommend that either the professional development program utilize some of the resources related to each of the belief statements offered by the Southern Poverty Law Center's Teaching Diverse Students Initiative, or another measure for beliefs be used, such as the The Multicultural Assessment Items offered by Dettmer, Thurston, Knackendoffel, and Dyck (2009) (appendix K).

Other suggestions on the quantitative portion of the research procedures involve the Levels of Use Survey. The Levels of Use Survey is a part of the Concerns Based Adoption Model (CBAM) which is used to assess level of practice and implementation. The framework for CBAM, when used holistically, includes three areas for measuring implementation of practices participants have been trained to use in professional development over time so that facilitators can provide ongoing support for changes implemented (Frank, 2009). The three areas measured are Stages of Concern, Levels of Use, and Innovation Configurations. 
Due to the design and limited timeline available for this study, the Levels of Use Survey was used to assess where participants identified themselves on the survey. Appendix F shows general descriptions of the seven levels. The Levels of Use Survey also includes an interview sequence component (appendix G). For future research, I would recommend the use of the Levels of Use survey, as well as the interview sequence for studies that allow for a longer time frame of completion. It would be interesting to conduct a separate study using all three areas of the CBAM as both a formative and summative assessment tool to address participants' level of implementation.

\section{Qualitative Procedures}

For the open-ended response questions, participants were asked to list specific strategies from the CRT tool that they will implement and to create a three to five step action plan for implementing those strategies. Research shows that when participants create a plan of action, they are more likely to implement those practices on their own in the future (Hoffman, Dahlman, Zierdt, 2009). The action plan possible in this research, however, was limited due to the scope and limited timeframe for completing this portion of the study. For future research opportunities, it is recommended that directions for completing a more integrated action plan of the strategies listed with the current curriculum available at the school site be included in this portion of the qualitative study.

The interviews were conducted via phone, through five structured interview questions. If possible, it is recommended that the interviews occur face to face to allow more time response time, as well as to ensure that participants could respond base upon the materials included in the professional development program. Some of the participant responses were limited, because of the participant's lack of immediate access to the materials used in the program. 


\section{$\underline{\text { Addressing Beliefs and Practice }}$}

Both quantitative and qualitative data indicated no statistically significant difference in the pre and post scores of the Common Beliefs Survey tool, as well as the area measuring attitude in the TAM measure. Because of the background experiences of participants, beliefs and attitudes were reported as confirmed, rather than changed. It is suggested that future research be done with a broader range of schools in different settings, particularly in schools where student populations are not as high in diversity. Furthermore, in order to impact beliefs of future participants that do not hold similar dispositions toward diversity, there is much to be considered.

The concept of Cognitive Dissonance (Lidwell, Holden, \& Butler, 2010) is an important one for educators to consider as they seek to change teacher and other school staffs' attitudes and beliefs related to diversity. When people are faced with dissonance they will seek to resolve the dissonance by minimizing the perceived risk of the dissonance, integrating more agreeable or "comfortable" ideas with the dissonant ones, or disregarding them altogether. Lidwell et al. (2010) advises that that the "probability of changing attitudes and beliefs [relies on the] critical point known as the point of minimum justification. Often times, those educators passionate about issues such as the achievement gap and disproportionality, as well as other inequitable educational consequences many RCELD students experience, can bombard pre-service teachers with too many dissonant thoughts that challenge previous beliefs and attitudes about difference and diversity. As teacher educators seek to engage in difficult or dissonant dialogues with school staff, they must consider this concept if they are to affect change in both beliefs and practice, beyond surface level integrations of diversity in K-12 school and classroom level multicultural education programs, which can negate the very purpose of such programs (Jay, 2003). 
There was a statistically significant difference found in both quantitative and qualitative findings measuring the impact of the use of the CRT tool in a professional development program, on participants' practice. It can't be understated, that in order for sustainable, meaningful curricular reforms to occur, there must be facilitated discussions and long-term follow-up during and after implementing professional development. Future research suggestions include follow up studies with this particular school, for longitudinal design, that includes facilitation and follow up. Qualitative studies specifically analyzing mediated discussions with participants regarding issues of race, culture, ethnicity, and language in schools, could provide rich insights into the way discussions are mediated, and how these discussions might affect practice.

\section{Final Thoughts}

The end result of the three phases of this research, led to the development, implementation, and evaluation of a culturally responsive tool to be used in professional development with school staff members to encourage CRT practice as a means of addressing the achievement gap and disproportionality in education. While the intent was to create a userfriendly tool for participants to use to encourage reflection and change in practice, there is certainly no quick, easy fix to addressing these issues. It takes a long-term commitment to issues of social justice in education to find useful and meaningful ways to address the inequitable structures and belief cycles that contribute to issues such as the achievement gap and disproportionality.

It is important to note that the school is only one setting for change. There are other, larger societal structures at work contributing to the devaluation of difference. Professional development is one means of addressing these issues. In order to affect change outside the school system, as well as within, collaboration with local and state community leaders and institutions is 
also crucial. Each school setting and community has its own context. Seeking the voices of parents and families within the local community is also important. The process of reform is multifaceted and is rarely, if ever, an exact science. The effort put forth in this research was to provide one means of facilitating practices that lead to reform. It is the hope of the researcher, that the culturally responsive tool presented continues to adapt and change for the specific needs of schools, classrooms, and individual students and their families, in the same way that we, as transformative intellectuals and culturally responsive educators must continue to adapt and change for the specific needs of our schools, classrooms, and individual students and their families.

\section{The Role of the Researcher}

It is difficult, if not impossible, to separate the human element out when conducting research, especially when qualitative procedures are involved. Through the multiple phases of this research, there were at times decisions that had to be made based solely on the preference and lens of the researcher and then the limitations and delimitations of those decisions also had to be addressed. I approached this research with 10 years experiences in education. The first eight years involved teaching in grades K-3 and the latter three involved coaching, mentoring, and research roles in teacher preparation programs. My first year teaching was a struggle for me as I started teaching in the middle of the year, with a group of first grade students that had experienced too much transition and hardship, as I was the fourth teacher to be assigned to their class that year. This beautiful, diverse group of students consisted of several students with emotional behavioral disorders and various learning disabilities, with the majority coming from economically disadvantaged backgrounds. 
I was at a loss and considered leaving them with a fifth new teacher, until I discovered, through trial and error, and a touch of prior familial background experiences, some valuable lessons. First, I had to find a way to step over my fears of the many angry parents and family members and find ways to connect and collaborate with them on behalf of their child. Second, I had to take ownership of all of my students, regardless of the categories they had been placed in, and commit to finding way to address their needs both academically and relationally as individuals. Finally, I had to spend many long hours researching new strategies to implement through talking with other teachers, administrators, and parents and then spend another set of hours reflecting on how effective those strategies were. What began as a gut-wrenching, emotional first-year teaching experience, ended in triumph and some solid lessons I've carried with me through these past 10 years as a teacher and teacher leader.

It is with this experience in mind that I chose to seek out the parent, family and community voices for this project, and when conflicts arose, I also chose to prioritize these voices over the professional. If it weren't for those parents and family members from that first teaching experience, I wouldn't have made the headway with those students that I did and I'm sure wouldn't be the teacher and researcher I am today. It took deliberate efforts to get out of my comfort zone and find new ways of being than I expected to have to find when I first entered that classroom. I also couldn't have sustained those first efforts if it weren't for the support and advice of other teachers, both general and special education, as well as other leaders within the school. This is why I chose to collaborate with so many other professionals to bring insights into this work. The road of collaboration with individuals, at times vastly different than ourselves, is not easy, but the rewards of committing to the struggle have led to new insights and more equitable experiences for the students we teach. I am fully convinced that no matter what race, 
culture, ethnicity, linguistic backgrounds we come from, with deliberate effort, motivated by a commitment to the belief that all experiences are highly valued, and worthy of our efforts, we can create transformative moments within our classrooms, that feed into transformational acts in the society at large. 
APPENDIX A: PILOT QUESTIONS REVIEWING THE COMMON BELIEFS SURVEY TOOL 


\section{Reviewing The Common Beliefs Survey Tool}

Thank you for providing us with your perspectives on the Common Beliefs Survey tool that will be used in future research to assess teacher and school staff beliefs related to diversity. All responses will be kept confidential. Your comments are valued and appreciated.

What is your current position? (i.e. grade/subjects taught, general or special education, instructional support staff, administration, etc.)

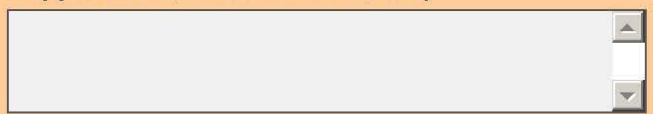

Approximately how long did it take you to complete the survey?
$\square$ 5-10 minutes
$\square$ 10-15 minutes
$\square$ 15-20 minutes
20-30 minutes
more than 30 minutes

Were the instructions for completing the survey clear?

$\square$ yes
$\square$ no

If no, please explain

Were any survey questions unclear or ambiguous? If yes, which ones?

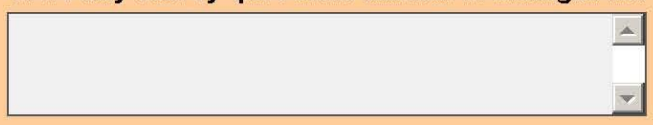

Did you object to answering any questions? If yes, please explain which questions and why.

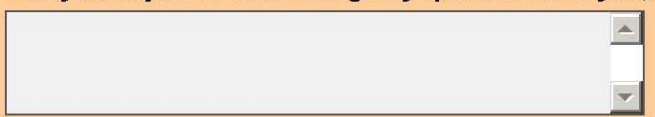

Are there any questions you feel should be omitted from the survey? If yes, please explain which questions and why.

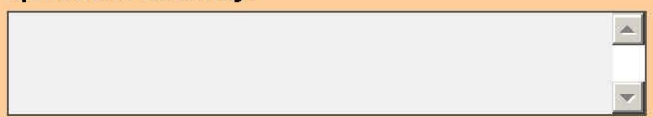




\section{Reviewing The Common Beliefs Survey Tool}

Are there any questions you would change the wording on? If yes, please explain which questions and include recommendations for changes.

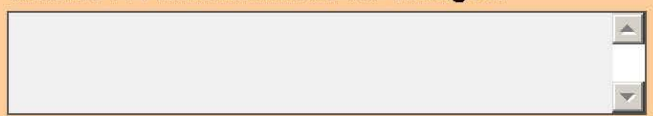

Are there any questions or topics that you feel should have been included with this survey that were not? If yes, please include recommendations here.

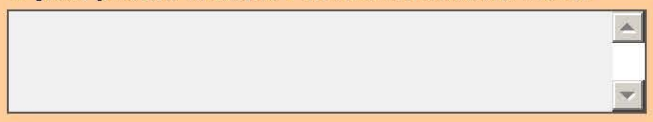

Overall, what are your feelings about this survey?

$\square$ mostly positive

$\square$ mostly negative

$\square$ neutral

Other (please specify)

Finally, please provide any suggestions for ways this survey could be improved for future use with teachers and other instructional support staff for assessing beliefs related to diversity issues in schools and classrooms.

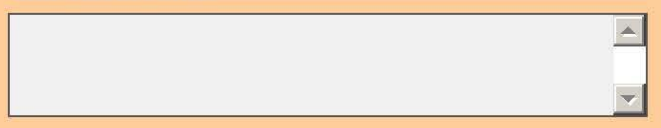


APPENDIX B: INITIAL VERSION OF THE CRT TOOL 


\section{Culturally Responsive Beliefs and Practices of Schools and General Education Classrooms}

Participants: Participants completing this checklist should include the following persons aware of school and classroom procedures and policies: general education teachers representing various grade levels, special education teachers, school psychologists, administration team members, instructional support staff, parents and community members of RCELD students.

Quality Indicators: Examples of best practices are offered to illustrate appropriate responses to the critical questions. The list may be edited to reflect options available to each school site.

Rubrics: A rubric is provided for each critical question to assess to what degree the school has addressed each item.

Note: To be as inclusive as possible, references to families within this checklist may refer to biological parents, step-parents, adoptive or foster parents, legal guardians, other family members such as grandparents, aunts, uncles, etc. and to "social family members." Social family members are not biologically related members of the student's family, but, nevertheless, play an important part in the student's family life and upbringing.

\begin{tabular}{|c|c|c|c|}
\hline Critical Questions & Participants & Quality Indicators & Rubric (Circle the \# most applicable) \\
\hline \multicolumn{4}{|c|}{ School Culture and Supports } \\
\hline $\begin{array}{l}\text { 1. Does the school culture support } \\
\text { and celebrate diversity and view } \\
\text { RCELD students (racial, cultural, } \\
\text { ethnic and linguistic diversity) as } \\
\text { assets? }\end{array}$ & & $\begin{array}{l}\text { - School staff participates in } \\
\text { ongoing staff development related } \\
\text { to diversity issues: including } \\
\text { opportunities for teachers to share } \\
\text { and reflect on their own cultural } \\
\text { beliefs and biases, opportunities } \\
\text { for teachers and staff to become } \\
\text { knowledgeable about the various } \\
\text { RCELD populations and resources } \\
\text { in the surrounding community } \\
\text { Resources are provided for } \\
\text { teachers to develop lessons } \\
\text { fostering an appreciation and deep } \\
\text { understanding of diversity } \\
\text { School environment contains } \\
\text { evidence of contributions/work } \\
\text { from individuals with diverse } \\
\text { backgrounds on a regular basis, } \\
\text { not just during a special week or } \\
\text { month } \\
\text { Classrooms contain evidence of } \\
\text { contributions/work from }\end{array}$ & $\begin{array}{l}\text { 1. The school makes little or no attempt to acknowledge and } \\
\text { celebrate diversity. } \\
\text { 2. The school acknowledges and celebrates diversity during a } \\
\text { special time of the school year. } \\
\text { 3. The school and classrooms acknowledge and celebrate } \\
\text { diversity on a regular basis. } \\
\text { 4. Acknowledgement and celebration of diversity permeates the } \\
\text { school and classrooms with frequent and varied examples. }\end{array}$ \\
\hline
\end{tabular}




\begin{tabular}{|c|c|c|c|}
\hline Critical Questions & Participants & Quality Indicators & Rubric (Circle the \# most applicable) \\
\hline $\begin{array}{l}\text { 2. Does the school have a positive } \\
\text { behavioral support system for } \\
\text { ALL students? }\end{array}$ & & 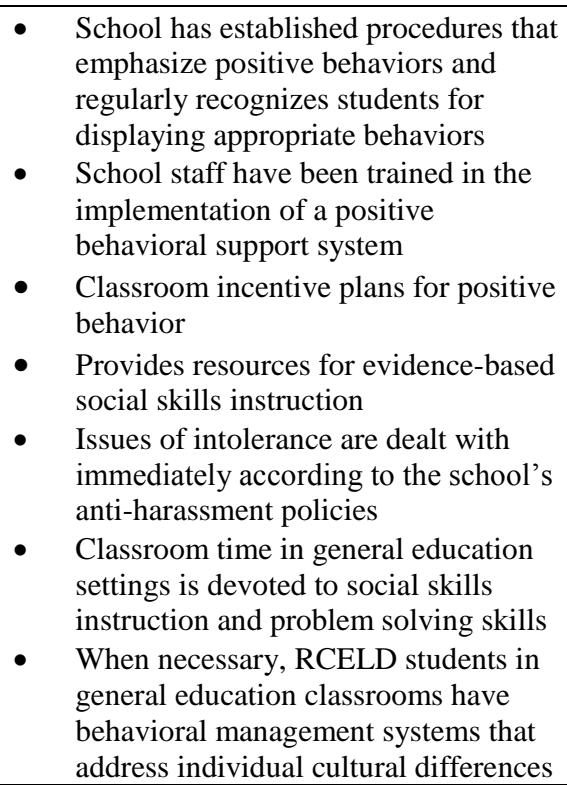 & $\begin{array}{l}\text { 1. The school does not have a positive behavioral support } \\
\text { system in place. } \\
\text { 2. The school has begun to implement a positive behavioral } \\
\text { support system for all students. } \\
\text { 3. The school has implemented a positive behavioral support } \\
\text { system for all students and staff have been trained in its use. } \\
\text { 4. The school has implemented a positive behavioral support } \\
\text { system for all students, staff have been trained in its use, and } \\
\text { school staff regularly discuss the effectiveness of school-wide } \\
\text { positive behavioral support interventions. }\end{array}$ \\
\hline
\end{tabular}




\begin{tabular}{|c|c|c|c|}
\hline Critical Questions & Participants & Quality Indicators & Rubric (Circle the \# most applicable) \\
\hline $\begin{array}{l}\text { 3. Has the school principal } \\
\text { established an attitude amongst } \\
\text { staff that "all students are our } \\
\text { students" as opposed to an } \\
\text { attitude of "my students and your } \\
\text { students?" }\end{array}$ & & 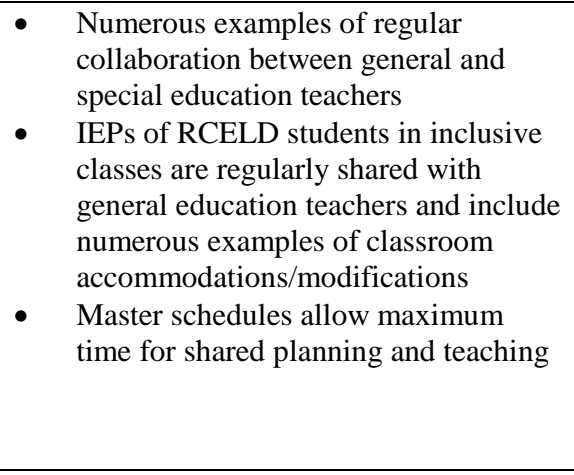 & $\begin{array}{l}\text { 1. The prevailing attitude of school staff fosters isolation and little or } \\
\text { no collaborative interaction between general education teachers, special } \\
\text { education teachers, and other support staff (e.g., related services, ESL). } \\
\text { 2. The prevailing attitude of school staff fosters minimal collaborative } \\
\text { interaction between general education teachers, special education } \\
\text { teachers, and other support staff. } \\
\text { 3. The prevailing attitude of school staff fosters regular collaborative } \\
\text { interaction between general education teachers, special education } \\
\text { teachers, and other support staff. } \\
\text { 4. The prevailing attitude of school staff fosters extensive and effective } \\
\text { collaborative interaction between general education teachers, special } \\
\text { education teachers, and other support staff. }\end{array}$ \\
\hline $\begin{array}{l}\text { 4.Do teachers (e.g. general } \\
\text { education, ESL, special } \\
\text { education) work collaboratively } \\
\text { to support all students? }\end{array}$ & & $\begin{array}{l}\text { - Peer support mentors are provided for } \\
\text { instructional team members } \\
\text { - } \quad \text { Co-teaching observed } \\
\text { Co-planning observed, including } \\
\text { regular, collaborative discussions } \\
\text { regarding specific staff and teacher } \\
\text { roles and responsibilities, as well as } \\
\text { accommodations for individual } \\
\text { students }\end{array}$ & $\begin{array}{l}\text { 1. There is little or no collaboration between general education } \\
\text { teachers, special education teachers, and other support staff (e.g., } \\
\text { related services, ESL). } \\
\text { 2. There is minimal collaboration between general education teachers, } \\
\text { special education teachers, and other support staff. } \\
\text { 3. There is regular collaboration between general education teachers, } \\
\text { special education teachers, and other support staff. } \\
\text { 4. There is extensive and effective collaboration between general } \\
\text { education teachers, special education teachers, and other support staff. }\end{array}$ \\
\hline $\begin{array}{l}\text { 5. Are differentiated reading } \\
\text { interventions (e.g., Title I, Read } \\
\text { 180, Reading Recovery) available } \\
\text { to RCELD students? }\end{array}$ & & $\begin{array}{l}\text { - Reading teachers or specialists are } \\
\text { providing services to RCELD students } \\
\text { in inclusive environments } \\
\text { Reading teachers/specialists are } \\
\text { regularly consulting with general } \\
\text { education teachers on reading } \\
\text { interventions and the effects of the } \\
\text { interventions } \\
\text { Multiple reading levels and } \\
\text { instructional groupings are used by } \\
\text { general education teachers } \\
\text { ESL, Special Ed and General Ed staff } \\
\text { receive common professional } \\
\text { development } \\
\text { When necessary, 1-to-1 reading } \\
\text { support is provided daily }\end{array}$ & $\begin{array}{l}\text { 1. There are no differentiated reading interventions provided to } \\
\text { RCELD students in general education classrooms. All students in } \\
\text { general education receive the same type and intensity of reading } \\
\text { instruction. } \\
\text { 2. General education teachers receive consultation services from } \\
\text { special education teachers, reading teachers or other specialists } \\
\text { periodically. There is some differentiation of reading interventions for } \\
\text { RCELD students in general education classrooms. } \\
\text { 3. General education teachers receive consultation and direct services } \\
\text { from special education teachers, reading teachers or other specialists } \\
\text { regularly. There are numerous examples of differentiation of reading } \\
\text { interventions for RCELD students in general education classrooms. } \\
\text { 4. General education teachers receive consultation and direct services } \\
\text { from special education teachers, reading teachers or other specialists on } \\
\text { a regular and consistent basis. There are numerous examples of } \\
\text { differentiation of reading interventions for RCELD students in general } \\
\text { education classrooms. }\end{array}$ \\
\hline
\end{tabular}




\begin{tabular}{|c|c|c|c|}
\hline Critical Questions & Participants & Quality Indicators & Rubric (Circle the \# most applicable) \\
\hline $\begin{array}{l}\text { 6. Has the school adopted a } \\
\text { problem solving approach that } \\
\text { values assessment to drive } \\
\text { instructional decisions? }\end{array}$ & & $\begin{array}{l}\text { Problem-solving teams are active } \\
\text { and engaged in problem solving } \\
\text { discussions on a regular basis } \\
\text { - Student progress-monitoring data } \\
\text { is used to track performance and } \\
\text { evaluate school practices } \\
\text { - Examples of problem-solving } \\
\text { teams implemented interventions } \\
\text { with data on targeted behavior(s) } \\
\text { of a student of RCELD for a } \\
\text { reasonable amount of time. } \\
\text { - Problem-solving teams provided } \\
\text { follow-up support and monitoring } \\
\text { of planned interventions } \\
\text { Multiple data sources are used to } \\
\text { evaluate student learning: i.e. } \\
\text { standardized tests, informal } \\
\text { assessments, observations, verbal } \\
\text { and written assessments, } \\
\text { assessment data from years prior } \\
\text { Families encouraged to participate } \\
\text { in problem solving discussions to } \\
\text { include information about students } \\
\text { home and family culture, } \\
\text { language, and social history. } \\
\text { Data from general education } \\
\text { classroom interventions designed } \\
\text { to provide academic and/or } \\
\text { behavioral support to a student of } \\
\text { RCELD }\end{array}$ & $\begin{array}{l}\text { 1. The school has not implemented a problem solving process } \\
\text { to review the academic performance of RCELD students. } \\
\text { 2. The school has implemented a problem solving process to } \\
\text { review the academic performance of RCELD students. } \\
\text { Systematic implementation and monitoring of recommended } \\
\text { interventions is inconsistent. } \\
\text { 3. The school has implemented a problem solving process to } \\
\text { review the academic performance of RCELD students. } \\
\text { Systematic implementation and monitoring of recommended } \\
\text { interventions is usually provided. } \\
4 \text {. The school has implemented a problem solving process to } \\
\text { review the academic performance of RCELD students. } \\
\text { Systematic implementation and monitoring of recommended } \\
\text { interventions is always provided and there is ample evidence of } \\
\text { revisions to interventions based upon analyzed performance } \\
\text { data. }\end{array}$ \\
\hline
\end{tabular}




\begin{tabular}{|c|c|c|c|}
\hline Critical Questions & Participants & Quality Indicators & Rubric (Circle the \# most applicable) \\
\hline $\begin{array}{l}\text { 8. Has the school established a } \\
\text { multi-tiered model of intervention } \\
\text { services? }\end{array}$ & & $\begin{array}{l}\text { - School examples of services } \\
\text { available to all students (e.g., } \\
\text { school-wide positive behavioral } \\
\text { support system, instructional } \\
\text { strategies in reading and math, } \\
\text { differentiated curriculum, test } \\
\text { taking strategies) } \\
\text { - School examples of time limited } \\
\text { specialized services for RCELD } \\
\text { students (e.g., extra support in the } \\
\text { classroom, small group or } 1: 1 \\
\text { instruction, home support, tutors, } \\
\text { after school programs) } \\
\text { School examples of long term } \\
\text { intensive specialized support } \\
\text { services for RCELD students (e.g., } \\
\text { collaboration with community } \\
\text { programs, crisis response plan) } \\
\text { Clear guidelines and criteria have } \\
\text { been established to move students } \\
\text { from one tier to another } \\
\text { Systematic follow-up occurs to } \\
\text { ensure interventions were } \\
\text { implemented, student progress was } \\
\text { monitored }\end{array}$ & $\begin{array}{l}\text { 1. The school has not implemented a multi-tiered (e.g., } \\
\text { prevention, intervention, and specialized support) model of } \\
\text { intervention services. } \\
\text { 2. The school has implemented a multi-tiered model of } \\
\text { intervention services but differentiated interventions for RCELD } \\
\text { students in need are inconsistent. } \\
\text { 3. The school has implemented a multi-tiered model of } \\
\text { intervention services and there are numerous examples of } \\
\text { differentiated interventions for RCELD students in need. } \\
\text { 4. The school has implemented a multi-tiered model of } \\
\text { intervention services and the extent of differentiated } \\
\text { interventions for students of students is significant. }\end{array}$ \\
\hline
\end{tabular}




\begin{tabular}{|c|c|c|c|}
\hline \multicolumn{4}{|c|}{ Instructional Team Beliefs } \\
\hline Critical Questions & Participants & Quality Indicators & Rubric (Circle the \# most applicable) \\
\hline $\begin{array}{l}\text { 9. Do school teams actively consider } \\
\text { other possible explanations (e.g., } \\
\text { insufficient instruction, limited English } \\
\text { proficiency, family risk factors) for the } \\
\text { student of RCELD who has low } \\
\text { achievement, rather than automatically } \\
\text { assuming a disability? }\end{array}$ & & $\begin{array}{l}\text { - School and classroom environmental } \\
\text { assessment is conducted to determine } \\
\text { possible explanations for the problems } \\
\text { experienced by the student of RCELD } \\
\text { - Systematic use of curriculum-based } \\
\text { assessment and error analyses data } \\
\text { - Problem-solving teams } \\
\text { recommendations focus on positive } \\
\text { behavioral interventions \& student } \\
\text { strengths } \\
\text { - Delineated and comprehensive referral } \\
\text { process }\end{array}$ & $\begin{array}{l}\text { 1. School teams believe that general education classroom } \\
\text { performance problems of RCELD students primarily stem } \\
\text { from student deficits and special education referral is the } \\
\text { preferred option. } \\
\text { 2. School teams believe that general education classroom } \\
\text { performance problems of RCELD students may not always } \\
\text { stem from student deficits but special education referral tends } \\
\text { to be the preferred option. } \\
\text { 3. School teams believe that general education classroom } \\
\text { performance problems of RCELD students may stem from } \\
\text { multiple issues (e.g., student deficits, cultural/linguistic/family } \\
\text { risk factors, and mismatch between instructional and learning } \\
\text { styles) and numerous general education classroom } \\
\text { interventions are employed prior to special education referral. } \\
\text { 4. School teams believe that general education classroom } \\
\text { performance problems of RCELD students may stem from } \\
\text { multiple issues. Based upon a thorough analysis of the } \\
\text { instructional environment, an extensive array of general } \\
\text { education classroom interventions are implemented prior to } \\
\text { special education referral. }\end{array}$ \\
\hline
\end{tabular}




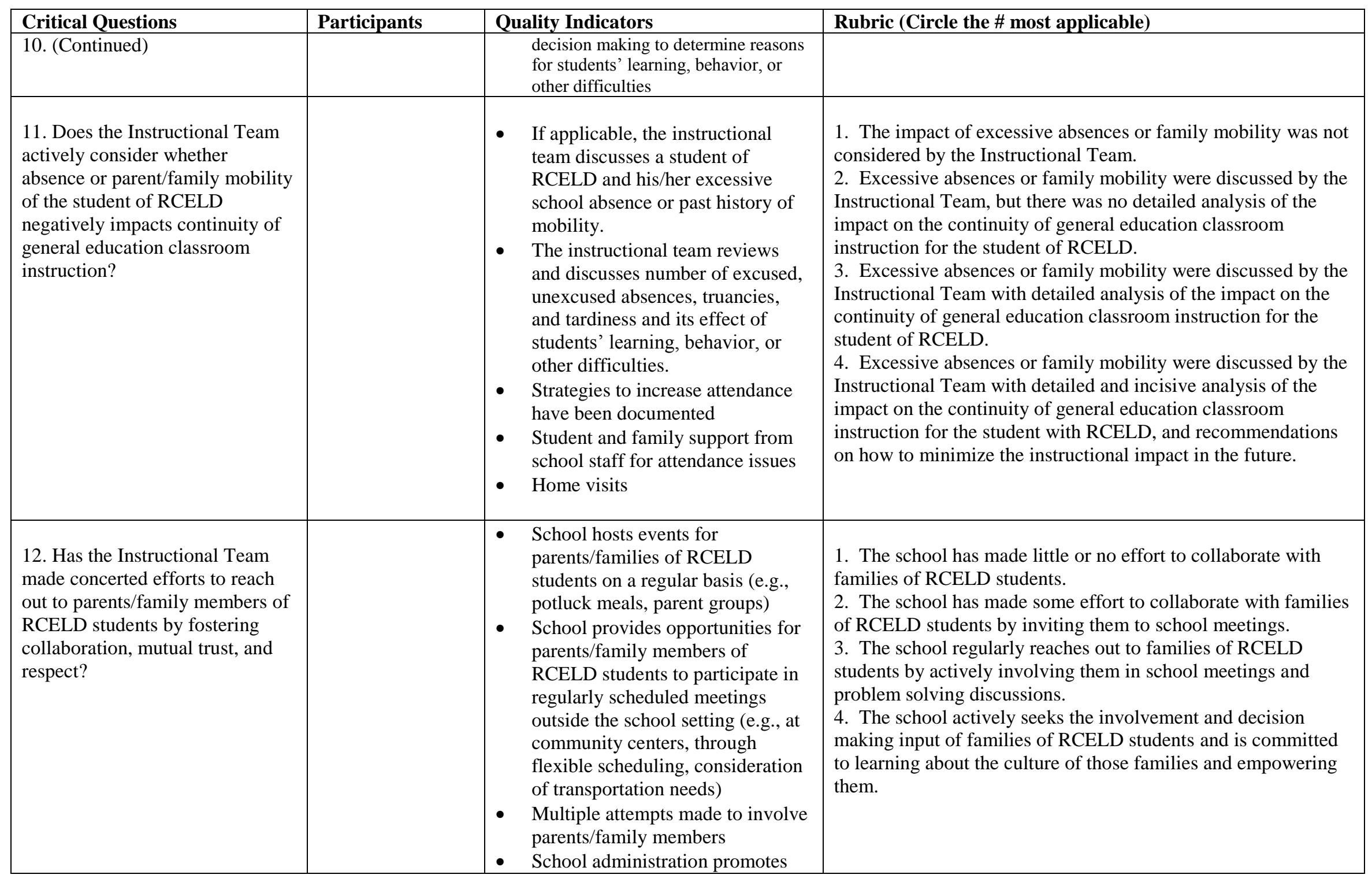




\begin{tabular}{|c|c|c|c|}
\hline Critical Questions & Participants & Quality Indicators & Rubric (Circle the \# most applicable) \\
\hline
\end{tabular}




\begin{tabular}{|c|c|c|c|}
\hline Critical Questions & Participants & Quality Indicators & Rubric (Circle the \# most applicable) \\
\hline $\begin{array}{l}\text { 14. Does the Instructional Team } \\
\text { incorporate culturally responsive } \\
\text { materials and content in the } \\
\text { curricula and use culturally } \\
\text { responsive teaching practices? }\end{array}$ & & $\begin{array}{l}\text { General education classroom materials } \\
\text { include stories and perspectives from } \\
\text { diverse cultures, as well as materials } \\
\text { provided in native language } \\
\text { represented in the classroom } \\
\text { General education classroom } \\
\text { instruction is varied (e.g., small } \\
\text { group, cooperative learning high } \\
\text { teacher-student interaction) } \\
\text { High energy and animation in the } \\
\text { classroom, real world relevant } \\
\text { learning activities, increased teacher- } \\
\text { student interactions } \\
\text { Culturally responsive instruction } \\
\text { including: acknowledging students' } \\
\text { differences as well as their } \\
\text { commonalities, validating students' }\end{array}$ & $\begin{array}{l}\text { 1. The Instructional Team rarely incorporates culturally } \\
\text { responsive materials, content, and teaching practices. } \\
\text { 2. The Instructional Team periodically incorporates culturally } \\
\text { responsive materials and content but culturally responsive } \\
\text { teaching practices are rarely displayed. } \\
\text { 3. The Instructional Team regularly incorporates culturally } \\
\text { responsive materials, content, and teaching practices. } \\
\text { 4. The Instructional Team regularly incorporates culturally } \\
\text { responsive materials, content, and teaching practices and school } \\
\text { staff. School staff constantly seek to add to their knowledge of } \\
\text { culturally responsive practices and the academic performance } \\
\text { data of RCELD students in general education classrooms is } \\
\text { regularly reviewed and analyzed to determine the effectiveness } \\
\text { of staff practices. }\end{array}$ \\
\hline
\end{tabular}




\begin{tabular}{|c|c|c|c|}
\hline Critical Questions & Participants & Quality Indicators & Rubric (Circle the \# most applicable) \\
\hline $\begin{array}{l}\text { 15. Does the Instructional Team } \\
\text { actively seek to identify the } \\
\text { reason for a RCELD student's } \\
\text { behavior, learning or other } \\
\text { difficulties? } \\
\text { (Consider items in numbers } 9,10 \text {, } \\
\text { and } 11 \text { above.) }\end{array}$ & & $\begin{array}{l}\text { - Analysis of problem behaviors are } \\
\text { regularly conducted to assess } \\
\text { RCELD students } \\
\text { - General education classroom } \\
\text { examples of informal, curriculum- } \\
\text { based, authentic assessments on } \\
\text { academic performance of RCELD } \\
\text { students } \\
\text { - General education classroom } \\
\text { examples of error analyses }\end{array}$ & $\begin{array}{l}\text { 1. The Instructional Team does not systematically gather and } \\
\text { analyze classroom performance data to identify the reasons for } \\
\text { behavior, learning or other difficulties of a student of RCELD. } \\
\text { 2. The Instructional Team periodically gathers classroom } \\
\text { performance data but no attempt to systematically analyze that } \\
\text { information to identify the reasons for behavior, learning, or } \\
\text { other difficulties of RCELD students is made. } \\
\text { 3. The Instructional Team regularly gathers and analyzes } \\
\text { classroom performance data to identify the reasons for behavior, } \\
\text { learning or other difficulties of the student of RCELD. } \\
\text { 4. The Instructional Team regularly gathers and analyzes } \\
\text { classroom performance data to identify the source(s) of }\end{array}$ \\
\hline
\end{tabular}




\begin{tabular}{|c|c|c|c|}
\hline Critical Questions & Participants & Quality Indicators & Rubric (Circle the \# most applicable) \\
\hline 15. (Continued) & & $\begin{array}{l}\text { conducted on academic work of } \\
\text { RCELD students } \\
\text { Parents are consulted to gain a better } \\
\text { understanding of parent expectations } \\
\text { for the student }\end{array}$ & $\begin{array}{l}\text { behavior, learning, or other difficulties for the student of } \\
\text { RCELD. This analysis of classroom performance data yields } \\
\text { tentative hypotheses as to possible instructional environment } \\
\text { variables that may be impact behavior, learning or other } \\
\text { difficulties. The Instructional Team seeks to verify these } \\
\text { tentative hypotheses by collecting student performance data. }\end{array}$ \\
\hline \multicolumn{4}{|c|}{ Instructional Team Practices } \\
\hline Critical Questions & Participants & Quality Indicators & Rubric (Circle the \# most applicable) \\
\hline $\begin{array}{l}\text { 16. Does the Instructional Team } \\
\text { use culturally responsive } \\
\text { behavior management practices } \\
\text { by considering the impact of } \\
\text { culture on school performance of } \\
\text { a student of RCELD? }\end{array}$ & & $\begin{array}{l}\text { General education classroom } \\
\text { examples of understanding behavioral } \\
\text { differences of RCELD students (e.g., } \\
\text { expressed preference for working } \\
\text { individually or in groups, seating } \\
\text { arrangements balanced by ethnicity } \\
\text { and gender, listening and responding } \\
\text { style, peer interaction patterns, } \\
\text { responses to authority, verbal and } \\
\text { nonverbal communication, turn taking } \\
\text { behaviors) } \\
\text { General education classroom rules and } \\
\text { procedures are accommodating to } \\
\text { diverse student behavioral styles } \\
\text { (students are included in the decision } \\
\text { making process and are responsible } \\
\text { for contributing to the discipline and } \\
\text { well being of the classroom and } \\
\text { students.) } \\
\text { Individualized behavior plans are } \\
\text { created as appropriate } \\
\text { When necessary, RCELD students in } \\
\text { general education classrooms have } \\
\text { behavioral management systems that } \\
\text { address individual cultural differences } \\
\text { Staff confer with family about home } \\
\text { expectations, values, customs, and } \\
\text { behavior management practices } \\
\text { Staff engage in self-assessments of } \\
\text { their own cultural expectations and } \\
\text { practices }\end{array}$ & $\begin{array}{l}\text { 1. The Instructional Team does not consider the impact of } \\
\text { culture on school performance of a student of RCELD. } \\
\text { 2. The Instructional Team discussed the student's culture but no } \\
\text { systematic analysis of its impact on school performance of a } \\
\text { student with RCELD was conducted. } \\
\text { 3. The Instructional Team discussed the student's culture and } \\
\text { conducted a systematic analysis of its impact on school } \\
\text { performance of a student of RCELD. } \\
\text { 4. The Instructional Team discussed the student's culture and } \\
\text { conducted a systematic analysis of its impact on school } \\
\text { performance of a student of RCELD. The systematic analysis of } \\
\text { the student's culture and potential impact on behavior included } \\
\text { staff discussions with the family about home expectations and } \\
\text { behavior management practices and staff self-assessments of } \\
\text { their own cultural expectations and practices. }\end{array}$ \\
\hline
\end{tabular}




\begin{tabular}{|c|c|c|c|}
\hline Critical Questions & Participants & Quality Indicators & Rubric (Circle the \# most applicable) \\
\hline $\begin{array}{l}\text { 17. Does the Instructional Team } \\
\text { establish a classroom } \\
\text { environment that accepts } \\
\text { individual student differences and } \\
\text { is positive, structured, and well } \\
\text { managed? }\end{array}$ & & $\begin{array}{l}\text { - General education classroom } \\
\text { examples of understanding } \\
\text { differences of RCELD students } \\
\text { - General education classroom rules } \\
\text { and procedures are } \\
\text { accommodating to diverse student } \\
\text { learning styles (all students are } \\
\text { actively involved in instruction } \\
\text { and other classroom activities to } \\
\text { the extent possible; understanding } \\
\text { of types of knowledge valued by } \\
\text { students' parents/families) } \\
\text { - General education classroom } \\
\text { procedures and routines are } \\
\text { actively taught to students with } \\
\text { periodic reminders and } \\
\text { implemented consistently } \\
\text { General education classroom } \\
\text { transitions are short and smooth } \\
\text { General education teacher-student } \\
\text { interactions are positive } \\
\text { Classroom time in general education } \\
\text { settings is devoted to social skills } \\
\text { instruction and problem solving skills }\end{array}$ & $\begin{array}{l}\text { 1. The Instructional Team does not establish a classroom } \\
\text { environment accepting of student differences. The classroom } \\
\text { environment is managed poorly and is not conducive to student } \\
\text { learning. } \\
\text { 2. The Instructional Team does not establish a classroom } \\
\text { environment accepting of student differences. The classroom } \\
\text { environment is primarily positive and well managed will all } \\
\text { students having the same behavioral expectations. } \\
\text { 3. The Instructional Team does allow for individual student } \\
\text { differences in establishing its classroom environment. The } \\
\text { classroom environment is primarily positive and well managed } \\
\text { with some modification of classroom rules and behavioral } \\
\text { expectations to accommodate for individual student differences. } \\
\text { 4. The Instructional Team does allow for individual student } \\
\text { differences in establishing its classroom environment. The } \\
\text { classroom environment is primarily positive and well managed } \\
\text { with extensive modification of classroom rules and behavioral } \\
\text { expectations to accommodate for individual student differences. } \\
\text { The classroom environment establishes a climate that celebrates } \\
\text { student differences. }\end{array}$ \\
\hline $\begin{array}{l}\text { 18. Does the Instructional Team } \\
\text { set realistic, high expectations } \\
\text { and standards for RCELD } \\
\text { students? }\end{array}$ & & $\begin{array}{l}\text { - General education teacher's } \\
\text { expectations for achievement for } \\
\text { RCELD students are realistic } \\
\text { - General education teachers set } \\
\text { high expectations for RCELD } \\
\text { students } \\
\text { - Standards-based curriculum for all } \\
\text { students } \\
\text { - Students are academically } \\
\text { - engaged in the classroom } \\
\text { - Academic expectations for }\end{array}$ & $\begin{array}{l}\text { 1. The Instructional Team quite often does not maintain realistic } \\
\text { and high expectations for the achievement of RCELD students. } \\
\text { 2. The Instructional Team usually maintains high expectations } \\
\text { for the achievement of RCELD students but quite often those } \\
\text { high expectations are unrealistic because the Instructional Team } \\
\text { does not regularly engage in culturally responsive teaching } \\
\text { practices. } \\
\text { 3. Instructional Team regularly maintains realistic and high } \\
\text { expectations for the achievement of RCELD students. Realistic } \\
\text { and high expectations for RCELD students are periodically } \\
\text { supported by culturally responsive teaching practices. } \\
\text { 4. Instructional Team regularly maintains realistic and high } \\
\text { expectations for the achievement of RCELD students. Realistic }\end{array}$ \\
\hline
\end{tabular}




\begin{tabular}{|c|c|c|c|}
\hline Critical Questions & Participants & Quality Indicators & Rubric (Circle the \# most applicable) \\
\hline 18. (Continued) & & $\begin{array}{l}\text { individual students are based on } \\
\text { multiple data sources and } \\
\text { individual ability rather than } \\
\text { broad-based assumptions } \\
\text { Encourages high rate of } \\
\text { observable, measurable student } \\
\text { responses (comprehension } \\
\text { questions answered, math facts } \\
\text { stated correctly, etc.) } \\
\text { A variety of scaffolding } \\
\text { techniques are used to enhance } \\
\text { instruction }\end{array}$ & $\begin{array}{l}\text { and high expectations for RCELD students are regularly } \\
\text { supported by culturally responsive teaching practices. }\end{array}$ \\
\hline $\begin{array}{l}\text { 19. Are learning strategies } \\
\text { explicitly taught to RCELD } \\
\text { students? }\end{array}$ & & $\begin{array}{l}\text { Students are specifically taught } \\
\text { thinking skills, specific learning } \\
\text { strategies, cognitive behavioral skills } \\
\text { (e.g., stop-and-think)and those skills } \\
\text { are modeled } \\
\text { All teachers regularly explain } \\
\text { how/why student's responses are } \\
\text { correct and incorrect (i.e. timely } \\
\text { feedback for error corrections and } \\
\text { positive reinforcement) } \\
\text { Balanced literacy instruction with } \\
\text { thinking skills taught }\end{array}$ & $\begin{array}{l}\text { 1. Systematic instruction in learning strategies is rarely, if ever, } \\
\text { provided to RCELD students. } \\
\text { 2. Learning strategies are sometimes explicitly taught to RCELD } \\
\text { students in general education classrooms. } \\
\text { 3. Learning strategies are regularly explicitly taught to RCELD students } \\
\text { in general education classrooms. } \\
\text { 4. Learning strategies are regularly explicitly taught to RCELD students } \\
\text { in general education classrooms. Thinking skills used in completing and } \\
\text { evaluating assignments are regularly clearly communicated to the } \\
\text { students. }\end{array}$ \\
\hline $\begin{array}{l}\text { 20. Does the Instructional Team } \\
\text { accommodate the needs of } \\
\text { RCELD students through } \\
\text { differentiated instruction that } \\
\text { reflects the interests and } \\
\text { experiences of RCELD students? }\end{array}$ & & $\begin{array}{l}\text { - General education teacher } \\
\text { employs a variety of teaching } \\
\text { methods and materials } \\
\text { RCELD students receive } \\
\text { additional review and practice in } \\
\text { difficulty areas in the general } \\
\text { education classroom } \\
\text { - General education classroom } \\
\text { teacher engages in direct, frequent, } \\
\text { and continuous monitoring of } \\
\text { instruction and student progress } \\
\text { performance } \\
\text { General education classroom } \\
\text { examples of differentiated } \\
\text { instruction to address the needs of } \\
\text { RCELD students }\end{array}$ & $\begin{array}{l}\text { 1. The Instructional Team does little or no differentiated } \\
\text { instruction for RCELD students. } \\
\text { 2. The Instructional Team regularly provides differentiated } \\
\text { instruction in at least one of the five factors of instruction: } \\
\text { (1) content = what is taught, } \\
\text { (2) process = how content is taught, } \\
\text { (3) product = how students demonstrate content mastery, } \\
\text { (4) affect = how students connect their thinking and feelings, and } \\
\text { (5) learning environment = how the classroom is designed and } \\
\text { students are grouped. } \\
\text { 3. The Instructional Team regularly provides differentiated } \\
\text { instruction in } 2 \text { or } 3 \text { of the five factors of instruction (see \#2 } \\
\text { above). }\end{array}$ \\
\hline
\end{tabular}




\begin{tabular}{|c|c|c|c|}
\hline Critical Questions & Participants & Quality Indicators & Rubric (Circle the \# most applicable) \\
\hline & & 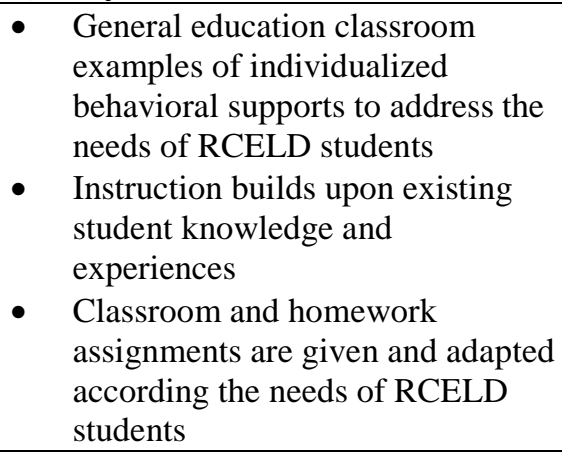 & $\begin{array}{l}\text { 4. The Instructional Team regularly provides differentiated } \\
\text { instruction in } 4 \text { or } 5 \text { of the five factors of instruction (see \#2 } \\
\text { above). }\end{array}$ \\
\hline
\end{tabular}

After completion of checklist, create an action plan:

- Based on an analysis of the above statements, it is recommended that the following goals should be addressed in the school improvement action plan:

- At the end of the year, consider what has changed, what has stayed the same, what plans have been made and/or adapted for future goals

*This checklist has been adapted from the work of Fiedler, Chiang, Van Haren, Jorgenson, Halberg, \& Boreson (2008) and expanded from the works of Gay, 2000; Lue Stewart (2009); Ladson-Billings (2001); and Delpit (2006) and many others cited in the reference section of this paper. 


\section{APPENDIX C: SECOND VERSION OF THE CRT TOOL USED IN ROUND TWO OF THE DELPHI STUDY}




\title{
A Culturally Responsive Checklist for Schools and Teachers
}

\begin{abstract}
Instructions:
This revised checklist has three sections: questions, quality indicators for each question, and resources for each question topic. Future professional development participants will answer critical questions based on the quality indicators provided on the pages following the questionnaire. Further explanation of each response is requested as well. Resources related to each question topic will also be provided.
\end{abstract}

\section{Key Terms:}

Participants: Participants completing this checklist will include the following persons aware of school and classroom procedures and policies: general education teachers representing various grade levels, special education teachers, school psychologists, administration team members, instructional support staff

RCELD Students: This acronym refers to students with racial, cultural, ethnic, and linguistic diversity. The acronym will be used throughout the study to refer also to historically underserved groups, (Artiles, Kozleski, Trent, Osher, \& Ortiz, 2010). Artiles, et al. (2010) uses this term to describe students with RCELD, but also includes students that come from economically disadvantaged backgrounds, that have "experienced sustained school failure over time," (p.280). For the purposes of this instrument, the acronym RCELD will include economically disadvantaged groups as well as any groups that have been historically underserved by the education system in the U.S.

Quality Indicators: Examples of best practices are offered to guide participants in selecting the criteria in the rubric that is most applicable to their school setting. The list may be edited to reflect options available at each school site.

Note:(1) To be as inclusive as possible, references to families within this checklist may refer to biological parents, step-parents, adoptive or foster parents, legal guardians, other family members such as grandparents, aunts, uncles, etc. and to social family members. (2) This checklist tool is meant to be used and adapted based upon the specific contexts of each school. 


\section{Section I: Questions Addressing Culturally Responsive Beliefs and Practices of Schools}

1. Does the school have a set of guiding principles in place related to addressing the needs of RCELD students? Are there any plans in place that address culturally responsive teaching practice?

a. There is little evidence of any set principles or plans for addressing the needs of RCELD students.

b. There is a statement in our school improvement plan or that has been mentioned in a faculty meeting about these issues, but there has been little discussion, professional development, or resources allocated that focus specifically on this issue.

c. There has been some professional development and resources that addresses this issue.

d. It is very clear that the needs of RCELD students are a priority. A significant amount of discussion, professional development, and resources have been designated for these issues on a regular basis.

Explain what evidence is already in place at your school site, what evidence you'd like to see in place, perceived barriers to some of the strategies mentions, and any additional thoughts, comments, and ideas related to this question:

2. Does the school staff work collaboratively to support all students?

a. There is little evidence of collaboration between general education teachers, special education teachers, and other support staff (i.e. related services, ESL).

b. There is some collaboration between general education, teachers, special education teachers, and other support staff; however special educators are still viewed as having traditional roles.

c. There is regular collaborative interaction between general education teachers, special education teachers, and other support staff, which includes some co-planning, coteaching, and discussions regarding specific staff and teacher roles and responsibilities.

d. The prevailing attitude of school staff fosters extensive and effective collaborative interaction between general education teachers, special education teachers, and other support staff, which includes regular co-planning, co-teaching, and discussions regarding specific staff and teacher roles and responsibilities, with a focus on meeting the needs of RCELD students. 
Explain what evidence is already in place at your school site, what evidence you'd like to see in place, perceived barriers to some of the strategies mentions, and any additional thoughts, comments, and ideas related to this question:

3. Does the school staff establish strong home/school connections by making concerted efforts to reach out to parents/family members of RCELD students by fostering collaboration, mutual trust, and respect?

a. There is little evidence that school staff have implemented a plan to collaborate with families of RCELD students.

b. There is some effort that school staff have collaborated with families of RCELD students, such as inviting them to school meetings.

c. School staff regularly reach out to families of RCELD students by involving them in school meetings and problem solving discussions.

d. School staff actively seek the involvement and decision making input of families of RCELD students and are committed to learning about the culture of those families and empowering them to become an active participant in the school and their child's education.

Explain what evidence is already in place at your school site, what evidence you'd like to see in place, perceived barriers to some of the strategies mentions, and any additional thoughts, comments, and ideas related to this question:

4. Does school staff view RCELD students and their families as assets?

a. There is little evidence that school staff have incorporated resources from RCELD students, their families, and community members throughout the school.

b. There has been some discussion about the need to utilize resources from family and community members representing various RCELD backgrounds throughout the school, however, efforts have been inconsistent.

c. There has been some consistent effort to utilize resources from family and community members representing various RCELD backgrounds throughout the school

d. There is clear evidence that RCELD students and their families are viewed as assets. Parents, families, and community members from RCELD backgrounds are invited regularly to share in school processes and to share their knowledge, expertise, and experiences with school staff and students. 
Explain what evidence is already in place at your school site, what evidence you'd like to see in place, perceived barriers to some of the strategies mentions, and any additional thoughts, comments, and ideas related to this question:

5. Does school staff incorporate culturally responsive materials and content in the curricula and use culturally responsive teaching practices?

a. There is little evidence that school staff incorporates culturally responsive materials, content, and teaching practices.

b. Some culturally responsive materials and content are incorporated in the curricula, but there is little evidence of specific culturally responsive practices being exhibited.

c. School staff regularly incorporate culturally responsive materials, content, and teaching practices.

d. School staff regularly incorporates culturally responsive materials, content, and teaching practices. School staff constantly seek to add to their knowledge of culturally responsive practices and there is ongoing review of the effectiveness of staff practices on RCELD student learning.

Explain what evidence is already in place at your school site, what evidence you'd like to see in place, perceived barriers to some of the strategies mentions, and any additional thoughts, comments, and ideas related to this question:

6. Does the school staff use culturally responsive behavior management practices by considering the impact of culture on school performance of RCELD students?

a. There is little evidence shown that school staff considers the impact of culture on school performance.

b. School staff discuss student's culture, but no systematic analysis of its impact on school performance.

c. School staff discuss student's culture and conducts systematic analysis of its impact on school performance.

d. School staff discuss student's culture and conducts systematic analysis of its impact on school performance. The systematic analysis of the student's culture and potential impact on behavior include staff discussions with the family about home expectations and behavior management practices and staff self-assessments of their own cultural expectations and practices. 
Explain what evidence is already in place at your school site, what evidence you'd like to see in place, perceived barriers to some of the strategies mentions, and any additional thoughts, comments, and ideas related to this question:

7. School staff use data from these multiple sources drive instructional decisions: formal and informal assessments, observations, analysis of data from previous school years, ongoing progress monitoring data, information from family about students' home and family culture, language, and social history to drive instructional decisions.

a. There is little evidence that school staff have implemented a problem solving process that includes more than one of the above sources.

b. There is some evidence that school staff have implemented a problem solving process that includes more than two of the above sources, but efforts are inconsistent.

c. School staff consistently implements a problem solving process that includes all but information from family about student's home and family culture, language, and social history to drive instructional decisions.

d. School staff have implemented a systematic, problem solving process that includes all of the above sources to drive instructional decisions.

Explain what evidence is already in place at your school site, what evidence you'd like to see in place, perceived barriers to some of the strategies mentions, and any additional thoughts, comments, and ideas related to this question:

8. Does the school staff actively seek to identify other possible explanations for RCELD students' behavior or learning difficulties rather than automatically assuming student deficit or disability? Reasons such as: family mobility, insufficient instruction, limited English proficiency, family risk factors, or cultural differences between school and home expectations, home/school communication barriers, and/or students' access to resources?

a. There is little evidence that school staff have implemented a problem solving process that considers other possible explanations for RCELD students' behavior or learning difficulties other than student deficit or disability.

b. There is some discussion of other possible factors for an RCELD student's behavior or learning difficulty, but few specific interventions are in place to address these other possible factors.

c. School staff have implemented a problem solving process that considers multiple issues that may affect an RCELD student's behavior or learning difficulty, and some related interventions are placed before considering special education referral, possible retention, or other academic or disciplinary decisions. 
d. School staff have implemented a problem solving process that includes a thorough analysis of student's home and instructional environment and an extensive array of classroom interventions are implemented prior to special education referral, possible retention, or other academic or disciplinary decisions.

Explain what evidence is already in place at your school site, what evidence you'd like to see in place, perceived barriers to some of the strategies mentions, and any additional thoughts, comments, and ideas related to this question:

9. Based on a review of your responses to the questions above, what, if any, changes would you like to see made school wide?

10. Are there any specific quality indicators/considerations for practice that you plan to implement in your classroom (or area of specialty)?

\section{Section II: Quality Indicators/Considerations for Practice}

Question 1: Does the school have a set of guiding principles in place related to addressing the needs of RCELD students? Are there any plans in place that address culturally responsive teaching practice?

- Resources are provided for staff to develop curricula that fosters an appreciation and deep understanding of diversity

- School staff participate in on-going staff development related to diversity issues: including opportunities for teachers to share and reflect on their own cultural beliefs and biases, opportunities for teachers and staff to become knowledgeable about the various RCELD populations and resources in the surrounding community

- ESL, special and general education teachers receive common professional development

- Professional development support is provided to assist all staff in meeting the ongoing needs of RCELD students

Question 2: Does the school staff work collaboratively to support all students?

- Master schedules allow maximum time for shared planning and teaching amongst general and special education teachers and other instructional support staff.

- Peer support mentors are provided for instructional team members as needed

- Co-planning and co-teaching occur regularly with a focus on meeting the needs of all students

- Special education teachers and general education teachers, as well as other instructional support staff participate collaboratively in ongoing analysis of the effectiveness of instruction, particularly with RCELD 
Question 3: Does the school staff establish strong home/school connections by making concerted efforts to reach out to parents/family members of RCELD students by fostering collaboration, mutual trust, and respect?

- School hosts events for parents/families of RCELD students on a regular basis (e.g., potluck meals, parent groups)

- School provides opportunities for parents/family members of RCELD students to participate in regularly scheduled meetings outside the school setting (e.g., at community centers, through flexible scheduling, consideration of transportation needs)

- Multiple attempts made to involve parents/family members

- School administration promotes staff knowledge of diverse cultures (i.e. through professional development, partnership with local colleges for participation in course work related to cultural equity, etc.)

- Problem-solving teams include parents/family members of RCELD students in meeting discussions to formulate instructional and behavioral recommendations

- Staff members offer to meet with parents outside the school setting (e.g., home visits or community sites)

- Staff develops relationships with surrounding RCELD communities to assist the school with translation, cultural interpretation, and other needs and also to elicit services appropriate to student needs

- Parents are encouraged to help their children maintain their native language while learning English.

- Printed materials (bulletin boards, school publications, etc.) are available in home languages of all children in the school

- Home visits/regular phone calls are encouraged to gain insight into students' lives and support systems, as well as to garner parent/family member input in the decision making process

- Parents/families/community members are invited regularly into classrooms

Question 4: Does school staff view RCELD students and their families as assets?

- Staff share realistic and high expectations for RCELD student achievement and behavior.

- All students, including RCELD students, are regularly recognized and honored for their work.

- School clubs and activities reflect the ethnic makeup of the student population

- Bilingual programming

- Materials translated for non-English speaking families

- School staff take opportunities to become knowledgeable about the various RCELD populations and resources in the surrounding community.

- See suggestions from question 3 as well.

Question 5: Does school staff incorporate culturally responsive materials and content in the curricula and use culturally responsive teaching practices? 
- Validating students' cultural identities in classroom practices (understands and integrates students' family makeup, immigration history and experiences, individual concerns, strengths, talents and interests into the curriculum; utilizes students' native language resources),

- Educating students about diversity

- Promoting equity and mutual respect among students,

- Motivating students to become active participants in their learning

- Encouraging students to think critically, challenging students to strive for excellence, assisting students in becoming socially and politically conscious (i.e. identifies and extinguishes myths about other cultures)

- Understands students' prior knowledge and experience with specific subject areas and topics in the curriculum

- Shows interest and encouragement of students' native language through use of some vocabulary to better communicate with students.

- Teachers regularly explain how/why students' responses are correct/incorrect (Timely feedback for error corrections and positive reinforcement)

- School environment contains regular evidence of contributions/work from individuals with diverse backgrounds, rather than just during a special week or month.

- Variety of scaffolding techniques are used to enhance instruction

- Classroom materials include stories and perspectives from diverse cultures, as well as materials provided in native language represented in the classroom

- Classroom instruction is varied (e.g., small group, cooperative learning high teacherstudent interaction)

- High energy and animation in the classroom, real world relevant learning activities, increased teacher-student interactions

- Acknowledging students' differences as well as their commonalities

- Homework assignments are adapted to specific needs of RCELD students

- Instructional use of multiple intelligences \& various learning styles

- Uses variety of methods and materials

- RCELD students receive additional review and practice in difficulty areas

- Direct, frequent, and continuous monitoring of RCELD student progress and instruction

- Differentiated instruction to address specific needs of RCELD students

Question 6: Does the school staff use culturally responsive behavior management practices by considering the impact of culture on school performance of RCELD students?

- Classroom rules and procedures are accommodating to diverse student learning styles (all students are actively involved in instruction and other classroom activities to the extent possible; understanding of types of knowledge valued by students' parents/families)

- Individualized behavior supports to address the needs of RCELD students

- Classroom examples of understanding behavioral differences of RCELD students (e.g., expressed preference for working individually or in groups, seating arrangements balanced by ethnicity and gender, listening and responding style, peer interaction patterns, responses to authority, verbal and nonverbal communication, turn taking behaviors) 
- Individualized behavior plans are created as appropriate

- When necessary, RCELD students in classrooms have behavioral management systems that address individual cultural differences

- Staff confer with family about home expectations, values, customs, and behavior management practices

- Staff engage in self-assessments of their own cultural expectations and practices

- General education classroom instructional groupings promote heterogeneous groups of students working together

- Implement flexible groupings of students for different purposes

- Efforts made to create positive learning environment where there is a community of learners that assist and collaborate with one another(i.e. time devoted to social skills instruction and problem solving skills)

- Promotes conversational interactions between students

- Reading buddies

- Cooperative learning groups

- Cross age peer tutoring

- Peer teaching is used where limited-English-proficient students can participate and practice English-language skills in small groups

- The Instructional Team regularly uses peer supports in classrooms and continuously seeks to empower students to take a more active responsibility for their learning and supporting each other.

- School has established procedures that emphasize positive behaviors and regularly recognizes students for displaying appropriate behaviors

- School staff have been trained in the implementation of a positive behavioral support system

- Classroom incentive plans for positive behavior

- Provides resources for evidence-based social skills instruction

- Issues of intolerance are dealt with immediately according to the school's antiharassment policies

- Classroom time and is devoted to social skills instruction and problem solving skills

- The school has implemented a positive behavioral support system for all students, staff have been trained in its use, and school staff regularly discuss the effectiveness of schoolwide positive behavioral support interventions.

- Classroom procedures and routines are actively taught to students with periodic reminders and implemented consistently

- Classroom transitions are short and smooth

- Teacher-student interactions are positive

Question 7: School staff use data from these multiple sources drive instructional decisions: formal and informal assessments, observations, analysis of data from previous school years, ongoing progress monitoring data, information from family about students' home and family culture, language, and social history to drive instructional decisions. 
- Academic expectations for individual students are based on multiple data sources and individual ability rather than broad-based assumptions

- Staff encourage high rate of observable, measurable students responses

- Problem-solving teams are active and engaged in problem solving discussions on a regular basis

- Student progress-monitoring data is used to track performance and evaluate school practices

- Examples of problem-solving teams implemented interventions with data on targeted behavior(s) of a RCELD student for a reasonable amount of time.

- Problem-solving teams provided follow-up support and monitoring of planned interventions

- Multiple data sources are used to evaluate student learning: i.e. standardized tests, informal assessments, observations, verbal and written assessments, assessment data from years prior

- Families encouraged to participate in problem solving discussions to include information about students home and family culture, language, and social history.

- Data from general education classroom interventions designed to provide academic and/or behavioral support to a RCELD student

- Classroom examples of informal, curriculum-based, authentic assessments on academic performance of RCELD students

Question 8: Does the school staff actively seek to identify other possible explanations for RCELD students' behavior or learning difficulties rather than automatically assuming student deficit or disability? Reasons such as: family mobility, insufficient instruction, limited English proficiency, family risk factors, or cultural differences between school and home expectations, home/school communication barriers, and/or students' access to resources?

- School and classroom environmental assessment is conducted to determine possible explanations for the problems experienced by the RCELD student

- Systematic use of curriculum-based assessment and error analyses data

- Problem-solving teams recommendations focus on positive behavioral interventions \& student strengths

- Delineated and comprehensive referral process

- If applicable, the instructional team discusses a RCELD student and his/her excessive school absence or past history of mobility.

- The instructional team reviews and discusses number of excused, unexcused absences, truancies, and tardiness and its effect of students' learning, behavior, or other difficulties.

- Strategies to increase attendance have been documented

- Student and family support from school staff for attendance issues

- Home visits

- Excessive absences or family mobility were discussed by the Instructional Team with detailed and incisive analysis of the impact on the continuity of general education classroom instruction for the RCELD student, and recommendations on how to minimize the instructional impact in the future. 
- Additional, culture-specific assistance is sought to provide appropriate instruction before referring RCELD students to next tier of intervention.

- Life stressors are assessed (i.e. divorce, death of a family member)

- Team discusses family risk factors (i.e. exposure to toxic substances or violence/abuse) and the effect on students' learning, behavior, or other difficulties

- Team discusses environmental, social, economic, and cultural factors to be considered

- Issues of insufficient instruction are explored, (i.e. review of previous interruptions of instruction in prior classes.)

- Students' parents/family have an equal voice in problem-solving and decision making to determine reasons for students' learning, behavior, or other difficulties

- Analysis of problem behaviors are regularly conducted to assess RCELD students

- Classroom examples of informal, curriculum-based, authentic assessments on academic performance of RCELD students

- Parents are consulted to gain a better understanding of parent expectations for the student

\section{Section III: Resources}

(Resources related to each question will be added for final round of feedback)

Question 1: Does the school have a set of guiding principles in place related to addressing the needs of RCELD students? Are there any plans in place that address culturally responsive teaching practice?

Question 2: Does the school staff work collaboratively to support all students?

Question 3: Does the school staff establish strong home/school connections by making concerted efforts to reach out to parents/family members of RCELD students by fostering collaboration, mutual trust, and respect?

Question 4: Does school staff view RCELD students and their families as assets?

$$
\text { - }
$$

Question 5: Does school staff incorporate culturally responsive materials and content in the curricula and use culturally responsive teaching practices?

Question 6: Does the school staff use culturally responsive behavior management practices by considering the impact of culture on school performance of RCELD students?

Question 7: School staff use data from these multiple sources drive instructional decisions: formal and informal assessments, observations, analysis of data from previous school years, ongoing progress monitoring data, information from family about students' home and family culture, language, and social history to drive instructional decisions.

Question 8: Does the school staff actively seek to identify other possible explanations for RCELD students' behavior or learning difficulties rather than automatically assuming student 
deficit or disability? Reasons such as: family mobility, insufficient instruction, limited English proficiency, family risk factors, or cultural differences between school and home expectations, home/school communication barriers, and/or students' access to resources?

*This instrument has been adapted from the work of Fiedler, Chiang, Van Haren, Jorgenson, Halberg, \& Boreson (2008) and expanded from the works of Gay, 2000; Lue Stewart (2009); Ladson-Billings (2001); and Delpit (2006) and many others. For a complete list of references email: angelagriner@knights.ucf.edu. 
APPENDIX D: FINAL VERSION OF THE CRT TOOL 


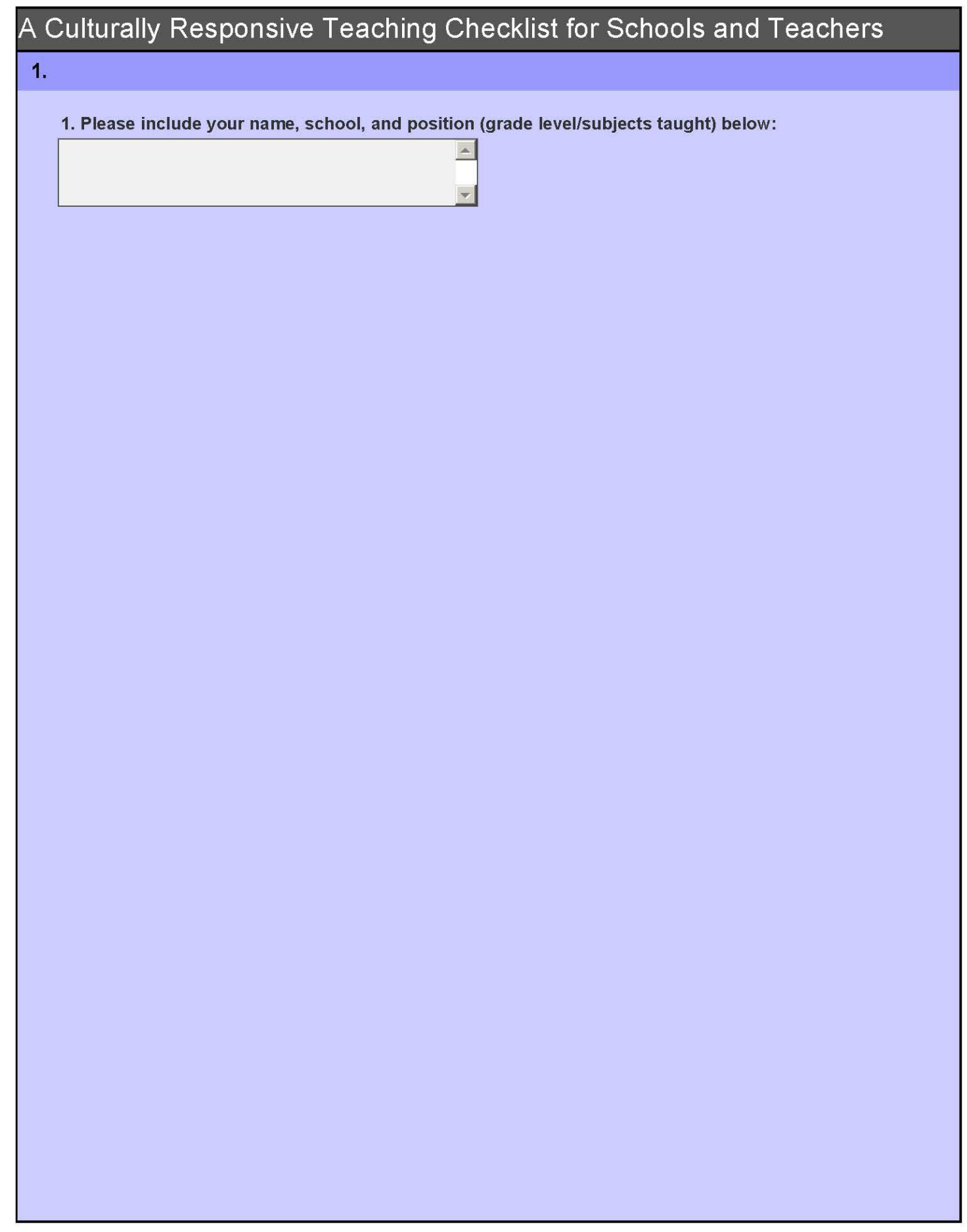

Page 1 


\section{A Culturally Responsive Teaching Checklist for Schools and Teachers}

\section{Introduction}

This checklist of strategies for culturally responsive teaching was compiled from a review of research in the field, as well as suggestions from expert researchers, teacher educators, administrators, teachers, and parents and community members representing students from diverse backgrounds.

INSTRUCTIONS FOR COMPLETING THE CHECKLIST: For each statement below, please do the following: (1)select your level of agreement, (2)select any of the quality indicators listed under each statement that you use or have seen in practice at your school,(3)use the quality indicators to guide you in selecting your response to each statement.

Note: To be as inclusive as possible, references to families within this checklist may refer to biological parents, step-parents, adoptive or foster parents, legal guardians, other family members such as grandparents, aunts, uncles, etc. and to social family members.

RCELD Students: This acronym refers to students who are racially, culturally, ethnically, and linguistically diverse (RCELD). This term is used to describe RCELD students, but also includes students that come from economically disadvantaged backgrounds, that have experienced sustained school failure over time. 


\section{A Culturally Responsive Teaching Checklist for Schools and Teachers}

3.

1. My school has a set of guiding principles in place related to addressing the needs of students from culturally and linguistically diverse backgrounds.
strongly agree
agree
neutral
disagree
strongly disagree

2. Place a check by any of the quality indicators below that you have used or have seen in practice at your school.

$\square$ A significant amount of discussion, professional development, and resources have been designated for these issues on a regular basis.

$\square$ Resources are provided for staff to develop curricula that fosters an appreciation and deep understanding of diversity

School staff participate in on-going staff development related to diversity issues: including opportunities for teachers to share and reflect on their own cultural beliefs and biases, opportunities for teachers and staff to become knowledgeable about the various RCELD populations and resources in the surrounding community

$\square$ ESL, special and general education teachers receive common professional development

Professional development support is provided to assist all staff in meeting the ongoing needs of RCELD students

Other (please specify)

3. The school staff works collaboratively to support all students.

strongly agree

agree

neutral

disagree

strongly disagree 


\section{A Culturally Responsive Teaching Checklist for Schools and Teachers}

4. Place a check by any of the quality indicators below that you have used or have seen in practice at your school.

There is extensive and effective collaborative interaction between general education teachers, special education teachers, and other support staff, which includes regular co-planning, co-teaching, and discussions regarding specific staff and teacher roles and responsibilities, with a focus on meeting the needs of RCELD students.

Master schedules allow maximum time for shared planning and teaching amongst general and special education teachers and other instructional support staff

Peer support mentors are provided for instructional team members as needed

co-planning and co-teaching occur regularly with a focus on meeting the needs of all students

Special education teachers and general education teachers, as well as other instructional support staff participate collaboratively in ongoing analysis of the effectiveness of instruction, particularly with RCELD

Paras, parent liason, teachers and community centers work together

Regular and special education teachers share the same expectations for students regardless of ability

Other (please specify)

5. The school staff establishes strong home/school connections by making concerted efforts to reach out to parenst/family members of students from culturally and linguistically diverse backgrounds by fostering collaboration, mutual trust, and respect.

strongly agree

agree

neutral

$\bigcirc$ disagree

strongly disagree 


\section{A Culturally Responsive Teaching Checklist for Schools and Teachers}

\section{Please select any of the quality indicators below that you use or have seen used at your school:}

$\square$ School hosts events for parents/families of RCELD students on a regular basis (e.g., potluck meals, parent groups).

$\square$ School provides opportunities for parents/family members of RCELD students to participate in regularly scheduled meetings outside the school setting,(e.g., at community centers, through flexible scheduling, consideration of transportation needs).

Multiple attempts are made to involve parents/family members

School administration promotes staff knowledge of diverse cultures, (i.e. through professional development, partnership with local colleges for participation in course work related to cultural equity, etc.).

Problem-solving teams include parents/family members of RCELD students in meeting discussions to formulate instructional and behavioral recommendations

Staff members offer to meet with parents outside the school setting, (e.g., home visits or community sites).

Staff develops relationships with surrounding RCELD communities to assist the school with translation, cultural interpretation, and other needs and also to elicit services appropriate to student needs.

Parents are encouraged to help their children maintain their native language while learning English.

$\square$ Printed materials (bulletin boards, school publications, etc.) are available in home languages of all children in the school.

Home visits/regular phone calls are encouraged to gain insight into students' lives and support systems, as well as to garner parent/family member input in the decision making process

Parents/families/community members are invited regularly into classrooms.

School staff regularly reach out to families of RCELD students by involving them in school meetings and problem solving discussions.

School staff actively seek the involvement and decision making input of families of RCELD students and are committed to learning about the culture of those families and empowering them to become an active participant in the school and their child's education.

School staff makes continuous contact over summer, (phone calls, post cards.)

School staff celebrate special events in students' lives, (birthdays, out of school acomplishments)

School staff provides voice mails in native languages of who may not be literate in their first language.

School staff makes attempts to understand what's important to families during holidays

School staff makes positive contacts with parents first, before problems arise

School staff encourages and provides a space for parent support groups to help parents from RCELD backgrounds become more involved.

Professional development allows time for teachers to get to know the communities of their students

Other (please specify)

Page 5 


\section{A Culturally Responsive Teaching Checklist for Schools and Teachers}

7. The school staff views students from culturally and linguisticlaly diverse students and their families as assets.

strongly agree

agree

neutral

disagree

strongly disagree

\section{Place a check by any quality indicators that you have seen used at your school:}

$\square$ There is clear evidence that RCELD students and their families are viewed as assets. Parents, families, and community members from RCELD backgrounds are invited regularly to share in school processes and to share their knowledge, expertise, and experiences with school staff and students.

$\square$ Staff share realistic and high expectations for RCELD student achievement and behavior.

All students, including RCELD students, are regularly recognized and honored for their work.

$\square$ School organizations, committees, clubs, and activities reflect the ethnic makeup of the student population.

Bilingual programming is used to support ESL students

School materials translated for non-English speaking families (or translators provided for voice mails and in person meetings)

$\square$ School staff take opportunities to become knowledgeable about the various RCELD populations and resources in the surrounding community.

School staff celebrates students' successes regularly.

See suggestions from question 3 as well.

Other (please specify)

9. The school staff incorporates culturally responsive materials and content in the curricula and use culturally responsive teaching practices.
strongly agree
agree
neutral
disagree
strongly disagree 


\section{A Culturally Responsive Teaching Checklist for Schools and Teachers}

10. Place a check by any of the quality indicators below that you have used or have seen in practice at your school.

School staff regularly incorporates culturally responsive materials, content, and teaching practices. School staff constantly seek to add to their knowledge of culturally responsive practices and there is ongoing review of the effectiveness of staff practices on RCELD student learning.

School staff Validates students' cultural identities in classroom practices (understands and integrates students' family makeup, immigration history and experiences, individual concerns, strengths, talents and interests into the curriculum; utilizes students' native language resources.

All students are educated about diversity.

School staff promotes equity and mutual respect among students.

Students are motiviated to become active participants in their learning; encouraged to think critically, strive for excellence, and become socially and politically conscious, (i.e. identifies and extinguishes myths about other cultures).

School staff seeks to understand students' prior knowledge and experience with specific subject areas and topics in the curriculum.

School staff shows interest and encouragement of students' native language through use of some vocabulary to better communicate with students

Teachers regularly explain how/why students' responses are correct/incorrect,(Timely feedback for error corrections and positive reinforcement).

School environment contains regular evidence of contributions/work from individuals with diverse backgrounds, rather than just during a special week or month.

A variety of scaffolding techniques are used to enhance instruction.

Classroom materials include stories and perspectives from diverse cultures, as well as materials provided in native language represented in the classroom.

Classroom instruction is varied (e.g., small group, cooperative learning high teacher-student interaction)

High energy and animation in the classroom, real world relevant learning activities, increased teacher-student interactions.

Students'differences as well as their commonalities are acknowledged.

Homework assignments are adapted to specific needs of RCELD students.

Teachers exhibit instructional use of multiple intelligences \& various learning styles.

$\square$ Teachers use appropriate technology integration within the classroom.

RCELD students receive additional review and practice in difficulty areas.

Direct, frequent, and continuous monitoring of RCELD student progress and instruction occurs

Differentiated instruction to address specific needs of RCELD students is used regularly. 


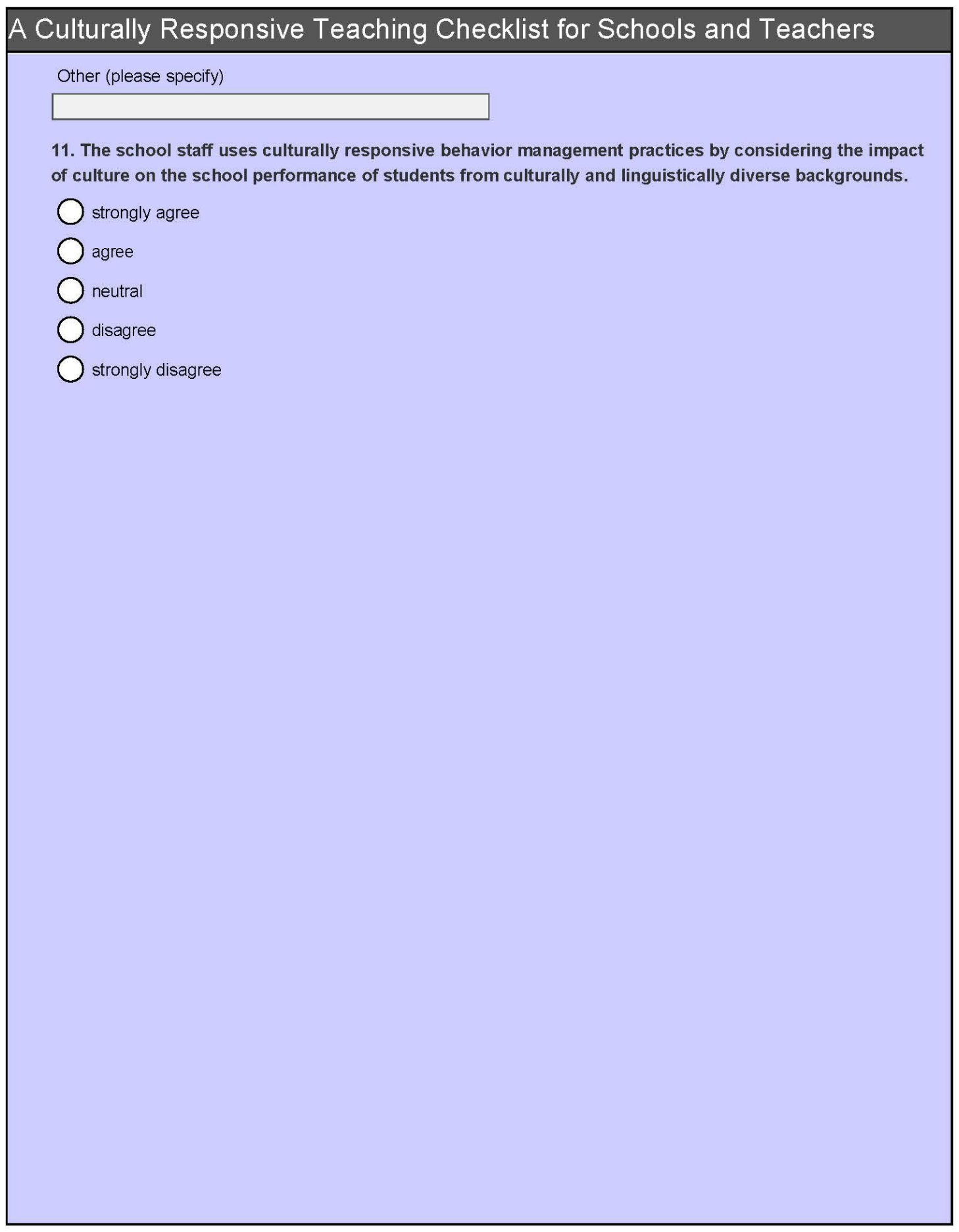

Page 8 


\section{A Culturally Responsive Teaching Checklist for Schools and Teachers}

\section{Place a check by any quality indicators that you have used or seen in practice at your school:}

School staff discuss student's culture and conducts systematic analysis of its impact on school performance. The systematic analysis of the student's culture and potential impact on behavior include staff discussions with the family about home expectations and behavior management practices and staff selfassessments of their own cultural expectations and practices.

Classroom rules and procedures are accommodating to diverse student learning styles, (all students are actively involved in instruction and other classroom activities to the extent possible; understanding of types of knowledge valued by students' parents/families)

Individualized behavior supports to address the needs of RCELD students.

Classroom examples of understanding behavioral differences of RCELD students,(e.g., expressed preference for working individually or in groups, seating arrangements balanced by ethnicity and gender, listening and responding style, peer interaction patterns, responses to authority, verbal and nonverbal communication, turn taking behaviors).

$\square$ Individualized behavior plans are created as appropriate.

When necessary, RCELD students in classrooms have behavioral management systems that address individual cultural differences.

Staff confer with family about home expectations, values, customs, and behavior management practices.

Staff engage in self-assessments of their own cultural expectations and practices

General education classroom instructional groupings promote heterogeneous groups of students working together

Teachers implement flexible groupings of students for different purposes.

Efforts are made to create positive learning environment where there is a community of learners that assist and collaborate with one another,(i.e. time devoted to social skills instruction and problem solving skills).

$\square$ Classrooms promote conversational interactions between students

The use of Reading buddies, Cooperative learning groups

Cross age peer tutoring, and peer teaching is used where limited-English-proficient students can participate and practice English-language skills in small groups.

The Instructional Team regularly uses peer supports in classrooms and continuously seeks to empower students to take a more active responsibility for their learning and supporting each other.

School has established procedures that emphasize positive behaviors and regularly recognizes students for displaying appropriate behaviors.

School staff have been trained in the implementation of a positive behavioral support system.

Classroom incentive plans for positive behavior are have been implemented.

Administration provides resources for evidence-based social skills instruction 


\section{A Culturally Responsive Teaching Checklist for Schools and Teachers}

$\square$ Issues of intolerance are dealt with immediately according to the school's anti-harassment policies.

Classroom time and is devoted to social skills instruction and problem solving skills.

The school has implemented a positive behavioral support system for all students, staff have been trained in its use, and school staff regularly discuss the effectiveness of school-wide positive behavioral support interventions.

Classroom procedures and routines are actively taught to students with periodic reminders and implemented consistently.

$\square$ Classroom transitions are short and smooth.

$\square$ Teacher-student interactions are positive.

Alternatives to school suspension are in place and regularly considered.

Other (please specify)

13. The school staff uses data from these multiple sources drive instructional decisions: formal and informal assessments, observations, analysis of data from previous school years, ongoing progress monitoring data, information from family about students' home and family culture, language, and social history to drive instructional decisions.
strongly agree
agree
neutral
disagree
strongly disagree 


\section{A Culturally Responsive Teaching Checklist for Schools and Teachers}

14. Place a check by the quality indicators that you have used or seen in practice at your school:

School staff have implemented a systematic, problem solving process that includes all of the above sources to drive instructional decisions.

Academic expectations for individual students are based on multiple data sources and individual ability rather than broad-based assumptions

Staff encourage high rate of observable, measurable students responses.

Problem-solving teams are active and engaged in problem solving discussions on a regular basis.

Student progress-monitoring data is used to track performance and evaluate school practices.

Examples of problem-solving teams implemented interventions with data on targeted behavior(s) of a RCELD student for a reasonable amount of time.

Problem-solving teams provide follow-up support and monitoring of planned interventions.

Multiple data sources are used to evaluate student learning: i.e. standardized tests, informal assessments, observations, verbal and written assessments, assessment data from years prior.

Families encouraged to participate in problem solving discussions to include information about students home and family culture, language, and social history

Data from general education classroom interventions designed to provide academic and/or behavioral support to a RCELD student.

Classroom examples of informal, curriculum-based, authentic assessments on academic performance of RCELD students are regularly used.

The instructional team considers working with other agencies is needed, such as mental health clinics for professional development and partnership on mental health issues that may be affecting student performance.

Other (please specify)

15. The school staff actively seeks to identify other possible explanations for RCELD students' behavior or learning difficulties rather than automatically assuming student deficit or disability? Reasons such as: family mobility, insufficient instruction, limited English proficiency, family risk factors, or cultural differences between school and home expectations, home/school communication barriers, and/or students' access to resources?
strongly agree
agree
neutral
disagree
strongly disagree 


\section{A Culturally Responsive Teaching Checklist for Schools and Teachers}

\section{Place a check by any quality indicators that you have used or seen in practice at your school:}

School staff have implemented a problem solving process that includes a thorough analysis of student's home and instructional environment and an extensive array of classroom interventions are implemented prior to special education referral, possible retention, or other academic or disciplinary decisions.

School and classroom environmental assessment is conducted to determine possible explanations for the problems experienced by the RCELD student.

$\square$ There is regular, systematic use of curriculum-based assessment and error analyses data.

Problem-solving teams' recommendations focus on positive behavioral interventions \& student strengths

Delineated and comprehensive referral process is in place.

If applicable, the instructional team discusses a RCELD student and his/her excessive school absence or past history of mobility.

The instructional team reviews and discusses number of excused, unexcused absences, truancies, and tardiness and its effect of students' learning, behavior, or other difficulties.

Strategies to increase attendance have been documented.

Student and family support from school staff for attendance issues.

Home visits occur often.

Excessive absences or family mobility are discussed by the Instructional Team with detailed and incisive analysis of the impact on the continuity of general education classroom instruction for the RCELD student, and recommendations on how to minimize the instructional impact in the future.

Additional, culture-specific assistance is sought to provide appropriate instruction before referring RCELD students to next tier of intervention.

$\square$ Life stressors are assessed,(i.e. divorce, death of a family member).

Team discusses family risk factors (i.e. exposure to toxic substances or violence/abuse) and the effect on students' learning, behavior, or other difficulties.

Team discusses environmental, social, economic, and cultural factors to be considered.

Issues of insufficient instruction are explored, (i.e. review of previous interruptions of instruction in prior classes).

Students' parents/family have an equal voice in problem-solving and decision making to determine reasons for students' learning, behavior, or other difficulties

Analysis of problem behaviors are regularly conducted to assess RCELD students.

Informal, curriculum-based, authentic assessments on academic performance of RCELD students is regularly used in the classroom.

Parents are consulted to gain a better understanding of parent expectations for the student

Mentoring programs have been implemented school wide. 


\section{A Culturally Responsive Teaching Checklist for Schools and Teachers}

$\square$ There are consistent discipline expectations for all students.

Other (please specify)

17. Are there any specific quality indicators that you plan to implement in your school or classroom? If yes, which ones?

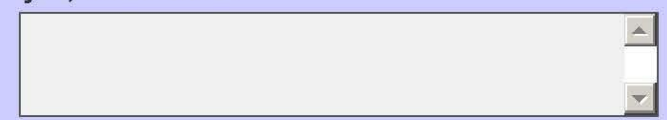

18. Create a 3-5 step action plan outline for implementing one or more of the quality indicators you plan on implementing from the above question.

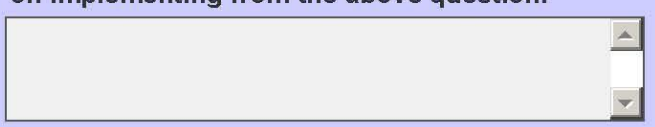


APPENDIX E: PRE AND POST SURVEY QUESTIONS 


\section{Pre-Survey}

Survey Description

This pre-survey is divided into two parts. The first portion of the survey will cover questions from the Common Beliefs Survey Tool. The second portion will cover questions addressing teaching practice. All responses will remain confidential. 


\section{Pre-Survey}

The Common Beliefs Survey Tool (Part I of Pre-Survey)

\section{INTRODUCTION}

Through a special collaboration with the Southern Poverty Law Center and the American Association on Teacher Education, we have obtained permission to use some of the developing tools from the project, "The Teaching Diverse Students Initiative." One tool is the "Common Teachers Belief Survey." Here are the descriptors as offered by the project:

Teachers want students to learn and many make an effort to be particularly responsive to racially and ethnically diverse students. Many of the beliefs teachers hold and lessons they are taught about students of color and how best to facilitate their learning have positive effects. Others, while they may seem sensible and are acted on with good intent, can have negative consequences.

The following is a sample of things many teachers say in conversations about what they do to meet the learning needs of students. After each statement you can indicate whether you agree that the statement reflects your approaches to teaching diverse students. Let's get started. 


\section{Pre-Survey}

1. Please provide your name, school, and position or grades/subjects taught.

2. I don't think of my students in terms of their race or ethnicity; I am color blind when it comes to my teaching:
Strongly Agree
Agree
Disagree
Strongly Disagree

3. The gap in the achievement among students of different races is about poverty, not race:
Strongly Agree
Agree
Disagree
Strongly Disagree

4. Teachers should adapt their instructional practice to the distinctive cultures of African Americans, Latino, Asian, and Native American students:

$\bigcirc$ Strongly Agree

Agree

$\bigcirc$ Disagree

Strongly Disagree

5. In some cultures, students are embarrassed to speak in front of others so I take this into account and don't call on these students in class:

$\bigcirc$ Strongly Agree

Agree

$\bigcirc$ Disagree

Strongly Disagree 


\section{Pre-Survey}

6. When students come from homes where educational achievement is not a high priority, they often don't do their homework and their parents don't come to school events. This is lack of parental support undermines my efforts to teach these students:
Strongly Agree
Agree
Disagree
Strongly Disagree

7. It is not fair to ask who are struggling with English to take on challenging academic assignments:
Strongly Agree
Agree
$\bigcirc$ Disagree
Strongly Disagree

8. I believe that I should reward students who try hard, even if they are not doing well in school because building their self-esteem is important:
Strongly Agree
Agree
$\bigcirc$ Disagree
Strongly Disagree

9. I try to keep in mind the limits of my students' ability and give them assignments that I know they can do so they so not become discouraged:
Strongly Agree
Agree
$\bigcirc$ Disagree
Strongly Disagree

10. Students of different races and ethnicities often have different learning styles and good teachers will match their instruction to these learning styles:
Strongly Agree
Agree
Disagree
Strongly Disagree 


\section{Pre-Survey}

11. Grouping students of different levels of achievement for instruction may benefit some students but it can undermine the progress that could otherwise be made by higher achieving students:
Strongly Agree
Agree
Disagree
Strongly Disagree

12. With all the pressures to raise student achievement, finding and using examples for the cultural, historic and everyday lived experiences of my students takes away valuable time from teaching and learning:
Strongly Agree
Agree
Disagree
Strongly Disagree

13. Before students are asked to engage in complex learning tasks, they need to have a solid grasp of basic skills:
Strongly Agree
Agree
$\bigcirc$ Disagree
Strongly Disagree

14. Talking about race with my colleagues could open up a can of worms; little good is likely to come from it:
Strongly Agree
$\bigcirc$ Agree
$\bigcirc$ Disagree
Strongly Disagree 


\section{Pre-Survey}

Demographic Information

15. Number of years teaching:

0-3 years

3-5 years

5-10 years

11-15years

16-20 years

21+ years

16. Age:

$18-20$

21-25

26-30

31-35

36-40

41-45

46-50

51-55

○6+

17. Gender:

Male

$\bigcirc$ Female 


\section{Pre-Survey}

\section{Cultural/Linguistic Background}

18. Your ethnic and racial background:

Hispanic, Latino, or Spanish origin (If so, please specify: Mexican, Mexican American, Chicano, Puerto Rican, Cuban, or another Hispanic, Latino, or Spanish origin: Argentinean, Columbian, Dominican Nicaraguan, Salvadoran, other.)

White Caucasian, of non Hispanic origin

African American, Black

American Indian or Alaska native

Asian Indian

Other Asian: (If so, please specify Chinese, Japanese, Korean, Filipino, Hmong, Laotian, Thai, Pakistani, Cambodian, Vietnamese, native Hawaiian,Guamanian or Chamorro, Samoan, other pacific islander-Fijian,

Tongan,other.)

More than one race: (Please specify.)

Please specify:

19. What is your linguistic background? Please list your first or native language, second language, and any other languages spoken.

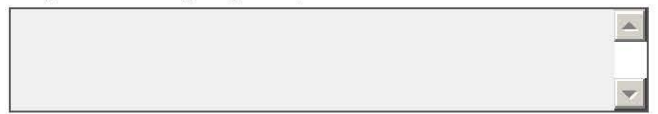




\section{Pre-Survey}

20. Religious affiliation

Nonreligious Secular

Agnostic Atheist

Christianity

Judaism

Buddhism

Hinduism Sikhism

$\bigcirc$ Unitarian-Universalism

Wiccan Pagan Druid

$\bigcirc$ spiritualism

Native American

Baha'i

Other (please specify)

21. Please list all Degrees and certification, as well as method of completion: e.g. college(s) attended, additional course work for certification, professional development, district trainings

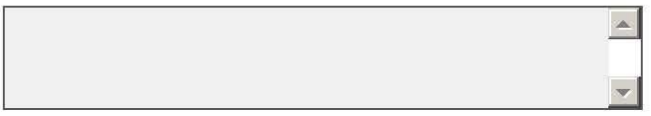

22. What training have you previously received related to working with diverse populations, e.g. course work, district or school level in-service, conferences, staff development?

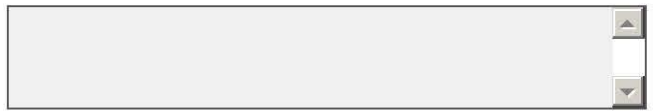




\section{Pre-Survey}

Questions Addressing Practice (Part II of Pre-Survey)

23. On which of the following levels would you consider yourself, in regards to the use of culturally responsive teaching practices in your school or classroom?

Level 0: Have little or no knowledge of what culturally responsive teaching (CRT) practices involve.

Level 1: Have recently received information about culturally responsive teaching (CRT) practices and am considering how strategies might be used in my school or classroom.

Level 2: Have made the decision to begin implementing CRT practices in my school or classroom, establishing a time to begin.

Level 3: Am implementing CRT practices in my school or classroom, but have had little time to reflect and integration is mostly surface-level.

Level 4: Am routinely using CRT practices in my classroom.

Level 5: Am collaborating with colleagues in order to achieve a collective impact on students through the use of CRT practices.

Level 6: Am examining latest developments in the research on CRT practices and have begun exploring new strategies to use, based upon the specific needs of the students at my school and within my classroom. 


\section{Pre-Survey}

\section{Please select the answer choice that represents your level of agreement wit...}

24. Using culturally responsive teaching (CRT) improves my effectiveness as a teacher.

Strongly agree

moderately agree

somewhat agree

neutral

somewhat disagree

$\bigcirc$ moderately disagree

strongly disagree

25. I can accomplish instructional tasks related to my job more productively using culturally responsive teaching.

Strongly agree

$\bigcirc$ moderately agree

somewhat agree

neutral

somewhat disagree

$\bigcirc$ moderately disagree

strongly disagree

26. Using culturally responsive teaching enables me to make better instructional decisions for my students.

Strongly agree

$\bigcirc$ moderately agree

somewhat agree

$\bigcirc$ neutral

somewhat disagree

$\bigcirc$ moderately disagree

strongly disagree 


\section{Pre-Survey}

27. Overall, I find culturally responsive teaching useful in my job.

Strongly agree

$\bigcirc$ moderately agree

somewhat agree

neutral

somewhat disagree

moderately disagree

strongly disagree

28. I find it easy to locate specific strategies for implementing culturally responsive teaching meaningfully into the content area I teach.

Strongly agree

moderately agree

somewhat agree

neutral

somewhat disagree

moderately disagree

strongly disagree

29. Using culturally responsive teaching makes it easier for my students to engage in learning.

Strongly agree

moderately agree

somewhat agree

neutral

somewhat disagree

moderately disagree

strongly disagree 


\section{Pre-Survey}

30. Learning to implement culturally responsive teaching in meaningful ways is easy for me.

Strongly agree

$\bigcirc$ moderately agree

somewhat agree

neutral

somewhat disagree

moderately disagree

strongly disagree

31. Overall, I find it easy to integrate culturally responsive teaching in meaningful ways into the specific curriculum I use in my classroom.
Strongly agree
moderately agree
somewhat agree
neutral
somewhat disagree
moderately disagree
strongly disagree

32. In my opinion, it is desirable to use culturally responsive teaching as an instructional tool.

Strongly agree

moderately agree

somewhat agree

neutral

somewhat disagree

moderately disagree

strongly disagree 


\section{Pre-Survey}

33. I think it is good for me to implement culturally responsive teaching into my classroom.

Strongly agree

$\bigcirc$ moderately agree

somewhat agree

neutral

somewhat disagree

moderately disagree

strongly disagree

34. Overall, my attitude towards culturally responsive teaching is favorable.

Strongly agree

$\bigcirc$ moderately agree

somewhat agree

neutral

somewhat disagree

$\bigcirc$ moderately disagree

strongly disagree

35. I will use culturally responsive teaching regularly to enhance instruction.

Strongly agree

$\bigcirc$ moderately agree

somewhat agree

neutral

somewhat disagree

moderately disagree

strongly disagree 


\section{Pre-Survey}

36. I will strongly recommend others use culturally responsive teaching to enhance instruction.

Strongly agree

$\bigcirc$ moderately agree

somewhat agree

neutral

somewhat disagree

moderately disagree

strongly disagree 


\section{Post-Survey}

Survey Description

As with the pre-survey, this post-survey is divided into two parts. The first portion of the survey will cover questions from the Common Beliefs Survey Tool. The second portion will cover questions addressing teaching practice. All responses will remain confidential. 


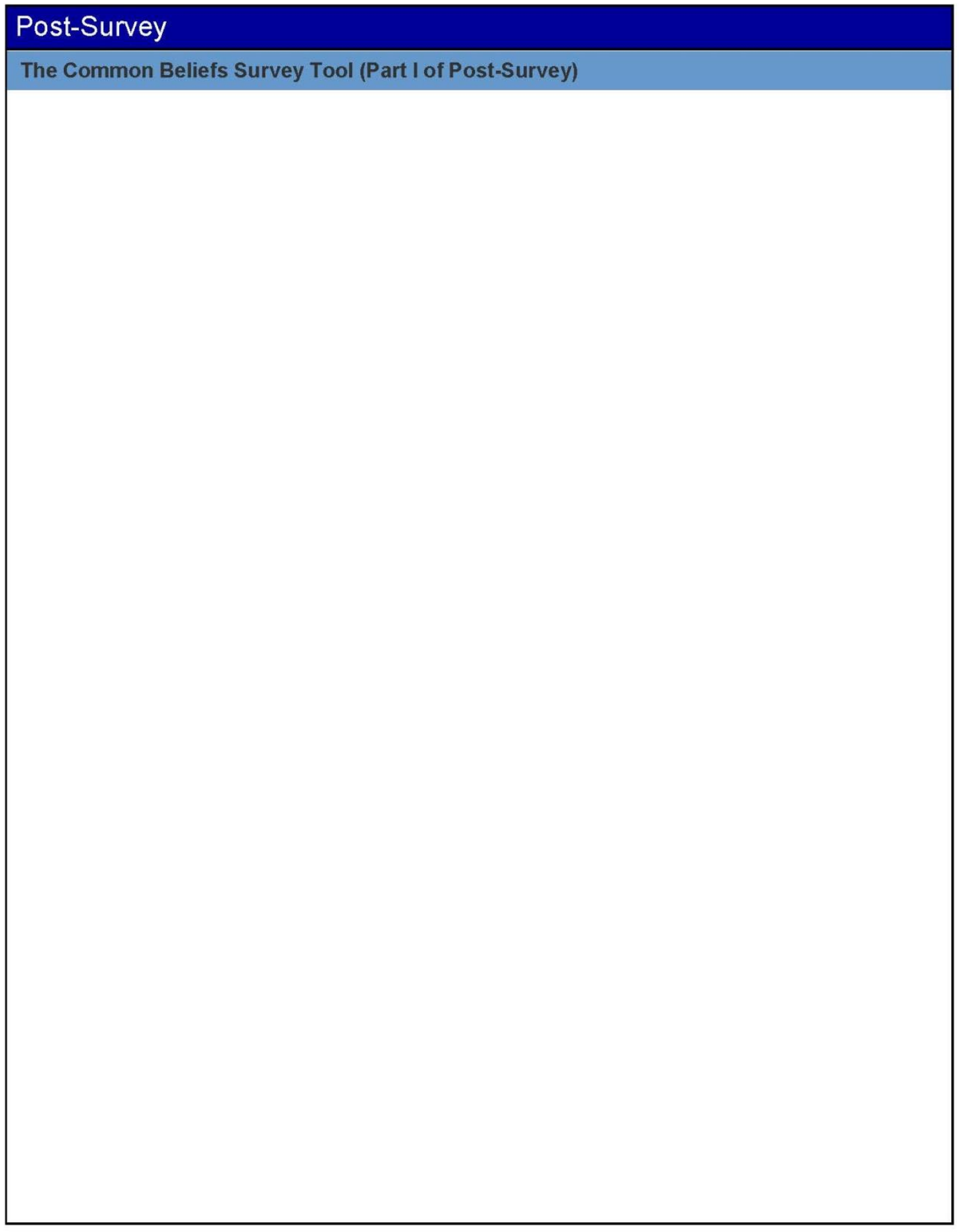

Page 2 


\section{Post-Survey}

1. Please provide your name, school, and position or grades/subjects taught.

2. I don't think of my students in terms of their race or ethnicity; I am color blind when it comes to my teaching:
Strongly Agree
Agree
Disagree
Strongly Disagree

3. The gap in the achievement among students of different races is about poverty, not race:
Strongly Agree
Agree
Disagree
Strongly Disagree

4. Teachers should adapt their instructional practice to the distinctive cultures of African Americans, Latino, Asian, and Native American students:

$\bigcirc$ Strongly Agree

Agree

$\bigcirc$ Disagree

Strongly Disagree

5. In some cultures, students are embarrassed to speak in front of others so I take this into account and don't call on these students in class:

$\bigcirc$ Strongly Agree

Agree

$\bigcirc$ Disagree

Strongly Disagree 


\section{Post-Survey}

6. When students come from homes where educational achievement is not a high priority, they often don't do their homework and their parents don't come to school events. This is lack of parental support undermines my efforts to teach these students:
Strongly Agree
Agree
Disagree
Strongly Disagree

7. It is not fair to ask who are struggling with English to take on challenging academic assignments:
Strongly Agree
Agree
Disagree
Strongly Disagree

8. I believe that I should reward students who try hard, even if they are not doing well in school because building their self-esteem is important:
Strongly Agree
Agree
$\bigcirc$ Disagree
Strongly Disagree

9. I try to keep in mind the limits of my students' ability and give them assignments that I know they can do so they so not become discouraged:
Strongly Agree
Agree
$\bigcirc$ Disagree
Strongly Disagree

10. Students of different races and ethnicities often have different learning styles and good teachers will match their instruction to these learning styles:
Strongly Agree
Agree
Disagree
Strongly Disagree 


\section{Post-Survey}

11. Grouping students of different levels of achievement for instruction may benefit some students but it can undermine the progress that could otherwise be made by higher achieving students:
Strongly Agree
Agree
Disagree
Strongly Disagree

12. With all the pressures to raise student achievement, finding and using examples for the cultural, historic and everyday lived experiences of my students takes away valuable time from teaching and learning:
Strongly Agree
Agree
Disagree
Strongly Disagree

13. Before students are asked to engage in complex learning tasks, they need to have a solid grasp of basic skills:
Strongly Agree
Agree
Disagree
Strongly Disagree

14. Talking about race with my colleagues could open up a can of worms; little good is likely to come from it:
Strongly Agree
$\bigcirc$ Agree
$\bigcirc$ Disagree
Strongly Disagree 


\section{Post-Survey}

Questions Addressing Practice (Part II of Pre-Survey)

15. On which of the following levels would you consider yourself, in regards to the use of culturally responsive teaching practices in your school or classroom?

Level 0: Have little or no knowledge of what culturally responsive teaching (CRT) practices involve.

Level 1: Have recently received information about culturally responsive teaching (CRT) practices and am considering how strategies might be used in my school or classroom.

Level 2: Have made the decision to begin implementing CRT practices in my school or classroom, establishing a time to begin.

Level 3: Am implementing CRT practices in my school or classroom, but have had little time to reflect and integration is mostly surface-level.

Level 4: Am routinely using CRT practices in my classroom.

Level 5: Am collaborating with colleagues in order to achieve a collective impact on students through the use of CRT practices.

Level 6: Am examining latest developments in the research on CRT practices and have begun exploring new strategies to use, based upon the specific needs of the students at my school and within my classroom. 


\section{Post-Survey}

Please select the answer choice that represents your level of agreement wit...

16. Using culturally responsive teaching (CRT) improves my effectiveness as a teacher.

Strongly agree

moderately agree

somewhat agree

neutral

somewhat disagree

moderately disagree

strongly disagree

17. I can accomplish instructional tasks related to my job more productively using culturally responsive teaching.

Strongly agree

$\bigcirc$ moderately agree

somewhat agree

neutral

somewhat disagree

$\bigcirc$ moderately disagree

strongly disagree

18. Using culturally responsive teaching enables me to make better instructional decisions for my students.

Strongly agree

$\bigcirc$ moderately agree

somewhat agree

$\bigcirc$ neutral

somewhat disagree

$\bigcirc$ moderately disagree

strongly disagree 


\section{Post-Survey}

19. Overall, I find culturally responsive teaching useful in my job.

Strongly agree

moderately agree

somewhat agree

neutral

somewhat disagree

moderately disagree

strongly disagree

20. I find it easy to locate specific strategies for implementing culturally responsive teaching meaningfully into the content area I teach.

Strongly agree

moderately agree

somewhat agree

neutral

somewhat disagree

$\bigcirc$ moderately disagree

strongly disagree

21. Using culturally responsive teaching makes it easier for my students to engage in learning.

Strongly agree

$\bigcirc$ moderately agree

somewhat agree

$\bigcirc$ neutral

somewhat disagree

moderately disagree

strongly disagree 


\section{Post-Survey}

22. Learning to implement culturally responsive teaching in meaningful ways is easy for me.

Strongly agree

$\bigcirc$ moderately agree

somewhat agree

neutral

somewhat disagree

moderately disagree

strongly disagree

23. Overall, I find it easy to integrate culturally responsive teaching in meaningful ways into the specific curriculum I use in my classroom.
Strongly agree
moderately agree
somewhat agree
neutral
somewhat disagree
moderately disagree
strongly disagree

24. In my opinion, it is desirable to use culturally responsive teaching as an instructional tool.

Strongly agree

moderately agree

somewhat agree

neutral

somewhat disagree

moderately disagree

strongly disagree 


\section{Post-Survey}

25. I think it is good for me to implement culturally responsive teaching into my classroom.

Strongly agree

moderately agree

somewhat agree

neutral

somewhat disagree

moderately disagree

strongly disagree

26. Overall, my attitude towards culturally responsive teaching is favorable.

Strongly agree

$\bigcirc$ moderately agree

somewhat agree

neutral

somewhat disagree

moderately disagree

strongly disagree

27. I will use culturally responsive teaching regularly to enhance instruction.

Strongly agree

$\bigcirc$ moderately agree

somewhat agree

neutral

somewhat disagree

moderately disagree

strongly disagree 


\section{Post-Survey}

28. I will strongly recommend others use culturally responsive teaching to enhance instruction.

Strongly agree

$\bigcirc$ moderately agree

somewhat agree

neutral

somewhat disagree

moderately disagree

strongly disagree 
APPENDIX F: LEVELS OF USE GENERAL DESCRIPTIONS 
Nonuse

Level 0-

Nonuse/Unaware

Level I-

Orientation

Level II-

Preparation

Level III-

Mechanical Use

Level IV a-

Routine Use

Level IV b-

Refinement

Level V-

Integration

Level VI-

Renewal
The user has little or no knowledge of the research-based practice, no involvement with the practice, and is doing nothing to become involved.

The user has recently acquired or is acquiring information about the research-based practice and has recently explored or is exploring its value orientation and its demands upon the user.

Decision Point A: Takes action to learn more detailed information about the research-based practice.

The user is preparing for first use of the research-based practice. Decision Point B: Makes the decision to use the research-based practice by establishing a time to begin.

\section{Use of the intervention}

The user focuses most effort on the short-term, day-to-day use of the research-based practice with little time for reflection. Changes in use are made more to meet user needs than student needs. The user is primarily engaged in a stepwise attempt to master the tasks required to use the practice, often resulting in disjointed and superficial use.

Decision Point C: Changes, if any, and use are dominated by user needs.

Use of the research-based practice is stabilized. Few if any changes are being made in ongoing use. Little preparation or thought is being given to improving the practice or its consequences. Decision Point D1: A routine pattern of use is established.

The user varies the use of the research-based practice to increase the impact on the students within immediate sphere of influence (e.g., the target group in the classroom). Variations are based on knowledge of both short- and long-term consequences for these students.

Decision Point D2: Changes use of the research-based practice to increase student outcomes based on formal or informal evaluation.

The user is combining his or her efforts to use the research-based practice with related activities of colleagues to achieve a collective impact on students within their common sphere of influence.

Decision Point E: Initiates changes in use of research-based practice based on input of and in coordination with what colleagues are doing.

The user reevaluates the quality of use of the research-based practice, seeks major modifications or alternatives to the practice to achieve increased impact on students, examines new developments in the field, and explores new goals for self and the system.

Decision Point F: Begins exploring alternatives to or major modifications of the research-based practice presently in use.

Taken from the work of Roach, Kratochwill, \& Frank (2009). 
APPENDIX G: LEVELS OF USE INTERVIEW SEQUENCE 


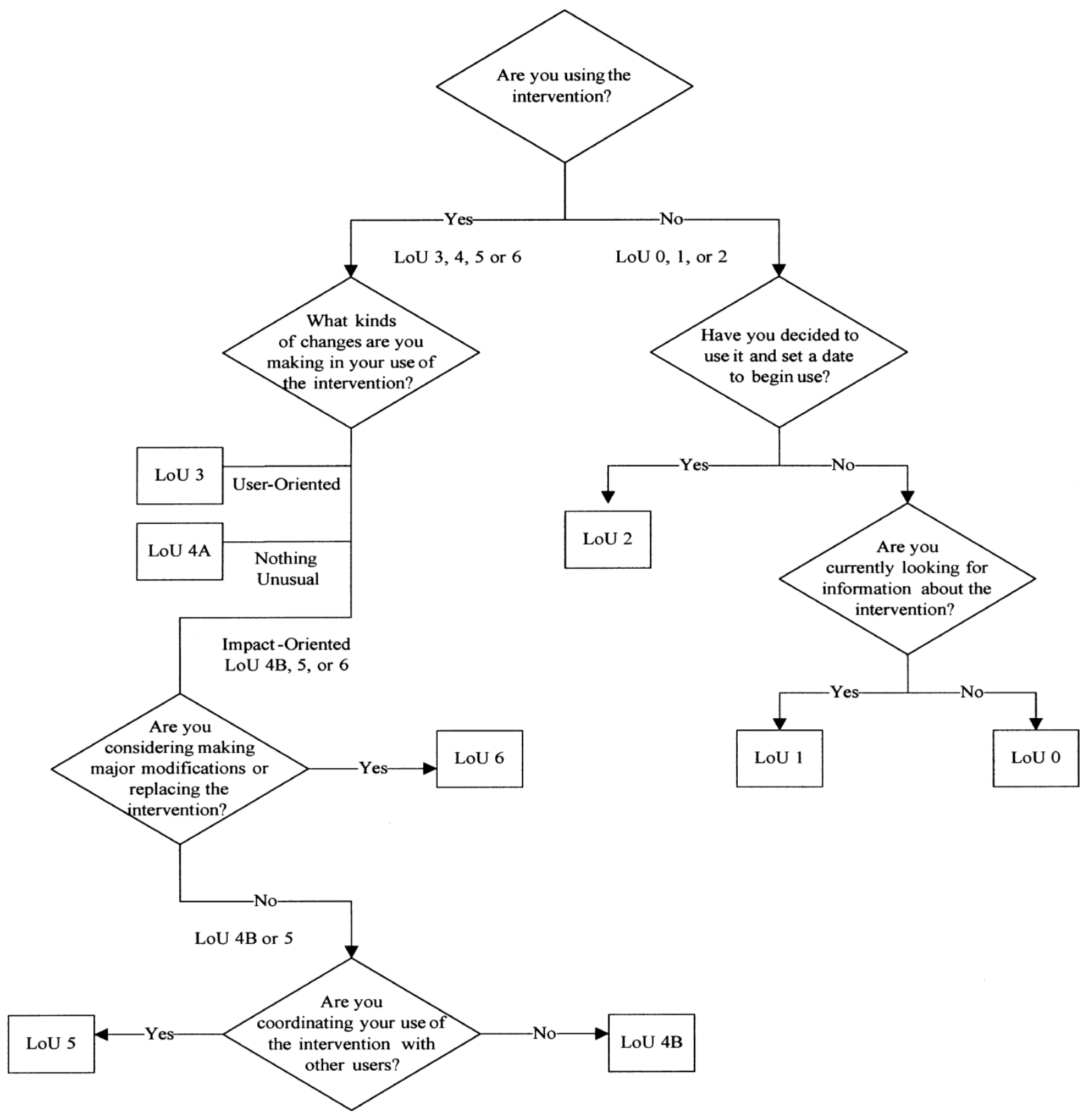


APPENDIX H: DELPHI ROUND ONE 
[REVIEWING A CULTURALLY RESPONSIVE CHECKLIST TOOL FOR SCHOOLS AND TEACHERS] Delphi Study: Round 1

\author{
Thank you for participating in this Delphi study to enhance a checklist tool that \\ will be used with schools and teachers to address the achievement gap and \\ disproportionality in education.
}

\title{
Introduction:
}

Your expertise is requested to provide feedback on the checklist tool included on pages $2-23$ of this document. The checklist tool on pages 2-23 is going to be used with schools and teachers for future professional development on culturally responsive teaching practices. However, before this tool is used, we'd like your feedback on how it can be improved. Please review the tool on the following pages of this document. Then, click on the survey link to provide your feedback on ways the checklist tool might be improved.

\section{What is a Delphi Study?}

This Delphi study involves a group of 15-20 experts representing a diverse group of individuals within the field of education. You are being asked to participate as one of those experts. Your feedback, along with other experts participating in this Delphi study, will be used to reach a majority consensus regarding ways to enhance this tool for use with schools and teachers in a professional development program on culturally responsive teaching practices.

You are being asked to participate in a total of three rounds of feedback. Your responses to the first round of questions related to the checklist tool will be collated and anonymously used to create a new set of questions for the second round of the study. The same will follow for the third and final round. Responses remain anonymous from other participants and each round of feedback will be done online through email and online surveys. Depending upon familiarity with the checklist tool, each of the three rounds will likely take 20-30 minutes to complete. Please follow the instructions below to complete the first round of this study.

\section{Instructions:}

Step 1: Review the Culturally Responsive Checklist Tool for Schools and Teachers, on pages 2-23 of this

document.

Step 2: Go to http://www.surveymonkey.com/s/N5VB5GR and answer questions to provide your feedback on ways

the checklist tool can be improved for use in future staff development for administrators, teachers, and other instructional support staff members. 
APPENDIX I: DELPHI ROUND TWO 


\section{[REVIEWING A CULTURALLY RESPONSIVE CHECKLIST TOOL FOR SCHOOLS AND TEACHERS] Delphi Study: Round 2}

Thank you again for participating in the first round of feedback for this Delphi study to enhance a tool that will be used with schools and teachers to address the achievement gap and disproportionality in education. Using participant feedback from the first round, the tool has been changed and adapted. Below is a summary of the statements participants made regarding the tool. The adapted checklist is attached. The original tool is also attached for your convenience if you would like to compare the original to see what specific changes have been made.

\section{Instructions:}

Step 1: Review the summary statements listed here from the first round of feedback, as well as the adapted tool attached to this email.

Step 2: Go to http://www.surveymonkey.com/s/W2QTLRG to provide feedback related to the adapted tool.

\section{Feedback Summary:}

Factors affecting feasibility: (50\% of respondents noted the tool as "definitely feasible"; $50 \%$ noted the tool as "possibly feasible".)

- Length-time, wording, and amount of questions may be intimidating to future participants

- Lay out-spacing is an issue;; headings should be included with each question; sections of the checklist aren't relevant to all staff; "N/A" should be added to rubric column; question format should be consistent

- Language: not appropriate for many family/community members to participate in; may be difficult for new teachers or particular staff members to complete; some inconsistencies in terms such as what/who makes up an instructional team; ensure language is relevant to participants; some confusion on roles of specific staff members listed, i.e. Reading Coach

Factors affecting importance: (67\% noted the tool as "very important"; $27 \%$ noted the tool as "important"; $6 \%$ noted the tool as slightly important.)

- Questions-some questions are redundant; some questions deter from focus on students coming from RCELD (racial, cultural, ethnic, and linguistically diverse) backgrounds; questions related to RTI (Response to Intervention) and PBS (positive behavioral supports) may not be as important since RTI and PBS are already mandated in Florida schools and could also deter from primary focus of the tool; questions should allow for schools to include more site based needs and initiatives

- Overall content-question of the purpose of the tool; issue with underlying assumptions that focus on traditional roles for special education teachers; tool should address participant beliefs, expectations, and attitudes towards students RCELD backgrounds; some questions and quality indicators appear to support surface level integrations of diversity and may subvert the stated intentions of tool; disability should be included in RCELD definition; include professional development examples and resources 
APPENDIX J: DELPHI ROUND THREE 
[REVIEWING A CULTURALLY RESPONSIVE CHECKLIST TOOL FOR SCHOOLS AND TEACHERS] Delphi Study: Round 3

Good evening,

I cannot thank each of you enough for your participation in this Delphi study to refine this instrument. There will be NO survey with this final round. Please simply review the summary of feedback statements below from the last round regarding the latest version of the tool and reply to this email with your responses to the three questions included at the bottom of this email. There have been no changes made to the attached document since the 2nd round. Changes will be made based upon the summary of feedback below and your round 3 responses to this email.

Summary of Feedback from Round 2:

a.Specific directions are needed on exactly how to complete the questionnaire and how to use the quality indicators section to answer the questions.

b.The open-ended response section for each question needs to clearly specify what participants are to do.

c.Language must be consistent within the answer choices to each question.

d.Feasibility of the tool depends on how it is presented to staff. Must have buy-in from staff and provide guidance during completion.

e.Some questions, like $3 \& 4$ could be combined, while others, like 1 and 5 need to be split apart. f.Need to incorporate a focus on Bank's Social Action approach throughout overall content of questionnaire.

g.Need to address ways to facilitate professional development and conversations regarding individual beliefs and assumptions about racial, cultural, and linguistic issues.

h.Consider a rating system of 1-4 or 1-10 for answer choices, instead of multiple choice rubric statements.

i.There was an even mix of participants stating that resources were either important or not important.

Please respond to these questions in your email reply:

1. Are there any statements above that you particularly agree with?

2. Are there any statements above that you particularly disagree with?

3. Are there any final recommendations that you'd like to add? 
APPENDIX K: MULTICULTURAL SELF-ASSESSMENT ITEMS 
A = Always; $\mathbf{U}=$ Usually $; \mathbf{S}=$ Sometimes $; \mathbf{R}=$ Rarely $; \mathbf{N}=$ Never

Personal Sensitivity

1. I realize that any individual in a group may not have the same values as others in the group.

2. I avoid words, statements, expressions, and actions that members of other culture groups and orientations could find offensive.

3. I read books and articles to increase my understanding and sensitivity about the hopes, strengths, and concerns of people from other cultures.

4. I counteract prejudicial, stereotypical thinking and talking whenever and wherever lean.

School Context Efforts

5. I include contributions of people from diverse populations as an integral part of the school curriculum.

6. I strive to nurture skills and develop values in students and colleagues that will help members of minority groups thrive in the dominant culture.

7. I know where to obtain bias-free, multicultural materials for use in my school.

8. I have evaluated the school resource materials to determine whether or not they contain a fair and appropriate presentation of people in diverse populations.

\section{Parent/Community Relations}

9. I invite parents and community members from various cultural backgrounds to be classroom resources, speakers, visiting experts, or assistants.

10. I value having a school staff composed of people from different culturalbackgrounds.

11. I exhibit displays showing culturally diverse people working and socializing together.

12. I advocate for schools in which all classes, including special education classes, reflect and respect diversity.

Note. From "Consultation, Collaboration, and Teamwork for Students with Special Needs (6th ed.)," by P. Dettmer, L. P. Thurston, A. Knackendoffel, and N. J. Dyck, p. 311. Copyright 2009 by Pearson. 
APPENDIX L: IRB APPROVAL LETTER 
University of Central Florida Institutional

Review Board

Officeof Research \& Commercialization

12201 Research Parkway, Suite 501

Orlando, Florida 32826-3246

Telephone: 407-823-2901 or 407-882-2276

www.research.ucf.edu/compliance/irb.html

\section{Approval of Exempt Human Research}

\section{From: UCF Institutional Review Board \#1 \\ FWA00000351, IRB00001138}

\section{To: Angela C. Griner}

Date: October15, 2010

Dear Researcher:

On 10/15/2010, the IRB approved the following activity as human participant research that is exempt from regulation:

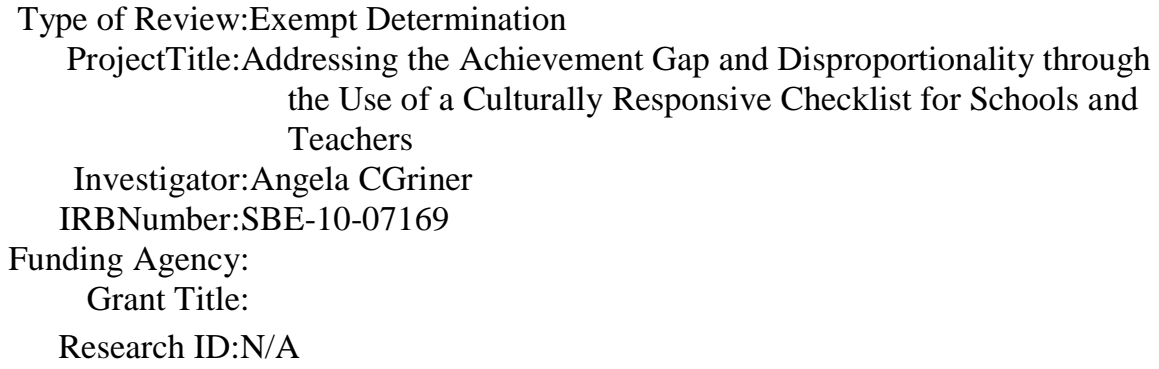

This determination applies only to the activities described in the IRB submission and does not apply should any changes be made. If changes are made and there are questions about whether these changes affect the exempt status of the human research, please contact the IRB. When you have completed your research, please submit a Study Closure request in iRIS so that IRB records will be accurate. In the conduct of this research, you are responsible to follow the requirements of the Investigator Manual.

On behalf of Joseph Bielitzki, DVM, UCF IRB Chair, this letter is signed by:

Signature applied by Joanne Muratorion 10/15/2010 04:15:17 PM EDT

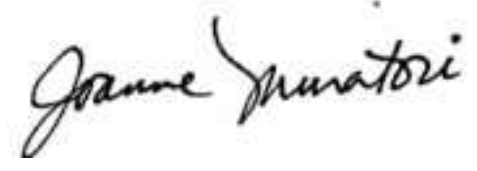

IRB Coordinator 


\section{REFERENCES}

Alves, J. (2006). Class struggles. Chronicle of Higher Education, 53(80),56.

Amatea, E. S., \& West- Olatunji, C. (2007).Joining the conversation about educating our poorest Children: Emerging leadership roles for school counselors in high-poverty schools.Professional School Counseling, 11, (2), 81-89.

Anton, M. (1999). The discourse of a learner-centered classroom: Sociocultural perspectives on teacher-learner interaction in the second-language classroom. Modern Language Journal, 83(3), 303-318.

Applebaum, B. (2008). "Doesn't my experience count?" White students, the authority of experience and social justice pedagogy.Race, Ethnicity and Education, 11(4), 405-414.

Applebaum, B. (2009). Is teaching for social justice a "liberal bias"? Teachers College Record, 111(2), 376-408.

Armor, D.J. (2006).“Brown” and Black-White achievement.Academic Questions, 19(2), 40-47.

Artiles, A., Kozleski, E., Trent, S., Osher, D., \& Oriz, A., (2010). Justifying and explaining disproportionality, 1968-2008: A critique of underlying views of culture. Exceptional Children, (76)3, 279-299.

Artiles, A., Reuda, R. Salazar, J., \& Higareda, I., (2005). Within-group diversity in minority disproportionate representation: English language learners in urban school districts. Exceptional Children, (71)3, 283-300.

Aveling, N. (2006). "Hacking at our very roots": Rearticulating White racial identity within the context of teacher education.Race, Ethnicity \& Education, 9(3), 261-274.

Bae, S. J., \& Clark, G. M. (2005, September). Incorporate diversity awareness into the 
classroom: What teachers can do. Intervention in School \& Clinic, 41(1), 49-51.

Banks, J.A. \& Banks, C.M. (2007).Multicultural education: Issues and perspectives (6 ${ }^{\text {th }}$ ed.). Hoboken, NJ: John Wiley \& Sons.

Banks, J.A., Cookson, P., Gay, G. Hawley, W., Irivine, J.J., Neito, S. Schofiled, J.W. \& Stephan, W. (2010).Diversity within unity: Essential principals for teaching and learning in a multicultural society. In K. Ryan \& J. M. Cooper (eds.) Kaleidoscope: Contemporary and Classic Readings in Education. (pp. 89-94). Belmont, CA: Wadsworth, Cengage Learning.

Banks, J.A. (2007). Approaches to multicultural curriculum reform. In J.A. Banks \& C.A. Banks’' (eds.) Multicultural Education: Issues and Perspectives.(pp.247-269). Hoboken, NJ: John Wiley \& Sons Inc.

Banks, J.A. (2004). Teaching for social justice, diversity, and citizenship in a global world.The Educational Forum, 68,289-298.

Banks, J.A. (2003). The canon debate: Knowledge construction and multicultural education. Educational Researcher, 22(5), 4-14.

Banks, J. A. (1993). Multicultural education: Historical development, dimensions, and practice. Review of Research in Education, 19, 3-49.

Beane, J. (2002). Beyond self-interest: A democratic core curriculum. Educational Leadership, 59(7), 25-28.

Bennett, C.L. (2003). Comprehensive multicultural education: Theory and practice. $\left(5^{\text {th }}\right.$ ed.) New York: Pearson Education, Inc.

Bennett, M. M. (2008). Understanding the students we teach: Poverty in the classroom. Clearing House: A Journal of Educational Strategies, Issues and Ideas, 81(6), 251-256. 
Bennet, C. (2001).Genres of research in multicultural education.Review of Educational Research, 71(2), 171-217.

Bergeron, B. (2008, January). Enacting a culturally responsive curriculum in a novice teacher's classroom: Encountering disequilibrium. Urban Education, 43(1), 4-28.

Bowmen, B. (1994).Cultural diversity and academic achievement. North Central Regional Educational Laboratory. Retrieved December 15, 2007, from http: //www.ncrel.org/sdrs/areas/issues/educatrs/ledrshp/le0bow.htm.

Brown, D. F. (2004). Urban teachers' professed classroom management strategies: Reflectionsof culturally responsive teaching. Urban Education, 39, 266-289.

Brown, M.R. (2007). Educating all students: Creating culturally responsive teachers, classrooms, and schools. Intervention in School and Clinic, 43(1), 57-62.

Bowman, B. (1994).Cultural diversity and academic achievement. North Central Regional Educational Laboratory. Retrieved December 15, 2007, from http://www.ncrel.org/sdrs/areas/issues/educatrs/leadrshp/le0bow.htm.

Burke, C. Adler, M. \& Linker, M. (2008).Resisting Erasure: Cultivating opportunities for humanizing curriculum.Multicultural Perspectives, 10(2), 65-72.

Carr, P. (2008). Education for democracy: With or without social justice? Teacher Education Quarterly 35 (4), 117-136

Carrasquillo, A. L., \& Rodriguez, V. (2002).Language minoritystudents in the mainstream classroom ( $\left.2^{\text {nd }} e d.\right)$. Clevedon, UK: Multilingual Matters.

Cicchelli, T., \& Cho, S. (2007).Teacher multicultural attitudes.Education and Urban Society, 39(3), 370-381.

Cochran-Smith, M. (2004).Walking the road: Race, diversity, and social justice in teacher 
Education.New York: Teachers College Press.

Cohen, D. K. (1990). A revolution in one classroom: The case of Mrs. Oublier. Educational Evaluation and Policy Analysis, 12, 311-329.

Coutinho, M. J. \& Oswald, D. P. (2000). Disproportionate representation in special education: a synthesis and recommendations. Journal of Child and Family Studies, (9)2, 135-56.

Cross, B. (2003). Learning or unlearning racism: Transferring teacher educationcurriculum to classroom practices. Theory into Practice, 42(3), 203-209.

Darling-Hammond, L. (1996). What matters most: A competent teacherfor every child.Phi Delta Kappan, 78 (3), 193-200.

Davis, E.A. \& Krajcik, J.S. (2005). Designing educative curriculum materials to promote teacher learning. Educational Researcher, 34(3), 3-14. http://edr.sagepub.com/cgi/content/short/34/3/3

Delpit, L. (2006). Other people's children: Cultural conflict in the classroom. New York: The New Press.

Dougherty, C. (2010, June 11). U.S. nears racial milestone:Whites are on verge of becoming a minority among newborns in long-expected shift. Wall Street Journal/U.S . Retrieved September 23, 2010 from http://online.wsj.com/article/SB10001424052748704312104575298512006681060.html

Duarte, F. \& Fitzgerald., A. (2006).Guiding principles for a reflexive approach to teaching organization studies. Journal of University Teaching and Learning Practice, 2(3), 15-23.

DuFour, R., DuFour, R., Eaker, R. \& Many, T. (2010).Collaborative teams in professional learning communities at work: Learning by doing. Bloomington, IN: Solution Tree Press. 
Evers, A., Lang, L., \& Smith, S. (2009). An ABC literacy journey: Anchoring in texts, bridging language, and creating stories. The Reading Teacher, 62(6), 461-470.

Fieldler, C.R., Chiang, B., Van Haren, B., Jorgensen, J., Halberg, S. \& Bereson, L. (2008). Culturally responsive practices in schools: A checklist to address disproportionality in special education. Teaching Exceptional Children (40)5, 52-59.

Freire, P. (2007/1997).Pedagogy of the oppressed. New York: The continuum international publishing group, Inc.

Freire, P. (2007/1997).Human rights and liberating education. In A. M. A. F. (Ed.), Daring to dream: Toward a Pedagogy of the Unfinished. (pp. 57-71). Boulder: Paradigm Publishers.

Garcia, S. \& Guerra, C. (2004). Deconstructing deficit thinking: Working with educators to create more equitable learning environments. Education and Urban Society, 36(2), 150168.

Gardner, D. (2007). Confronting the achievement gap inIn K. Ryan \& J. M. Cooper (eds.) Kaleidoscope: Contemporary and Classic Readings in Education. (pp. 154-159). Belmont, CA: Wadsworth, Cengage Learning.

Gay, G. (2000). Culturally Responsive Teaching: Theory, Research, \& Practice. New York: Teachers College Press.

Gay, G. (2002). Preparing for culturally responsive teaching.Journal ofTeacher Education, 53(2), 106-116.

Giroux, H. (2010). Teachers as transformative intellectuals. In K. Ryan \& J. M. Cooper (eds.) Kaleidoscope: Contemporary and Classic Readings in Education. (pp. 35-40). Belmont, CA: Wadsworth, Cengage Learning. 
Giroux, H. (2001). Theory and resistance in education: Towards a pedagogy for the opposition. Westport, CT: Bergin \& Garvey.

Giroux, H. (2009). Education and the crisis of youth: Schooling and the promise of democracy. The Educational Forum, 73, 8-18.

Gorey, K.M. (2009). Comprehensive school reform: Meta-analytic evidence of Black-White achievement gap narrowing. Education Policy Analysis Archives, 17(25), 1-14.

Haberman, M. (1991).The pedagogy of poverty versus good teaching. Phi Delta Kappan, 290294.

Hoffman, P., Dahlman, A., \& Zierdt, G. (2009). Professional learning communities in partnership: A 3-year journey of action and advocacy to bridge the achievement gap. School-University Partnerships: The Journal of the National Association of Professional Development Schools, 3(1).

Hooks, B. (1994).Teaching to transgress. New York: Routledge.

Horowitz, D. (2006). From left to right-the free exchange of ideas. Presidency 9(2), 22-27.

Howard, T. C. (2002). Hearing footsteps in the dark: African American students' descriptions of effective teachers. Journal of Education for Students Placed At-Risk, 7, (4), 425-444.

Howard, M. (2009). RTI from all sides: What every teacher needs to know. Portsmouth, NH: Heinemann.

Howell, R., Patton, S., \& Deiotte, M. (2008).Understanding Response to Intervention: A practical guide to systematic implementation. Bloomington, IN: Solution Tree Press.

Hursh, D. (2007). Exacerbating inequality: The failed promise of the No Child Left Behind Act. Race, Ethnicity and Education, 10(3), 295-308.

Irizarry, J. G. (2007). Ethnic and Urban Intersections in the classroom: Latino students, hybrid 
identities, and culturally responsive pedagogy. Multicultural Perspectives9(3), 21-28

Jay, M. (2003). Critical race theory, multicultural education, and the hidden curriculum of hegemony. Multicultural Perspectives, 5(4), 3-9.

Kearsley, G. (1994). Explorations in learning \& instruction: The theory into practice database. Retrieved September 24, 2010 from http://www.gwu.edu/ tip/.

Kincheloe, J. (2007). Critical pedagogy in the twenty-first century: Evolution for survival. In K. Ryan \& J. M. Cooper (eds.) Kaleidoscope: Contemporary and Classic Readings in Education.(pp. 9-42). Belmont, CA: Wadsworth, Cengage Learning.

Kea, C., Campbell-Whatley, G. D., \& Richards, H.V. (2004).Becoming culturallyresponsive educators: Rethinking teacher education pedagogy. Denver, CO: NationalCenter for Culturally Responsive Educational Systems.

Klingner, J.K., Artiles, A.J., Kozleski, E., Harry, B., Zion, S., Tate, W., Duran, G.Z., \& Riley, D. (2005). Addressing the disproportionate representation of culturally and linguistically diverse students in special education through culturally responsive educational systems. Education Policy Analysis Archives, 13 (38).Retrieved September 24, 2010 from http://epaa.asu.edu/epaa/v13n38/.

Kopkowski, C. (2006, November). Culturally responsive teaching.NEA Today. Retrieved September 24, 2010 from http://www.nea.org/home/14439.htm

Kozol, J. (1992). Savage inequalities: Children in America's schools. New York: Harper Collins Publishers, Inc.

Kozol, J. (2006) Shame of the nation. New York: Harper Collins Publishers, Inc.

Kozol, J. (2008) Letters to a young teacher. New York: Harper Collins Publishers, Inc. 
Kraft, M. (2007). Toward a school-wide model of teaching for social justice: An examination of the best practices of two small public schools. Equity and Excellence in Education, 40, 77-86.

Ladson-Billings, G. (2001). Crossing over to Canaan: The journey of new teachers in diverse Classrooms.San Francisco: Jossey-Bass, A Wiley Company.

Ladson-Billings, G. (2007). Culturally Relevant Teaching: Theory and Practice in J.A. Banks \& C.A. Banks’ (eds.) Multicultural Education: Issues and Perspectives.(pp.221-245). Hoboken, NJ: JohnWiley \& Sons Inc.

Ladson-Billings, G. (2009). The dream-keepers: Successful teachers of African-American Children ( $\left.2^{\text {nd }} e d.\right)$. San Francisco: Jossey-Bass, A Wiley Imprint.

Ladson, Billings, G. (1995). Toward a theory of culturally relevant pedagogy.American Educational Research Journal, 32 (3), 465-491.

Lalas, J. (2007). Teaching for social justice in multicultural urban schools: Conceptualization and classroom implication. Multicultural Education, 14(3), 17-21.

Lee, O. (2003). Equity for culturally and linguistically diverse students in science education: Recommendations for a research agenda. Teachers College Record, 105(3), 465-489.

Leistyna, P. (2007). Neoliberal non-sense in P. McLaren \& J.L. Kincheloe (eds.) Critical Pedagogy: Where are we now?(pp. 97-123). New York: Peter Lang.

Lidwell, W., Holden, K., \& Butler, J. (2010). Universal principles of design. Beverly, MA: Rockport Publishers.

Loewen, J.W. (1995). The lies my teacher told me: Everything your American history text book got wrong. New York: Touchstone. 
Loucks-Horsley, S. (1996). Professional development for Science education: A critical and immediate challenge in Rodger Bybee's (ed.).National Standards \& the Science Curriculum, Dubuque, IA: Kendall/Hunt Publishing Co.

Lue Stewart, M.S. (2009). Creating culturally responsive learning environments in classrooms serving Haitian and Haitian American students. Unpublished manuscript, University of Central Florida, Orlando, FL.

Marshall, P. L. (2002). Cultural diversity in our schools. Bellmont, CA: Wadsworth Group.

Mawhinney, T. S. \& Sagan, L. L. (2010).The power of personal relationships. In K. Ryan \& J. M. Cooper (eds.) Kaleidoscope: Contemporary and Classic Readings in Education. (pp. 13-18). Belmont, CA: Wadsworth, Cengage Learning.

Meece, J. (2003). Applying learner-centered principles to middle school education.Theory into Practice, 42(2), 109-116.

Meier, D. (2010). "As though they owned the place": Small schools as membership communities. In K. Ryan \& J. M. Cooper (eds.) Kaleidoscope: Contemporary and Classic Readings in Education.(pp. 89-94). Belmont, CA: Wadsworth, Cengage Learning.

McIntosh, P. (1988). White privilege: Unpacking the invisible knapsack. Excerpt from McIntosh 1988 Working Paper \#189, published in Peace and Freedom, July/August 1989; reprinted in Independent School, Winter 1990.

Michels, B. \& Maxwell, D. (2006). An after-school program for interpreting local history. TechTrends 50(2), 62-66.

Moll, L., Amanti, C., Neff, D., \& Gonzalez (2005). Funds of knowledge for teaching: Using a 
Qualitative approach to connect homes and classrooms. In N. Gonzalez, L. Moll, \& C. Amanti (eds.), Funds of Knowledge: Theorizing Practices in Households, Communities, and Classrooms.(pp.71-88). Mahwah, NJ: Lawrence Erlbaum Associates, Inc.

Montgomery, W. (2001).Creating culturally, responsive inclusive classrooms. Teaching Exceptional Children, 33(4), 4-9.

National Education Association. (2007). Truth in labeling: Disproportionality in special education. Washington, D.C.: Author.

National Center for Education Statistics. (2010). The condition of education 2010. Washington, D.C.: Author.

Nieto, S., \& Bode, P. (2008). Affirming diversity: The sociopolitical context of multicultural education ( $5^{\text {th }}$ ed.). New York, NY: Pearson/Allyn \& Bacon.

Nieto, S. (2006). Solidarity, courage and heart: What teacher educators can learn from a new generation of teachers.Intercultural Education, 17(5), 457-473.

Noddings, N. (2005). The challenge to care in schools: An alternative approach to education $\left(2^{\text {nd }} e d.\right)$. New York: Teachers College Press.

Normore, A. H., Rodriguez, L., \&Wynne, J. (2007) Making all children winners: Confronting social justice issues to redeem America's soul. Journal of Educational Administration, 45(6), 653.

North, C. E. (2009). Teaching for social justice? Voices from the front lines. Boulder: Paradigm Publishers.

North, C. E. \& Philip, T. M. (2007). Unpacking the methodological issues in research for social 
Justice. In K. Kumashiro \& B. Ngo (eds.) Six Lenses for Anti-Oppressive Education. (pp. 253-258). New York: Peter Lang Publishing, Inc.

Office of Special Education and Early Intervention Services. (2009). Focus on Results.

Washington, D.C.: Author.

Oswald, D.P., Coutinho, M.J., Best, A.M., \& Singh, N.N. (1999). Ethnic representation in special education: The influence of school-related economic and demographic variables. The Journal of Special Education, 32, 194-206.

Ogbu, J. (1992). Understanding cultural diversity and learning.Educational Researcher, 21(8), 514.

Petrina, S. (2004). The politics of curriculum and instructional design/theory/form: Critical problems, projects, units, and modules. Interchange: A Quarterly Review of Education, 35(1),81-126. Retrieved September 12, 2010 from http://www.springerlink.com/content/ut34092p3u18lk12/fulltext.pdf

Phuntsog, N. (2001, April). Culturally responsive teaching: What do selected United States elementary school teachers think? Intercultural Education, 12 (1), 51-64.

Reschly, D.J. (2009). Prevention of disproportionate special education representation using Response to Intervention. Teacher Quality Issue Report by the National Comprehensive Center for Teacher Quality. Retrieved June 10, 2011 from http://www.tqsource.org/forum/documents/TQ_Issue_Paper_RTI_Disproportionality.pdf

Risko, V. \& Walker-Dalhouse, D. (2008). Tapping students' cultural funds of knowledge to address the achievement gap. The Reading Teacher 61(1), 98-100.

Roach, A.T., Kratochwill, T.R. \& Frank, J.L. (2009).School-based consultants as change 
facilitators: Adaptation of the Concerns-Based Adoption Model (CBAM) to support the implementation of research-based practices. Journal of Educational and Psychological Consultation, 19, 300-320.

RTI Teaching Learning Connections (2010). Response to intervention awareness. Orlando, FL: Author.

RTI Action Network (2010). What is RTI?National Center for Learning Disabilities: Washington, D.C.: Author.

Sears, A. \& Hughes, A. (2006). Citizenship: Education or indoctrination? Citizenship Teaching and Learning 2(1), 3-17.

Seidl, B. \&Pugach, M. C. (2009).Support and teaching in the vulnerable moments: Preparing special educators for diversity. Multiple Voices for Ethnically Diverse Exceptional Learners, $11(2), 57-75$.

Sharkey, J. \& Layzer C. (2000). Whose definition of success? Identifying factors that affect English language learners' access to academic success and resources, TESOL Quarterly, 34(2), 352-368.

Schiro, M. (2008).Curriculum theory: Conflicting visions and enduring concerns.Los Angeles, CA: Sage.

Schmid, C. L. (2001). Educational achievement, language-minority students, and the new second generation. Sociology of Education, 74, 71-87.

Schofiled, J.E. (2007). The color-blind perspective in school: causes and consequences in J.A. Banks \& C.A. Banks' (eds.) Multicultural Education: Issues and Perspectives.(pp. 271295). Hoboken, NJ: John Wiley \& Sons Inc.

Shealey, M., \& Lue, M., (2006). Why are all the black kids still in special education? Revisiting 
the issue of disproportionate representation. Multicultural Perspectives, 8(2), 3-9.

Shor, I. \& Freire, P. (1987).A pedagogy for liberation. New York: Bergin \& Garvey.

Slattery, P. (2006).Gender, sexuality, race, and ethnicity in a multicultural and diverse milieu. In P. Slattery, Curriculum development in the postmodern $\left(2^{\text {nd }}\right.$ ed.) (pp. 143-186). New York, NY: Routledge.

Sleeter, C. (2001). Preparing teachers for culturally diverse schools: research and the overwhelming presence of whiteness. Journal of Teacher Education, 52(2), 94-106.

Sleeter, C. E. (2001).An Analysis of the Critiques of Multicultural Education. In J.A. Banks \& C.A. Banks' (eds.) Handbook of Research on Multicultural Education (pp. 81-94). San Francisco: Jossey-Bass.

Sleeter, C. (2001). Preparing teachers for culturally diverse schools: research and the overwhelming presence of whiteness. Journal of Teacher Education, 52(2), 94-106.

Sleeter, C. \& Grant, C. A. (2007).Making choices for multicultural education: Five approaches to race, class, and Gender. Hoboken, NJ: John Wiley \& Sons, Inc.

Sleeter, C. (1996).Multicultural education as social activism. New York: State University of New York Press.

Sobel, D. (2005). Place-based education: Connecting classrooms and communities. Barrington, MA: The Orion Society.

Stevenson, R. B. (2008). A critical pedagogy of place and the critical place(s) of pedagogy. Environmental Education Research, 14(3), 353-360.

Swartz, E. (2009). Diversity gate keeping: knowledge and maintaining inequalities. Review of Educational Research, 79 (2), 1044-1083.

Tabak, I. (2006). Prospects for change at the nexus of policy and design.Educational 
Researcher,35(2), 24-30.

Teddlie, C., Kirby, P.C., \& Stringfield, S. (1989). Effective versus ineffective schools:

Observable differences in the classroom. American Journal of Education, 97, 221-236.

Tutu, D. (2007). Believe: The words and inspiration of Desmond Tutu. Auckland, New Zealand: PQ Blackwell Limited.

Venkatesh, V. \& Davis, F. D. (2000). A theoretical extension of the technology acceptance model: Four longitudinal field studies, Management Science 46(2), 186-204

Venkatesh, V. (2000). Determinants of perceived ease of use: Integrating control, intrinsic motivation, and emotion into the technology acceptance model, Information systems research, 11, 342-365

Venkatesh, V., Morris, M., Davis, G.., \& Davis, F. (2003). User acceptance of information technology: Toward a unified view, MIS Quarterly 27(3), 425-478.

Villegas, A. M. (2007). Dispositions in teacher education: A look at social justice. Journal of Teacher Education, 58(5), 370-380.

Villegas, A. M., \& Lucas, T. (2007).The culturally responsive teacher. Educational Leadership, 64(6), 28-33.

Villegas, A. M., \& Lucas, T. (2002). Preparing culturally responsive teachers: Rethinking the curriculum. Journal of Teacher Education, 53 (1), 20-32.

Weiner, L. (2006). Challenging deficit thinking. Educational Leadership, 64(1), 42-45.

Weinstein, C. S., Tomlinson-Clarke, S., \& Curran, M. (2004). Toward a conception of culturally responsive classroom management. Journal of Teacher Education 55(1), 25-38. 